\title{
WestVirginiaUniversity
}

THE RESEARCH REPOSITORY @ WVU

Graduate Theses, Dissertations, and Problem Reports

2012

\section{Civic Education in West Virginia: Guidelines and State Standards in a Case Study}

Carolyn Jackson Brejwo

West Virginia University

Follow this and additional works at: https://researchrepository.wvu.edu/etd

\section{Recommended Citation}

Brejwo, Carolyn Jackson, "Civic Education in West Virginia: Guidelines and State Standards in a Case Study" (2012). Graduate Theses, Dissertations, and Problem Reports. 505.

https://researchrepository.wvu.edu/etd/505

This Dissertation is protected by copyright and/or related rights. It has been brought to you by the The Research Repository @ WVU with permission from the rights-holder(s). You are free to use this Dissertation in any way that is permitted by the copyright and related rights legislation that applies to your use. For other uses you must obtain permission from the rights-holder(s) directly, unless additional rights are indicated by a Creative Commons license in the record and/ or on the work itself. This Dissertation has been accepted for inclusion in WVU Graduate Theses, Dissertations, and Problem Reports collection by an authorized administrator of The Research Repository @ WVU.

For more information, please contact researchrepository@mail.wvu.edu. 


\title{
Civic Education in West Virginia: Guidelines and State Standards in a Case Study
}

\author{
by \\ Carolyn Jackson Brejwo
}

Dissertation submitted to the College of Human Resources and Education at West

Virginia University in partial fulfillment of the requirements for the

Degree of

Doctor of Education

in

Curriculum and Instruction

Robert A. Waterson, Chair

Mary Haas

Samuel Stack

Ronald Iannone

Sebastian Diaz

Department of Curriculum and Instruction

Morgantown, West Virginia

2012

Keywords: Civic Education; State Standards; Bloom's Taxonomy, West Virginia Copyright 2012 Carolyn J. Brejwo 


\title{
ABSTRACT \\ Civic Education in West Virginia: Guidelines and State Standards in a Case Study
}

\author{
Carolyn J. Brejwo
}

Civic teachers are members of their community and are responsible for preparing their students to be future citizens. West Virginia is one of nine states that requires students to pass a class whose title includes the word "civic." All $12^{\text {th }}$ grade students in the state must take a year long civic education course. The goal for the course is offered by the state in published documents. The documents lay out a course that is guided in part by the definition of civic education offered by the National Council for Social Studies (NCSS). West Virginia offers a much broader and deeper extrapolation of the goals through its Content Standards and Objectives for $12^{\text {th }}$ grade civic education and the state documents are operationalized by a teacher in the state. This paper explores the definitions of and relationships between documents that govern and define civic education along with practice of a classroom teacher.

From working with a classroom teacher, it became increasingly clear that an additional issue in civic education is the cognitive level that the state and the teacher believe are critical to civic education. The state documents categorized its objectives along the "Taxonomy of educational objectives: Handbook I, the cognitive domain" (Bloom, et., al., 1956). This Taxonomy is a widely recognized and used device by which educators can understand and plan the cognitive levels of lessons. This paper explores the practice of using Bloom's Taxonomy in civic education, the appropriate use of the Taxonomy, and the use of the Taxonomy by a classroom teacher. The researcher concluded that the Taxonomy continues to be a relevant tool for planning and shapes the way that teachers and the state think about the goal of civic education. 


\title{
DEDICATION
}

\author{
Dedicated to \\ Jeffrey Peter Brejwo \\ my husband \\ Stella, Susannah and Petra \\ my girls \\ Timothy, Rebecca \\ Benjamin, Melissa \\ Laurel \\ Claire, Kevin, Jackson, and the Twins
}

Thank you. 


\section{ACKNOWLEDGMENTS}

My darling family tolerated hours of writing, traveling to schools, and decades of reading that have culminated in this research project.

Mom and Dad, you allowed me to read late into the night. (Sorry for pretending to go to sleep and then getting up and reading for hours after you went to bed.) You encourage me to study hard and value education for education's sake. Mom, thank you for listening to me and sharing your passion for education. Thank you for watching my girls while I wrote and researched. Thank you for driving Ben and I to class with the girls as we jammed into the Honda. Your kindness and support for all of your children seems limitless.

Dad, thank you for all of the dinners and allowing my girls to watch videos on your TV while Petra napped on your bed and I wrote in your chair. Thank you for having opinions on, ok, really everything, and encouraging me to follow my interests, passions and education.

Ben, Laurel \& Claire: Thank you for all the hours spent mocking me for reading at the dinner table, for you are my heart. We've been yelling with volume and intensity about all topics for so long that when I don't get to speak to you regularly, I begin to ache. Thank you for letting me yell about education, history and all things political for many years. You are the flint against which I have polished my ideas and voice. Without you, I would be lost. Melissa and Kevin, thank you for being my family and friends. My nephew, Jackson, has done a great job distracting me from writing while showing me songbirds in the trees and toads in the yard. 
Petra, I tried to write this while you were growing in my belly. It did not work very well, so Chapter 4 was typed one-handed. Thank you for being a precious, mellow baby.

Susannah, you are a beautiful little girl who sat next to me and typed your own dissertation on your Babu's iPad. Thank you for making me laugh with your 4 year old humor and smile.

Stella, while I work on my writing, you have learned to subtract three digit numbers. I think you worked harder than I did. Thank you for inspiring me to keep at it and never giving up, even when learning to borrow.

Jeff, thank you for your support, your haranguing and your example. You pushed me to take this leap and I deeply appreciate your confidence that I could pull this off even when I whined at you. Thank you for loving me and listening to me. Thank you for encouraging me to use my God-given interests and abilities.

Grandma and Grandpa, thank you for telling me, "I could handle this". Your confidence is infectious and your support, never-ending.

Dr. Waterson, no one ever had a better, kinder and more understanding advisor than me. Thank you for your support and your reminder that I have a strong voice and perhaps, I should tone it down. In this, I refuse. You have been simply wonderful. The list of friends, family members, and professors who have encouraged me is endless. Thank you. 


\section{TABLE OF CONTENTS}

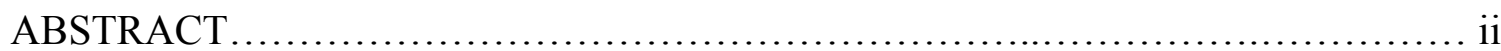

DEDICATION .................................................................... iv

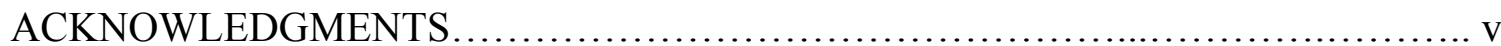

TABLE OF CONTENTS ....................................................... vii

LIST OF TABLES...............................................................

\section{CHAPTERS}

\section{INTRODUCTION}

Introduction .............................................................. 1

Nature of the Problem ............................................... 1

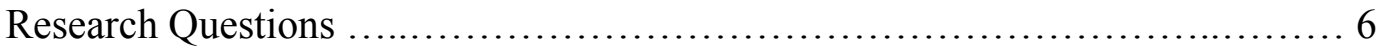

The Cultural Context …...................................................... 7

The Place of Civic Education .................................................. 9

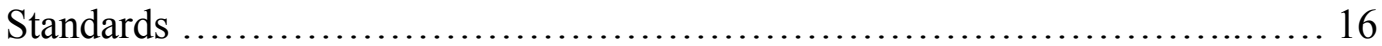

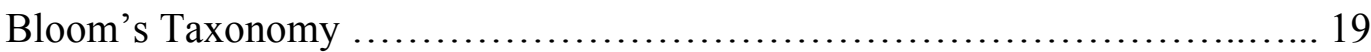

Student Achievement ................................................... 22

Bloom's Taxonomy and Civic Education ............................. 24

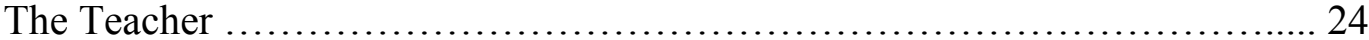

Planning or Assessment? ............................................. 27

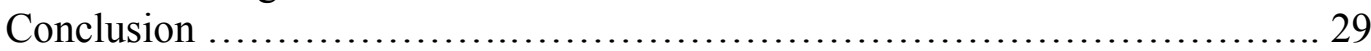

\section{LITERATURE REVIEW}

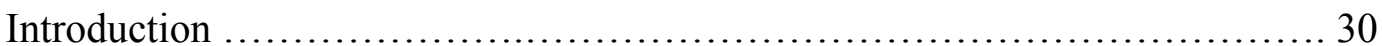

Cultural Context ............................................................ 32

Appalachian Community Member .................................... 33

The Place of Civic Education ............................................ 36

The Goal of Civic Education ................................ 38

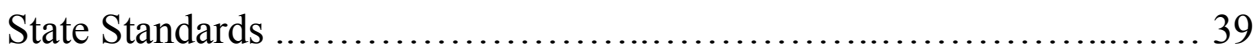

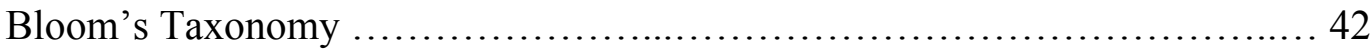

Benjamin Bloom: A Profile ......................................... 43

Taxonomic Domains ....................................... 45

Intended use of Bloom's Taxonomy .......................... 47

Current Use of Bloom's Taxonomy ........................... 48

Taxonomy and Assessment ..................................... 50

Cognitive education above all others ................................. 52

Bloom's Taxonomy in Higher Education ............................. 55

Student Achievement ......................................................... 57 
Bloom's Taxonomy and Social Studies ............................... 60

Curriculum ........................................................ 62

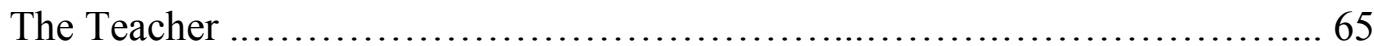

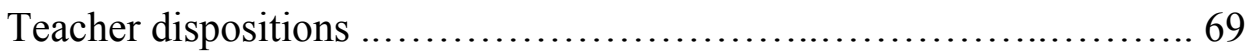

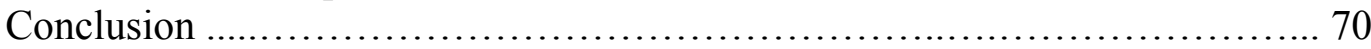

III. METHODS

Methods and Procedures ........................................................ 72

Theoretical Framework ....................................................... 75

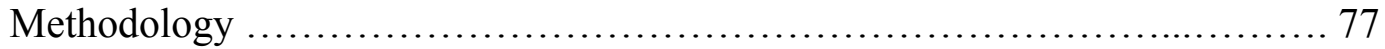

Research Questions .................................................. 78

Sampling Method ............................................... 79

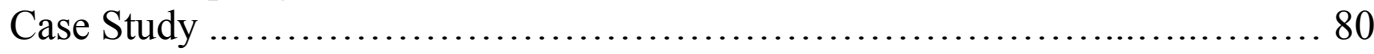

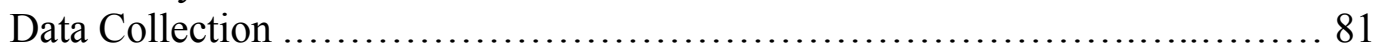

Content Analysis Procedures ............................................ 82

Using the NCSS Definition ....................................... 82

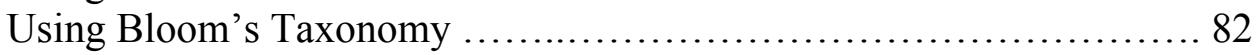

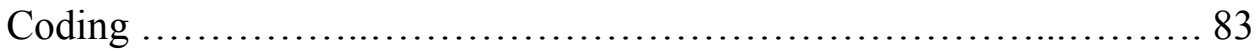

Coding the Standards ..................................... 86

Coding the Lesson Plans ........................................ 86

Coding Handouts and Exams .................................. 87

Coding the Observations ..................................... 87

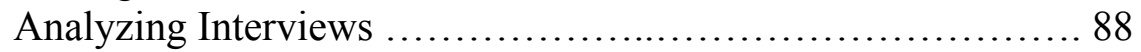

Conclusion ...................................................... 88

\section{FINDINGS}

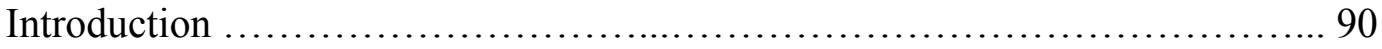

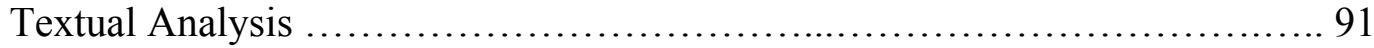

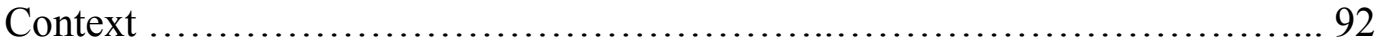

The Standards .................................................................. 94

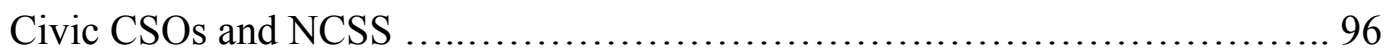

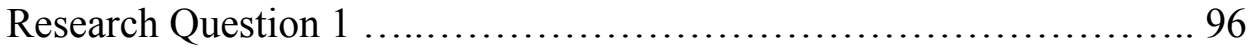

Research Question 2 ................................................ 100

Research Question 3 ............................................. 102

Research Question 4 ............................................... 105

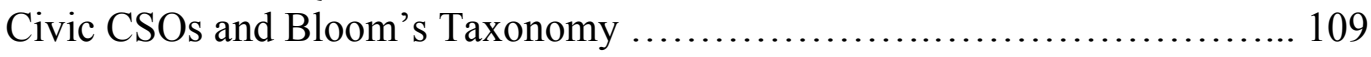

Research Question 5 .............................................. 111

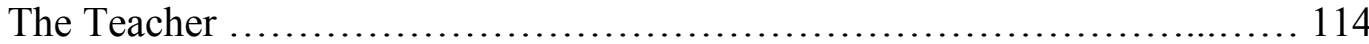

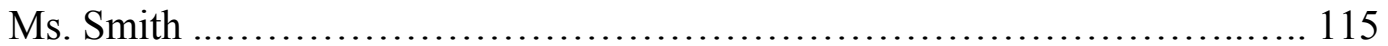

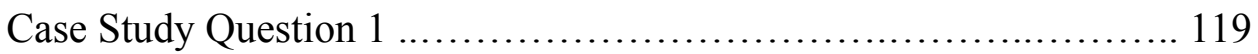

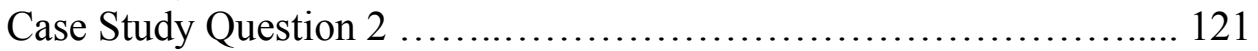

Pedagogy and Community .................................. 124

The Balance of Standards ...................................... 126

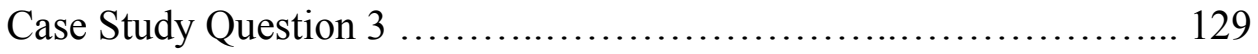


Case Study Question 4 ........................................ 131

Case Study Question 5 ........................................ 134

ABCD Chart ................................................ 136

Conclusion ................................................... 141

V. CONCLUSIONS \& RECOMMENDATIONS

Introduction .......................................................... 143

The Documents .................................................... 145

NCSS and West Virginia Civic Education ........................ 146

Bloom's Taxonomy .............................................. 150

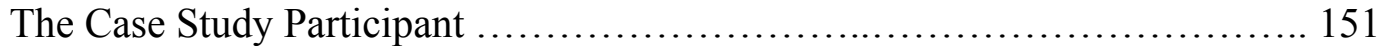

Future Areas for Investigation ...................................... 155

REFERENCES

References .............................................................. 158

Electronic Resources ............................................... 176 


\section{LIST OF TABLES}

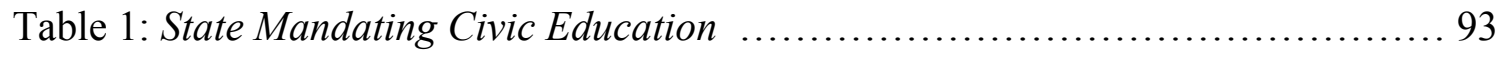

Table 2: Verbs of Standards for Citizenship and Civics at the $12^{\text {th }}$ Grade Level ........ 98

Table 3: Performance Descriptor Verbs ........................................ 103

Table 4: Performance Descriptors by the Numbers ............................. 104

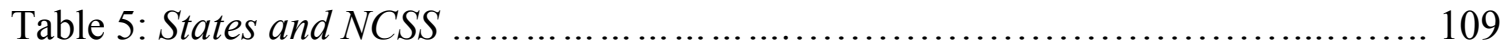

Table 6: Bloom's Taxonomy and State Standards ................................ 111

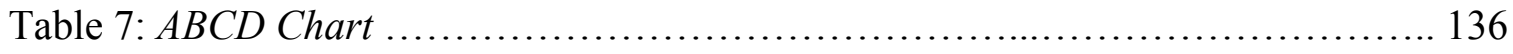

Table 8: ABCD Chart Organized by Lesson ....................................... 137

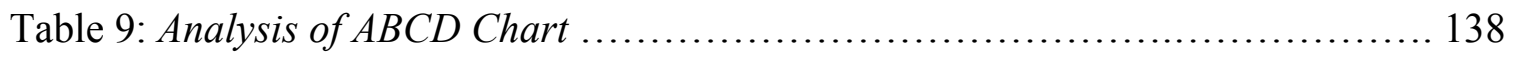

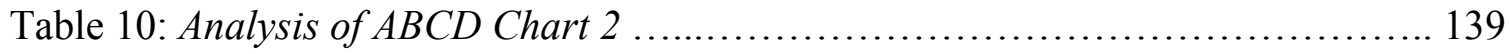

Table 11: ABCD Chart and the Standards ...,................................... 140 


\section{Chapter 1}

\section{Introduction}

West Virginia requires high school students to take a class titled, Civics for the $21^{\text {st }}$ Century (West Virginia Department of Education, 2004). This class is shaped by West Virginia state standards, a document that is a commonly used educational tool. This tool includes the definition of civic education offered by the National Council for the Social Studies (NCSS) and derives it's structure from Bloom's Taxonomy, formally titled "Taxonomy of education objectives: Handbook I, the cognitive domain" (Bloom, et al., 1956). NCSS offers educational stakeholders a definition by which schools can determine compliance with a common definition. Additionally, West Virginia uses Bloom's Taxonomy to structure the cognitive educational process that teachers use for planning lesson activities and content.

Using document analysis and a case study design, this research study will consider how the West Virginia $12^{\text {th }}$ grade civic class documents comply with the NCSS definition of civic education, how Bloom's Taxonomy impacts the work that the state mandates, and how a single teacher views and applies these documents in her classroom.

\section{Nature of the Problem}

In an educational milieu governed by conflicting goals, expectations and experiences, the preparation of citizens emerges as a vital educational outcome. In West Virginia, this goal is addressed in the social studies education curriculum in two ways. First, each grade level course has state-mandated Curriculum Standards and Objectives (CSOs), which address civics as a required component. The second is that all high school students must take a year-long course in civic education. This course covers the 
history of government, the role of the community member, geographic concerns and financial responsibility of the individual (West Virginia Department of Education [WVDOE], 2005). Beginning with the class of 2008, all graduates of West Virginia high schools have been required to take this course. This process demonstrates the commitment of West Virginia to civic education and civic competency among its students. West Virginia's commitments echo the commitment of the NCSS, which calls for civic competency to be the primary goal of social studies education (NCSS, 2010).

Yet, depending upon whom you ask, civic education has many different descriptors and happens in different ways. Some argue that it is part of the curriculum that every child receives every year in social studies. Others see it as synonymous with government classes. The relationship between civics and government courses is that they share an interest in common ways of living. Government courses are designed to teach students about the objective political systems that exist in this and other nations by grounding them in the knowledge of the function of the state and authority structures (Niemi \& Smith, 2001). Government classes reflect a model derived from the political science discipline, which emphasize empirical knowledge critical to participation but does not reflect the personal identity of the citizen the way that a civics course should. This distinction is recognized early in education with the 1916 report of the Social Studies Committee of the Commission on the Reorganization of Secondary Education, which argued that the need to Americanize the immigrants could be met by increasing education in "civics, government and problems of democracy" (Niemi \& Smith, 2001; Hertzberg, 1981). 
The muddled definitions of civic education, government education and notions of democracy create something of a Gordian knot. The untangling may appear to be impossible, but as the knot is picked apart, it becomes clear that there are distinct areas of education and practice in these separate categories of study. For others, civics is its own area of study and instruction. NCSS defines social studies as "the integrated study of the social sciences and humanities to promote civic competence" (NCSS, 2010. p. 9). NCSS defines civic competence as "the knowledge, intellectual processes, and democratic dispositions required of students to be active and engaged participants in public life" (NCSS, 2010. p. 9). Civics, as defined by NCSS, comprises knowledge, attitudes and actions of a citizen. Government classes require students to understand the structures and laws of governments. It does not require the development of democratic dispositions or student engagement in public life. From this, one may safely say that civic education is a distinct discipline from government education and it comprises the knowledge, dispositions and actions of its citizenry.

When West Virginia adopted social studies standards in 2004, it mandated a fourth year of social studies education for its graduates (WVDOE, 2004). With this restructuring, the state made an intentional choice in calling this requirement "civics" and not "government". Many educators recognize there is a pedagogical and curricular difference between civics and government courses. In a simplistic fashion, civics classes expand a government class by combining the core knowledge of political science with civic dispositions and actions, two distinct characteristics of knowing that are seemingly difficult to assess and challenging to implement. If civic education is different from 
government education, then a civics class should be different from a government class. How the classes may differ is described in the WV CSOs.

Following common educational practice, the WVDOE developed course description and CSOs for the new required course (WVDOE, 2004). West Virginia described the goals and processes of the course in language that uses descriptive verbs that allow teachers, parents, and other stakeholders in education to understand what students will be doing throughout the course. The former WV Secretary of Education Steven Paine said, "the standards provide a consistent, clear understanding of what students are expected to learn, so teachers and parents have a roadmap for what they need to do to help them" (Common Core State Standards Initiative, 2010). The standards are shaped by the state but they are additionally shaped by documents that guide both social studies and education more broadly.

Since the adoption of these standards in 2004 and the requirement of civic education for graduation in 2008 , there has been no formal evaluation of the alignment with the NCSS vision for civic education. The NCSS definition requires social studies education to always keep in mind the goal of creating future citizens. The organization, which articulates and advocates for social studies education, provides teachers a framework from which to approach education. This framework is increasingly vital in civic education, a course, which is fundamentally concerned with meeting the stated objectives of NCSS and the development of citizens.

This professional approach is critical for teachers, but administrators use a different standard to shape education in West Virginia. The WV CSOs and lesson plans developed by teachers for their own classrooms use a taxonomic approach to learning. 
The taxonomy, that is used, was written in 1956, by Benjamin Bloom and a team of researchers at the University of Chicago. This taxonomy organizes learning along a cognitive continuum. By engaging in textual analysis, the state documents that guide education can be categorized along the taxonomy. West Virginia requires teachers to organize their lesson plans along Bloom's Taxonomy. As a tool for the teachers, the CSOs follow taxonomic development. The civics standards can be evaluated along a continuum to establish the cognitive level required of students.

Both of these texts guide the teacher in decision-making in the classroom. The teacher uses the NCSS definition to construct the value and weight of the class. The teacher also is to use Bloom's Taxonomy to construct lessons. This project investigates, through a case study, how one teacher uses these documents, how the guiding documents shape standards, and how the state mandates impacts how a teacher understands civic education.

Teachers around the state interpret the standards and apply them in their own classroom. Therefore, the pedagogical choices and understanding of a practicing civics teacher is a relevant area to explore how the structure of state documents ultimately impacts the education that students receive. The standards shape the practice of teachers and teachers translate the standards, interpreting their meaning. This research project seeks to offer a textual analysis of West Virginia $12^{\text {th }}$ grade civics standards. The standards will be evaluated for compliance and completion of the NCSS definition of civic education. They will also be analyzed for their use of the cognitive taxonomic progression. The project considers a single civic teacher in West Virginia to evaluate 
and qualitatively interpret how the standards impact her teaching, how she understands them, and translates them into classroom planning and practice.

The goal of the study is to use a case study to begin to understand how standards fit into the planning and assessment of teachers, how teachers practice achieving the goals of the standards and how teachers measure, assess and value student outcomes. Teachers are the lynch pin in education as they engage in "a complex, deliberative, inherently uncertain, contextual, social, cultural and political process" (Cochran-Smith \& Lytle, 2006). As civic education is central to the mission of social studies education, the impact that standards have on a teacher's practice is a critical component of curricular and pedagogical issues that requires research into how they are interpreted and used by social studies teachers who teach civics.

\section{Research Questions}

The research is driven by guiding questions that shape the inquiry following a grounded theory approach. Guiding questions permit the researcher to develop a method of inquiry, which uses the data that it generates to reinforce and reevaluate the questions. This process allows for the refinement of the research questions and the verification of the data through internal analysis.

The document analysis considered the following questions.

1. What is the frequency with which the WV $12^{\text {th }}$ grade civic Standards meet the three components of civic education (actions, dispositions, and knowledge)?

2. How does the WV $12^{\text {th }}$ grade civic Course Description align with the NCSS definition of civic education? 
3. How do the WV $12^{\text {th }}$ grade civic Performance Standards align with the NCSS definition of civic education?

4. How do the WV $12^{\text {th }}$ grade civic Standards align with the NCSS definition of civic education (NCSS, 2010)?

5. Using Bloom's Taxonomy as a framework, how do the West Virginia $12^{\text {th }}$ Grade Civic Standards demonstrate cognitive learning?

The guiding questions for the West Virginia $12^{\text {th }}$ grade civic teacher are as follows:

1. How do you view the community of your school?

2. How do you define civic education?

3. How do you assess civic education?

4. How do your lesson plans and state documents inform your pedagogy?

5. How does the classification of lessons on the basis of Bloom's Taxonomy impact your planning and implementation of classroom practice?

The guiding research questions are designed to explore the relationship between the guiding documents and case study participant.

\section{The Cultural Context}

West Virginia is a state with a unique history and set of social and cultural norms that impact the nature of civic engagement and the process by which education must be evaluated. It is the only state in the Union that is entirely contained with the Appalachian Mountain region. The population is $94.4 \%$ white and $17 \%$ of the population lives below the poverty line (U.S. Census Bureau, 2011). In comparison, the United States is $74.3 \%$ white and $13 \%$ of the population lives below the poverty line. 
Twenty-five percent of West Virginia's children are raised in poverty (Annie E Casey Foundation, 2012). Seventy-three percent of $4^{\text {th }}$ grade students are ranked as Below Proficient in Reading and sixty-nine percent are Below Proficient in Math (Annie E Casey Foundation, 2012). The state ranks $47^{\text {th }}$ in educational markers (WV Kids Count Fund, 2012). Since income is a predictor of civic engagement, these deficits negatively impact the preparation of students to be civic actors (Hahn, 2001a).

The state is shaped by a long-standing history of absentee ownership of resources (Aurora Lights, 2010) and tightly knit communities (Bell, 2009). The mountains and economy have worked to create a strong sense of membership in a community that discourages leaving for economic or educational options. In these communities, the school functions as a gathering place for the community, but education is often perceived to be superfluous to the lives of students, who for generations were destined for jobs in the local coal mines and other manufacturing industries (Zarret \& Eccles, 2009).

Recognizing these characteristics, the state has sought to modernize both its economy and education system. Through initiatives such as the Promise Scholarship, the state has placed a high value on rewarding West Virginia students with academic scholarships to the West Virginia's colleges and universities (Promise Scholarship Program Staff, 2012). Additionally, the state has worked to improve teacher quality and abilities, increasing both the standards of teacher education and licensing standards during the 1990s. West Virginia University, the state's land-grant institution, has worked to develop a program that allows pre-service teachers to earn the undergraduate and Master's degree in five years (Benedum Collaborative, 2011). The attention is on 
well-prepared and well-educated teachers both at the state level and the university level. With increased standards, student test scores have risen, while the neighboring state of Virginia, which followed a model of alternative certification for teachers, saw test scores fall (Darling-Hammond, 2000).

In social studies education, these curricular and pedagogical changes were addressed in the state standards for each grade level and in the addition of civic education as a graduation requirement. West Virginia requires four full years of social studies education in order to graduate (WVDOE, 2004). Demonstrating leadership and high standards for their students, the Board of Education has integrated civics across the social studies content area and added CSOs to every grade level that address both citizenship and civic education. The dual approach to civics education indicates a deep desire to educate the next generation, not simply in the facts of government, but with the habits of the heart, knowledge of the mind and practice of the body in civic education.

\section{The Place of Civic Education}

Derived from the Latin word civitatum meaning citizen, civics combines knowledge, dispositions, and action, which promote an engaged citizenry (NCSS, 2010; Oxford English Dictionary, 2010). Throughout history, the definition, role and responsibility of citizens has been culturally defined. In American education, civic education has changed over time reflecting the character and situation in which schools have operated. There are contrasts between the roles of the citizen throughout the history of the country, however, universally, the role of the citizen has specific responsibilities and provided particular privileges. The Romans, from whose language we adopted the term, had a carefully defined system by which they identified citizens. 
This process was dependent upon birth or order of the emperor and, in an empire comprised of colonies, the possession of citizenship was highly valued.

In modern America, citizenship looks very different than in ancient Rome, however, possession of citizenship continues to have value. Citizenship gives access to political power and specific rights under the law. These are the basic rights and responsibilities given to citizens regardless of the type of government under which people live. Democratic societies that govern with the consent of the citizens hold on to the fundamental notion that each citizen has rights and responsibilities to the government. These rights and responsibilities form the core of the civics discipline.

The concern of civic education hardly begins with the NCSS and the $21^{\text {st }}$ century, but rather reflects the entire history of American Education. Theorists and educators have been concerned with defining and understanding the ultimate goal of education. Many of different political and social persuasion throughout history have defined this goal as the development of civic education of students. Thomas Jefferson (Lipscomb \& Bergh, 1820) to John Dewey (2004) and Nel Noddings (2005) all articulated this goal. These three theorists have distinct visions for what citizenship entails and who should have access to it. Yet, they share the perspective that the public school should prepare citizens.

Most broadly, success is defined as preparing a student for life in their community. In 1642, Massachusetts General Court passed a law regarding apprenticeship that required the heads of households to provide their children, "to read and understand the principles of religion and the capital laws of this country" (Urban \& Wagoner, 2009. p. 43). As Massachusetts was a religious colony, "understanding 
principles of religion" may also be understood as understanding common ways of living, which is inherently civic. Regardless of the current separation of religious teaching from public education, this sentiment of common life is foundational to our public educational system.

Early American educational goals of reading and writing were first and foremost to prepare students to be civic actors in their community. They were to be prepared to engage in thinking and consideration of their community, to know and understand the foundational character of their community, and to act in their community's best interest. This emphasis on civic education is often overlooked by some who wish to argue that education was a skills related task, preparing students with the 3 "R's", reading, 'riting, \&'rithmatic (Hymel, Schonert-Reichl, \& Miller, 2006).

The tension between content knowledge and social concerns may seem to be a product of modern thinking. This allows those who are opposed to schools as civic actors to justify a position whereby schools are responsible for preparing students to be economically skilled workers. The question becomes how those who are proficient in reading, writing and arithmetic learn to be actors in their community. The study of civics, then, is not simply the study of the functions, forms, and developments of government, but rather is focused on the citizen and the citizen's role in government and in a democratic society.

Society's vision for civic education may vary from the narrowly defined study of the workings of government or broadly in keeping with the NCSS vision as preparation to be an engaged, active member of a community. This is an inherent tension as to the role that civic education plays in American classrooms (Thornton, 2005). Resolving this 
tension is the responsibilities of states and school districts across the nation as they make curricular choices that guide teachers in the preparation of students for a future as members of the American democracy and global citizens.

This curricular choice may most clearly be seen in the adoption of standards and graduation requirements by individual states and districts. These requirements communicate to the community what classes are to be taught and provide a broad outline of the content. Standards develop this framework further, describing what students should be able to do and what they should know at the end of a class. In social studies education, these standards function as a way to define the courses within given academic areas.

Social studies education is comprised of the academic disciplines of history, government, anthropology, sociology, geography, and economics (NCSS, 2010). There is no common definition of how or when these separate academic areas should interact with each other or when they should be taught to students. In West Virginia, social studies education is primarily taught as history courses with social studies CSOs at every grade level. There is one geography course at the $7^{\text {th }}$ grade level and a civics course for $12^{\text {th }}$ grade (WVDOE, 2005). The CSOs for each course are broken out into components so there are civics standards at a variety of grade levels and other areas of social studies education are similarly described in the CSOs.

The civics course is the $12^{\text {th }}$ grade social studies requirement for the state of West Virginia. This course is designed to meet the definition of civic education as promoted by NCSS that civic education is "the knowledge, intellectual processes, and democratic dispositions required of students to be active and engaged participants in 
public life" (NCSS, 2010 p. 9). This is distinct from a course in political science or government. However, for many, courses in government are interchangeable with courses in civics. The distinction between the two may be seen by the emphasis on knowledge or cognitive learning in government classes and the three-fold emphasis on knowledge, action and beliefs in a civics class (Bos, Williamson, Sullivan, Gonzales, \& Avery, 2007). The selection of course titles, materials and definitions are statements of intent. When states make these selections, they are making political decisions influenced by a particular definition of the goals of social studies education (Journell, 2010).

West Virginia includes civics and citizenship standards at every grade. Civics, like all of education, does not exist in a vacuum, but rather is part of an overarching goal of preparing future citizens. NCSS argues that civic engagement is dependent upon teaching students to read, write and be facile with mathematics. NCSS says that, "civic competence rests on this commitment to democratic values, and requires the abilities to use knowledge about one's community, nation, and world; apply inquiry processes; and employ skills of data collection and analysis, collaboration, decision-making and problem-solving" (NCSS, 2010. p. 9). Therefore, civic engagement is dependent upon the whole of a student's education and the student's willingness and ability to use their educational skills for the good of their community. It is also takes cognitive knowledge very seriously. Knowledge is not minimized in favor of emotive or behavior learning, but rather knowledge is paired with emotive and behavioral educational approaches.

Civics focuses on the relationships defined within society, and transcends political structures. It approaches controversial public issues, current discourse, and 
interpersonal relationships in ways that are typically outside of the scope of government classes. One political issue that arises in the selection between civics and government courses is that civics seeks to teach students to act and feel, two practices that some in society view as the purview of the family and potentially subversive. Teaching government classes may be perceived as safer for teachers and schools who are concerned with charges of partisanship or ideological persuasions. Schools are challenged to prepare students with knowledge of the history of American government, political science, political action, community engagement, controversial public issues and an array of other sub-topics. These and many other issues may be discussed and taught in the civics classroom (Hess, 2011).

In modern educational terms, there is tension between a model for education that seeks to prepare citizens and a model that seeks to prepare workers. This tension may be exacerbated as financial compensation for schools is linked with standardized test results. Standardized tests emphasize knowledge that can be answered through multiplechoice assessment. They have to have a single correct answer. By tying standard scores to federal funding of education, schools are pressured to present material to students that will lend itself to simplified mechanisms of assessment. Civic content allows for and even encourages students to develop their own conclusions and beliefs that do not conform to this model. This is not to imply that assessment does not matter or that assessment cannot be performed but that assessment as a function of selecting a single correct answer is inadequate.

States have responded to the federal funding pressure by increasing instruction in mathematics and reading which are tested subjects and avoiding controversy in the 
classroom, which may negatively draw attention to the school (Hinde, 2008; Kahn \& Sporte, 2008; Parker, 2006; Boston, Pearson \& Halperin, 2005). Between the overwhelming volume of material and the tension inherent in the topic, teachers and schools may chose to avoid controversy through reducing the demands placed on teachers and following a knowledge-rich, action- and disposition-neutral curriculum. This curtailment may negatively impact student interest and learning outcomes. It certainly raises the question of what society's goal for education is.

For some, the goal of education is to prepare future workers in society. This is an economic model of education and one that prioritizes the future employment of students. At the other end of the spectrum, there is an educational model that prioritizes preparing thinkers with little concern for employment. This argument is that education is to prepare students to think about their world and consider their role in it. Both of these descriptions represent extremes and most theorists and educators fall into the middle. However, tension does emerge between the two perspectives. The history of education has seen swings in which perspective dominates and Krugman (2005) defines the current trend, as one in which there is a shift away from educating citizens and towards educating consumers and producers. The way in which society sees education will heavily influence which model schools and curriculums will pursue. States articulate their perspective in a variety of ways, but the development of state standards offers a clear window into their perspectives. 


\section{Standards}

Civic education, then, is constrained by society's goals for education. These goals are articulated through the formation of state standards, which are policy documents adopted by individual states or districts. Standards are, then, complimented by the selection of textbooks. State or district officials oversee the selection of textbooks and standards with input from the community and teachers. While the community may offer feedback on standards, these individuals would need to be civically active and engaged. The reality is that the community is generally removed from this process (Orlich, 2011). Officials are elected and thus primarily concerned with their careers and not upsetting the electorate or compromising their jobs.

Textbooks are prepared by companies who want to make a profit, and thus write material in ways that do not lend themselves to questioning society's status quo or to being construed as controversial. Some argue that standards are shaped by people who have little interest in challenging society and primarily seek to perpetuate common societal norms (Orlich, 2011). This continuity of reform ideology began with A Nation At Risk and continues to this day.

While state documents may seem to limit education, they also provide teaches with the freedom to meet societies goals for education. The state is responsible for constructing guidelines that enable teachers to achieve the goals of the state. The structure of education in America depends upon a state to define and support education. These individuals are elected or appointed by elected officials. They are responsible to the community. This gives society the ability to select educational leaders who share their values with respect to education. Teachers work for this democratic system and are 
responsible to their employer to execute society's goals. The standards and textbooks provide information to teachers about what society wants them to do. However, Altoff (2008) argues that these documents tend to emphasize the knowledge domain of cognition, which is antithetical to meaningful civic education. Orlich (2011) contends that beyond this they are authoritarian in design and fail to take into account the student as an individual.

Once society agrees upon and articulates the goals of education, teachers and other stakeholders are able to pursue these goals or question them. The articulation is a critical component of education as it provides a common language and experience from which interested and engaged parties can begin to evaluate and debate the relative merits of the goals of education. This process is inherently civic in nature as the community is able to make decisions, though, participation may be minimal from those outside of the educational system.

The critical mission of school is to prepare students to live in a democratic society. This has economic and civic overtones to it. It is the transmission of cultural values or norms from one generation to the next. While, cultural norms have changed over time, each generation is able to reinterpret them, so education is not a stagnate process but a vital transformative process by which the values of society are transmitted, challenged and changed. This cultural work is dependent upon stakeholders throughout society who are invested in the success of education. There are any numbers of stakeholders in education who are responsible for these various steps. Community members, politicians, school board members, school administrators, teachers, parents and even students are responsible in different ways for the success of societies' schools. 
Each of these groups may have different perspectives on the outcomes of education. Conflicting goals and voices are part of the process by which education within a community is understood and processed. However, implicit in this debate is a sense of tension where competing interests seek different outcomes. Some researchers and educational theorists call for student-centered learning as if the solution to the tension is to look to the students and ignore a formalized curriculum. This, however, has been demonstrated to be counter-productive if student-centered merely includes adding activities for students to engage in (Hutchens \& Eveland, 2009).

Education is dependent upon planning, implementation, assessment and revision of desired goals of education (Blumberg, 2009). Throughout history, the desired goals are only part of the contested and transformed curriculum. The curricular and pedagogical approaches used have shifted over time and modern education is shaped by the history that has transpired. Understanding this history and contextualizing modern practice into this history is itself a critical component of civic education.

In social studies education, the contested pedagogy and curriculum are increasingly complicated as what counts as legitimate knowledge and perspective as well as the methods of presentation are complicated by the subject matter that is at its heart, culturally driven (Moon \& Koo, 2011). Culturally derived subject matter is contested by various voices in society. This, along with critical pedagogical choices, leaves some teachers in social studies open to charges of teaching from political ideology rather than from a "best-practice" model.

The charge of political action has long been made in social studies education as if there is knowledge and practice that is not socially and historically bound. All 
educational practices must operate within historical and cultural context. While teachers are not generally political agents looking to change society through indoctrination, they are responsible for the weighty task of transferring culturally relevant and acceptable knowledge from one generation to the next (Kohli, 2000). Teachers may feel that they walk a fine line, balancing the goals of society with best practices in curriculum and pedagogy.

Within this tension, teachers have a responsibility to determine how standardization may help their students. Thornton (2005) argues, "all teachers are either creators or consumers (or both) of curriculum materials. In any case, they must, in some way, appraise materials, because the very act of selection of materials is an evaluative act.... unless materials are expected to teach themselves, teachers must bring purpose to the selection and use the material" (pp. 101-102). Teachers must decide how much standardization impacts their curricular and pedagogical choices. This question may be further informed by considering whether the application of a standardizing structure benefits the students, teachers or other stakeholders in education in equal or unequal proportions.

\section{Bloom's Taxonomy}

Society has a responsibility to guide the direction of education but also to prepare teachers who have professional judgment trusted by society. Teachers are responsible for the preparation of society's children and they use planning, implementation, assessment and revision as guides in their process. In the American educational system, one structural form, which has been used widely in education, is commonly known as Bloom's Taxonomy. Titled "Taxonomy of educational objectives: 
Handbook I, the cognitive domain", this taxonomy structures the cognitive processes of learning into increasingly complex forms. For the purposes of this paper, it will be referred to as "Bloom's Taxonomy." It was developed by Benjamin Bloom and a team of educational researchers and published in 1956 (Bloom, Englehart, Furst, Hill, \& Krathwohl, 1956).

The Taxonomy was developed to organize test questions at the university level for professors. The project divided educational domains into cognitive, affective and psychomotor development. The authors created two of the three taxonomies and the cognitive development is widely used in educational circles. It continues to shape educational practice, standards and assessment throughout the United States.

The team of researchers were interested in higher education, but the Taxonomy has been heavily influential in K-12 education. In some ways Benjamin Bloom spent his professional career arguing against the broad implementation of the Taxonomy and arguing for recognizing the needs of learners and recognition of both the affective and psychomotor domains of learning.

The cognitive domain was broken down into six categories, which are Knowledge, Comprehension, Application, Analysis, Synthesis and Evaluation (Bloom, et al., 1956). For the educators involved in the development of this Taxonomy, all cognitive learning could be placed along this scale. Some of these categories are further defined in the Taxonomy to more precisely label learning. These six categories were broken down into subcategories and also lumped into two broader categories of higher order and lower order thinking skills (Eber \& Parker, 2007). Lower order thinking was composed of three categories: knowledge, comprehension and application. Higher order 
thinking was composed of analysis, synthesis and evaluation (Forehand, 2005). These categories were believed to represent a linear process of learning with all students beginning with the development of knowledge and moving through the Taxonomy towards evaluation.

The use of the Taxonomy is critical in understanding its role in education. The Taxonomy was developed as an assessment tool and not a planning tool. The learning function of the Taxonomy is to define what students have learned. It is a tool for assessment. As Guskey (2007) argues of the role of assessment is that it is "part of the instructional process to diagnose individual learning difficulties and to prescribe remediation procedures" (p. 12). For the college professors, the Taxonomy was to help them assess how their students had learned at the conclusion of a course. However, in the ensuing years, the Taxonomy has taken on a planning role for teachers and administrators while simultaneously becoming part of the K-12 educational world.

Bloom's Taxonomy has been widely circulated in K-12 educational settings as a method by which course objectives may be set on a state level, teachers can plan instruction and assessment devices can be understood. Since Bloom's Taxonomy was published in 1956 it has become ubiquitous with valued educational outcomes. The use of the Taxonomy as a tool for planning is to define at what Taxonomic level students should be and how teachers should teach material. By combining the Taxonomy with the development of state standards and curriculum plans, teachers and educational stakeholders have create a seamless progression through content material and stages of learning for all students. At least this is what is offered to society on paper. 
State standards, including those in West Virginia, are shaped to fit Bloom's Taxonomy and the content of the courses are designed to follow this path from beginning to end or from lack of knowledge to full cognitive ability. Reading the standards across the grade levels offers a seamless picture whereby students are able to travel the road to education. However, this is not in keeping with the designed use of Bloom's Taxonomy and there are some significant issues that arise in using the Taxonomy as a planning tool.

Bloom believed in setting goals, constructing behavioral plans, and in assessing students. He believed in the ability of all students to meet goals and argued it was the responsibility of schools to meet the educational needs of every student (Bloom, 1978). However, he believed that this process was an individual process and not one that could be planned and organized for a group. The process of goal setting was to develop a societal agreement about the nature and content of education and the assessment was to see how well teachers have succeeded in bringing students towards those goals (Bloom, 1978).

\section{Student Achievement}

Bloom's Taxonomy is a method by which standards are written and organized but also was written as a way of categorizing student achievement. Bloom's Taxonomy introduced educators to categories of cognitive processes and divided thinking between higher and lower order skills. The assumption in the Taxonomy is that students can be assessed as having achieved levels of cognitive processes.

The Taxonomy created levels by which student outcomes could be understood and categorized. As educators began to use Bloom's Taxonomy, the language was 
expanded and educators and other stakeholders in education recognized that each of the categories implied a skill level. These skills could then be identified as goals of a given course. Through language, specifically verbs, educators could categorize their lessons and goals while monitoring student achievement in terms of the Taxonomy.

As this practice developed, educators and stakeholders began to identify and recognize that the progressive nature of the Taxonomy allowed for a "leveling" of student achievement. Bloom, who was committed to mastery learning, believed that educators should engage in "the systematic ordering of our basic knowledge in such a way that what is known and true can be acted on, while what is superstition, fad, and myth can be recognized as such and used only when there is nothing else to support us in our frustration and despair" (Bloom, 1972, p. 334). However, he believed that without mastery of lower order skills, the higher order skills could not be adequately undertaken and achieved.

The use that Bloom's Taxonomy has developed in current usage emphasizes value in particular places. With the vast quantity of what could be taught to students, society must make decisions about what should be taught and Bloom's Taxonomy made the act of establishing value easy without facing the challenges of making the decisions using other criteria. The Taxonomy, in that sense, seems to be value-neutral and objective. It allows decisions to be based on actions and not on context as if this is culturally more values-neutral. The structure becomes a safety net for those who are in a position to make decisions. 


\section{Bloom's Taxonomy and Civic Education}

Both Bloom's taxonomic approach and civic education, as defined by NCSS, have a three-fold understanding of education. Bloom understood education as comprising the cognitive, the affective and the psychomotor domains. These domains relate to civic education, which includes knowledge (cognitive), action (psycho-motor), and beliefs (affective). Civic education requires the use of all three domains in order to achieve the goals of NCSS and the state of West Virginia. The civics curriculum must be holistic in that it must blend knowledge, dispositions and action in the development of civic identity. This approach requires states to construct standards that encourage teachers to include participation.

This implies that the cognitive domain as described by Bloom's Taxonomy is inherently limiting civic education from the perspective of standards. It was not developed to describe how students feel or what they do but only what they think. This limitation is central to this study, which seeks to evaluate whether using Bloom's Taxonomy as a planning tool impacts how civic education is planned for by the state and implemented by the teacher.

\section{The Teacher}

State standards, curriculum choices, Bloom's Taxonomy and educational goals are broadly impersonal components of education. The teachers and students are the people involved in the work of education every day as seen in the classroom. Yet, it is the teacher who receives from the state or district the curriculum, standards and cultural mandate and is held responsible for bringing students along to a pre-determined conclusion of education (Carr \& Harris, 2001). The role of the teacher is critical in 
understanding how the standards are turned from a document into education in action. The teacher takes the standards, interprets them, and puts them into practice.

Teachers in West Virginia have seen standards for their profession raised during the opening decade of the $21^{\text {st }}$ Century. Darling-Hammond (2000) looked at changes in teacher education programs and found that the state of Virginia made it easier to receive a temporary teaching certificate. When they did this, their test scores decreased. During the same period of time, West Virginia raised the standards in teacher education and student test scores increased. The role and training of the teacher is a critical component in the classroom, thus considering the civics standards without considering the teacher leaves a hole in the analysis of civic education in West Virginia.

Teachers are powerful filters of curriculum material and, in civic education, are able to impact what type of citizens they are educating. Civics education is a priority of the West Virginia State government. The current teaching standards, Teach 21st Century, emphasize the role of the civic student (WVDOE, 2009). With this emphasis, it is critical both from a governmental and societal perspective to consider the role teachers play in helping students become engaged citizens as they apply the curricular and pedagogical practices in their classrooms.

As educators imagine students working through textbooks and curriculum, they must remember, as Susan Noffke said, "curriculum conceptualization (should be) a process of creating and nurturing instances both of understanding and of opportunities for action" (Noffke, 2000. p. 74). The curriculum that the teachers offer to students is driven by what the teachers know and what they are comfortable with. Those in academics and policy positions need to help teachers be comfortable with teaching civic 
dispositions and civic action and this is only possible if teachers have the resources, support, and time to enact broader goals in civics education.

The state's goals and student engagement do not stand in opposition to one another but teachers have to balance what they are required to do using a standard's framework while they respond to what they see in their classroom. This balance calls on the teachers to have a deep understanding and appreciation of the state's goals and the ability to measure, formally and informally, how their students are progression. By using best practices such as discussions of community and political issues, they are able to achieve both goals (Feldman, Pasek, Romer \& Jamieson, 2007; Hess \& Posselt, 2002).

As teachers construct lesson plans that describe the content that they teacher, what the student outcomes should be, and the relational position of the lesson to Bloom's Taxonomy, the teachers gives language to their practice that allows other educational stakeholders to delve into the classroom practice. By applying a perceived values neutral system such as Bloom's Taxonomy, many stakeholders believe that students will benefit. The benefit can be seen by way of standardize the education that students receive. The commonality of standards and curriculum have the effective of making education less dependent upon the teacher, however, this broad level of standardization is not necessarily an educational strength (Love, 2009).

Bloom's Taxonomy can be used to benefit teachers both in respect to curriculum and pedagogy as the language by which they identify what level of process they are using (Guskey, 2007). In social studies, learning may be assessed along an individual continuum. Different students begin with different skills, but it is critical that schools 
work to help all students reach desired outcomes (Bloom, 1972). Bloom's Taxonomy allows teachers to assess where their students' cognitive levels. Benjamin Bloom encouraged teachers to take as much time as students need to build their knowledge and properly prepare their students. The assessing was only valuable if it allowed teachers to be more responsive to the individual development of their students.

\section{Planning or Assessment?}

This points back to the role that planning and evaluation play in the classroom. Teachers that use Bloom's Taxonomy in their planning and evaluation must recognize that their students may learn on multiple levels simultaneously and that the learning may be individually dependent. "While there are many factors influencing whether or not students learn... the single most important factor is the quality of teachers' practice" (Hess, 2009a. p. 53). Teachers can use tools from Bloom's Taxonomy to evaluate their own practice and to critically consider their curricular and pedagogical process. The Taxonomy can help a teacher understand where students are, but does not indicate when they will move on to a new level of understanding. Attempting to make a declaration for a group of students may be counter-productive and does not reflect what Bloom's Taxonomy was designed to do.

This multiplicity of processes interrupts the original goal of Bloom's Taxonomy. The original goal was to assess student learning and to help professors identify at what level students are processing a given course. However, history students in K-12 classrooms are assessed using standard mechanisms and at low levels of Bloom's Taxonomy where teachers are using the Taxonomy to plan instruction. History students, as Whelan (2006) argues, "in most cases, students studying history are merely expected 
to 'consume' the conclusions of others, and not 'produce' any knowledge or meaning for themselves" (p. 41). This presentation of knowledge does not allow students to connect or experience the material in a manner in which they can genuinely construct knowledge and move through the various levels of Bloom's Taxonomy.

Teachers have the opportunity to show students the breadth and depth of the world, and how each individual is able to take their place within culture and to work in their community, be it defined locally or globally. Further, civics teachers have the responsibility to teach students about the formal structures of society such as government, and the informal structures such as community and how they are connected.

West Virginia explicitly uses Bloom's Taxonomy in educational planning. The teachers use a chart called an "ABCD Chart" for every lesson plan (See Table 7). K-12 teachers categorize every lesson with one of these letters. "A" and "B" represent lower order skills where "C" and " $\mathrm{D}$ " represent higher order thinking. " $\mathrm{A}$ and "C" represent the application of the cognitive knowledge in the classroom and "B" and " $D$ " represent the application of the knowledge outside of the classroom.

This process of categorization demonstrates that Bloom's Taxonomy continues to be highly relevant in today's educational milieu in West Virginia. Educational research must continue to evaluate and consider the role that Bloom's Taxonomy plays in education both as a formative and summative document. For civic educators, it is critical to consider how taxonomic education befits teachers, students, administrators, politicians and other stakeholders in education. By creating a process by which students 
are expected to move through and define education, society ascribes value to given paths and certifies particular outcomes.

This process is civic as it addresses how society defines full membership. Patrick (1999) contends, "students may learn that constitutional liberal democracy lives or dies in the minds and hearts of citizens. And they may learn that its success or failure depends ultimately on the knowledge, skills, habits and actions of committed citizens" (p. 36). According to NCSS, skills and dispositions cannot be taken away from knowledge, but must be combined to provide true civic education (NCSS, 2010). The cognitive taxonomy addresses knowledge, which is one third of civic education as defined by NCSS. By considering Bloom's Taxonomy, WV CSO's, the vision of NCSS and the work of a WV civic teacher, a picture emerges of how society views civic education, what is valued, and what is rejected from civic education.

\section{Conclusion}

NCSS defines civic education as the knowledge, dispositions and action (NCSS, 2010). The research questions ask how the state of West Virginia fits their documents into the NCSS definition. From this, it became clear that Bloom's Taxonomy heavily influences West Virginia's education plan and that the Taxonomy is connected to NCSS definition of civic education. The goal of the research is to consider the interaction between these three documents.

The textual analysis is paired with a case study analysis of a West Virginia civics teacher. The research presents an image of what civic education should entail and what it does entail. By combining the textual analysis with a case study, the researcher will present a carefully considered analysis of civic education in West Virginia. 


\section{LITERATURE REVIEW \\ Introduction}

This research project considers a West Virginia civics teacher and how her practice is informed by relevant documents. These documents begin with the West Virginia state standards. The standards are the backbone of the civics class. They shape the content and methods by which students are taught. The standards are informed by two documents, which are connected to one another and provide educational stakeholders with an academic defense for the standards.

The literature relevant to the study includes the history and role of Bloom's Taxonomy, the development and use of state standards, with particular emphasis placed on the cultural context of West Virginia and the deliberative role of the teacher in the civic classroom. The body of each of these individual reviews must be tied together through the framework guided by the definition of civic education. The CSO's do not

directly reference NCSS but the language of NCSS permeates West Virginia's Standards (NCSS, 2009).

Civic education must begin with a recognition of a common expectation and definition. NCSS defines civic education as "the knowledge, intellectual processes, and democratic dispositions required of students to be active and engaged participants in public life" (NCSS, 2010. p. 9). West Virginia's first standard references "civic dispositions" and they also reference "involved citizens" (NCSS, 2009). Civics combines cognitive skills with attitudes to enable action in students. This participation is a critical component civic education as identified by Boston, Pearson \& Halperin (2005) as they argue, 
"participation in citizenship is our birthright as Americans, its inheritance is not automatic. It comes with a two-fold price: we are, each of us, expected to enlarge it and to pass it on to our children- both by personal example and through the education we provide for them. Paradoxically, it is as if the only way to hold on to our freedom is to give it away -and liberally- to those who come after us" (p. 37).

For these theorists, education is only complete when students are prepared to engage in their community as citizens. The literature demonstrates that the above argument echoes NCSS and many others who agree that civic education is the knowledge, behaviors and practices of civic education (NCSS, 2010; Reimers \& Cardenas, 2010; Vander Veldt and Ponder, 2010; Rapoport, 2009; Westheimer and Kahne, 2004; Butts, 1988).

Within education, however, the cognitive process or the knowledge of civics is the area that school systems most commonly address and assess. Boston, Pearson \& Halperin (2005) report,

"the Albert Shanker Institute has done state-by-state reviews of how well states are teaching students the academics required for civic knowledge. It found that not one of the 48 states that claim to have instructional standards in history and social science has developed a standards document that has a clear focus on civic/political education and that is also accompanied by materials that are teachable in the time available" (p. 9).

The challenge for civic education is to find space with in the educational system that allows for students to develop their cognitive, behavioral and affective skills that empower them to be engaged members of their community while educational practicitioners are confident in the assessment of their students.

The literature provides a portrait of what civic education should look like. "Civic education should be cross-disciplinary, participatory, related to the lives of students, conducted in a non-authoritarian environment, and presented by teachers who are aware of the challenges of social diversity" (Hinde, 2008. p. 79). Knowledge, action 
and dispositions must be taught in balance in order to appropriately prepare students to engage in civic life. Keeping the desired outcome at the foreground of the discussion, it must be recognized that students need to accept and internalize the value of what they are learning. The balance can be emphasized through the construction of state standards and other documents that guide teachers and give students a balanced education.

This assessment is a critical part of education and should in some ways be welcomed by teachers. Bloom's Taxonomy functions through the United States and particularly in West Virginia as a method by which teachers plan and assess students (Dettmer, 2006). In education, goals are called objectives and objectives are reached through planning and assessments. The function of objectives and plans are contested and debated in the field, but for Bloom, they were the central responsibility of schools (Bloom, 1972). This relationship between objectives and plans are the central concern of this paper, with particular attention paid to the taxonomic development found imbedded in objectives and plans.

\section{Cultural Context}

Teachers and students live and work in a social context that provides a background to their practice and learning. West Virginia has a particular history and social space that is critical to understand the value and place of civic education as well as particular state standards. Kunzman (2006) argues that civic education must integrate the knowledge of politics with the public experience of students. The life of students is critical to their experience in the classroom (Dewey, 2004), and no where in the curriculum is this connection between school life and community life more critical than in civic education. 


\section{Teacher as Appalachian Community Member}

Before teachers can be effective teachers, they must be viewed as members of the community. The history of education in West Virginia is highly shaped by community and relationships between individuals. The teachers work in rural communities that are marked by geography and economics (Bell, 2009). The relationship of teachers to their community is inherently civic and this relationship defines how teachers approach their content and how they view education. The geography of the state created small communities in the rural mountainous areas that developed in isolation from one another and yet strikingly similar. This is contrasted with the Northern and Eastern panhandle areas that were more industrialized.

Economics tie the communities together as they work in logging and coal mining, two dangerous professions marked by absentee owners and a high level of manual work. Even as the economic base has shifted, the communities remain, tied together by common histories.

The rural teacher has a particular challenge of teaching students how to be citizens of a culturally diverse nation in a globally connected world. This challenge increases when the community is insular and socially homogenous. Peggy Laughlin and Lydiah Nganga (2008) examined the issue of teaching pre-service teachers culturally responsive pedagogy in rural white America, focusing their research on central Wyoming. Their study considered how the culturally homogeneous nature of the area in which they worked impacted the development of pre-service teachers as responsive and aware educators. 
Laughlin and Nganga considered language arts and socials studies classes to investigate how students understand multiculturalism and how they view teaching in a diverse environment. The relationship between the teachers and the content was found in their connection to the presentation of this material. Teaching can be a relational activity where material is tied to the attitude of a teacher and that teacher's presentation to students. This picture of relational education recognizes that teachers are part of their community and it is this relationship places the teacher in a distinctly civic role.

By considering 45 pre-service teachers, they investigated how the teachers approached multicultural education through literature and if a multidisciplinary approach impacted the teachers' thinking and practice related to multicultural education. Initially, they found that the pre-service teachers did not believe that literacy was connected to culture and few viewed multicultural education as important. The research subjects were both teaching classes and in classes that emphasized multicultural literacy and pedagogy, making them both learner and student. The study did conclude that the students developed culturally relevant pedagogical approaches throughout the research study (Laughlin \& Nganga, 2008). The students also reported increased value of explicit education in multicultural pedagogy.

Multiculturalism is a topic that is closely tied to civic awareness, as most of the United States is heterogeneous in its populations and most of American schools face a diverse student body. West Virginia, like central Wyoming, is primarily rural and white. It is critical that these areas of the country are considered as places in need of distinct strategies to increase awareness of multiculturalism to raise civic dispositions of tolerance and acceptance where most children come from homogeneous cultures. This 
awareness of and value towards multicultural education stems from civic dispositions as citizens who have an emotional understanding and sympathy for those who have a different cultural experience. The root of this dispositional development is knowledge and Laughlin and Nganga emphasize preparing pre-service teachers with the knowledge to teach dispositional development.

In 2004, Heilman (2004) considered the diversity within what appeared to be a homogenous white community in Indiana. By engaging in action research in a multicultural education class, she found that less than half of her students believed that the background of their students impacted them in the classroom. Heilman argues,

"Without explicit curriculum that addresses the historical experiences, local culture, language, dialect, learning styles, school experiences, and even popular cultural representations of marginalized ethnic white students, pre-service teachers can easily transmit cultural and social class bias and are at risk of neglecting or misinterpreting the needs of many students" (p. 76).

Cultural norms other than ethnicity or socio-economic status may be at work to alienate some students in classrooms. Teachers must guard against this in a democratic society where the protection of the minority is a primary civic disposition (Heilman, 2004). West Virginia, as a highly homogenous white society, is not free from discrimination and while outsiders may perceive the community to be homogenous, to insiders, diversity among the student body still exists and teachers have a responsibility to guard against ignoring this diversity.

These two studies demonstrate that it is critical that teachers be responsive to the diversity in the classroom even when it is not quickly recognizable. Dispositions towards multicultural identity and experiences can be taught and teachers can be prepared to teach their students awareness on a knowledge level and sympathy on a 
dispositional level. Teachers can do this while recognizing that students have unique cultural identities that should not be minimized.

Effective civic education should help students develop into empathetic, capable, and involved members of their communities (Cohen, Pickeral, \& Levine, 2010; Thornton, 2005). These traits are not conditioned upon living in a diverse community, nor are they less valuable for children who may live in isolated parts of the country. Teachers must be proactive in identifying diversity and using the community in which they operate to prepare students to live in more ethnically diverse places of the globe.

\section{The Place of Civic Education}

Civic education is fully implemented when the complete expression of knowledge, disposition and action are recognized and emphasized in the classroom. This comes when teachers identify students as active participants in their education. State documents and standardized assessment approaches tend to overlook the role of the active, engaged student. When teachers begin to see themselves as civic actors and engage in civically minded instruction, they naturally begin to view their students as critically active learners. This models what Nel Noddings (1998) called "caring teaching". For Noddings, this method of education which inherently requires civic engagement, requires modeling, dialogue, practice and confirmation. Through these four steps, education becomes a civic practice where teachers, through their own practice, demonstrate and lead students to value and practice civic awareness.

Yet, while this is recognized as critically important by many, standards fail to take this into account. As standards represent the common goals for education, the reflect a perspective that what is taught must be assessed and must be "knowledge rich" 
at the expense of being active and emotive. Rothstein (2009) argues that "we will have to resolve contradictory national convictions that schools should teach citizenship and character, but not inquire about students' personal opinions". This represents a cultural values dispute between those who believe that education is concerned with shaping individuals in a democratic society and those who believe schools should provide cognitive knowledge in exclusion of character development.

The emotive and active civic education must be required by the state in order for it to be taught and it both what students do and believe should be assessed not on the basis of ideology but on the basis of growth and development for the individual. It is not enough for teachers to assess what students know nor is enough for standards to emphasize knowledge, but rather the fullness of civic education must be embraced and culturally the behaviors and beliefs of students must be part of the explicit, prescribed curriculum.

The value of civic education can be seen in the work of Bos, Williamson, Sullivan, Gonzales, and Avery, who, in a 2007 study, investigated how students view their political rights and responsibilities. They studied the relationship between high school students' actions and their beliefs related to political rights. What emerged was very concerning for the researchers. They found that, "students who thought themselves largely entitled to every political right that we posed to them were less likely to participate in extracurricular activities related to civics and no more likely than others to vote" (p. 1277).

Students who know what they are entitled to under the Constitution of the United States failed to grasp or practice the fact that they have responsibilities to their society. 
These students engaged minimally in their community. The knowledge strand of civics not only failed to help students act civically, but the emphasis on knowledge objectives may have hindered them from engaging in political action. This points to the critical nature of the NCSS definition of civics that emphasizes knowledge alongside of dispositions and action. By teaching civic action and engagement, teachers empower students to see themselves as critical members of society. Without their participation the fabric of civic rights and responsibilities have little meaning.

The Goal of Civic Education. Civic education strives for acknowledgement in schools where the goal of education is hotly debated (Eisner, 2001). There are two competing narratives and in their extreme positions, can be summarized by asking the following: is the aim of education to teach students to read, write, and understand mathematics? Or is the aim of education to teach the next generation how to work, live, and succeed in a community? With the emphasis on accountability, civics education has been marginalized in favor of reading and mathematics instruction (Misco \& Shiveley, 2010; Doppen, Misco, \& Patterson, 2008). These questions should not live in opposition to one another but should be seen as complimentary aims. All social studies education is dependent upon knowledge, but civic knowledge does not operate in a vacuum.

Even the finest teachers face pressure to adjust their instruction in order to emphasize knowledge over dispositions. In civics, knowledge of political and governmental structures tends to be emphasized. Misco and Shiveley argue, 
"it would seem that creating learning experiences for students that foster the development of dispositional commitments including incontrovertible and democratic rights of liberty, opportunity, and dissent, as well as freedoms of participation, inquiry, expression, and worship, are much easier to prescribe than enact" (Misco \& Shiveley, 2010).

This model contradicts many of the stated plans for curriculum and civics courses including those presented in West Virginia CSOs (WVDOE, 2005).

Educational standards tend to emphasize knowledge along the cognitive taxonomic approach painted Bloom's Taxonomy. In civic education, which is defined as including knowledge, dispositions and action, standards and assessment tools emphasize knowledge. Rarely do standards push teachers beyond the cognitive framework to consider how to prepare students to be civic actors of the coming generation.

\section{State Standards}

Standards are the locus where practice and policy meet. It is critical that state documents are constructed to encourage and enhance participatory civic education through state course requirements. As standards have increased, civic education has been increasingly limited to the knowledge domain for ease of assessment (Journell, 2010; Bos, Williamson, Sullivan, Gonzales and Avery, 2007; Vinson, 1999). The skill and attitude domains, therefore, have been minimized.

Vinson (1999) argues that if "students and teachers conform, adapt their behavior- teaching and learning- to the standards, they are successful” (p. 312). Since Vinson first published this article, the legislation, No Child Left Behind (NCLB) has increased testing and accountability measures. This has forced greater levels of 
conformity while minimizing civic education as less critical than literacy and math (Hinde, 2008; Kahn \& Sporte, 2008; Parker, 2006; Boston, Pearson \& Halperin, 2005).

The standards that a state adopts for a given course reflects the community's vision for that course. Hinde (2008) sees in her study that the vision that society has of education is no longer the development of civic virtue. Rather, the vision is to produce workers, consumers or economic cogs for the advancement of an economy. If civic education is to direct students to think and act toward their community, then this trend in education only communicates to them their exclusion from society. They are to be workers for society rather than active shapers in their community. These two roles are often seen as divergent, however they are not mutually exclusive.

This exclusionary model is advanced through the development of standards. "Standards", Vinson (1999) argues, "provide a mechanism by which an individual or small group can impose decisions upon others, decisions made based upon their own understandings, interests and needs" (p. 312). Standards also "provide the teacher with greater guidance in terms of possible suggestions for teaching and assessing their students, and not simply what the students need to know" (Barbour, Evans, and Ritter, 2007. p. 28). The standards, then, function as a contract between the state, the community and the teacher as the state writes the standards, the community agrees to the standards, and the teacher implements the standards. In this sense, standards are the ontological knowledge that culture assumes should exist from one generation to another. The control of standards is then an issue of power as those who control the standards control what knowledge is valid. 
As society collectively has agreed that standards should be employed in the classroom, there remains debate over how they should be used (Journell, 2010). The literature suggests that the common usage is to control what is taught and to assess the competence of the teacher and learning of the students (Ross, 2006). Standards are powerful mechanisms of control. While many may say that standards are a minimum level of instruction that teachers should reach, many more believe they function as the maximum goals of a course (Crocco \& Costigan, 2007).

This debate has led to tension between standards, accountability and the curriculum. When standards define the curriculum, Crocco and Costigan (2007) argue that they "narrow" the curriculum. The narrowing is the result of the increase in standards and requirements. Standards and other requirements create a level at which teachers can justify their job as complete. As requirements and testing focus on particular areas of the curriculum such as reading, writing and mathematics, other areas are minimized since teachers and school administrators know that no one is watching or assessing what is being taught to students.

These forces have led to a clear abandonment of social studies education, particularly in elementary school. Teachers have reported reduced amount of time on social studies education as the government has mandated greater levels of accountability through testing (Good, et al. 2010). This study reports that classroom teachers do not teach social studies education at the elementary school level due to the mandate for testing preparation. They are very clear that classroom instruction time is consumed by test preparation and social studies and science have followed art and music and been cut from the daily work of students. 
Through government mandates such as No Child Left Behind and the ties of educational assessment of standards to financial benefits for schools, schools are decreasing their time preparing future citizens and are focused on the outcomes of each year, rather than developing long-term goals for students. This shift makes it increasingly critical that teachers engage more fully in the process of standard development. Through this process teachers are able to develop and pursue education that has as its goal the whole of the students' lives.

Civic teachers, in particular, should recognize that what they are doing is preparing future citizens and that this requires knowledge, action and belief about society. Teachers, then should take a serious stand in moving the the standards towards recognizing and valuing a full definition of civic education. This process is what Parker (1996) calls, "the deliberative arts of hammering out law and public policy together and the consequent tensions between oneness and sameness" (p. 122).

In education, law and public policy are expressed through state standards and course descriptions. Teachers have a professional and civic responsibility to critically evaluate what is being required of them in the classroom and to engage their community in addressing the needs of the students in a given community and state. Only through active engagement in shaping the standards and methods of assessment, can teachers be assured of the professional role that they have in society.

\section{Bloom's Taxonomy}

The roles of standards and curriculum have been significantly shaped through a taxonomic approach to education (Polikoff, Porter \& Smithson, 2011; Anderson, 2002). The most widely used taxonomy, or linear progression of learning, was developed by 
Benjamin Bloom and 34 other educational researchers at the University of Chicago in 1956 (Booker, 2007). The Taxonomy was developed along a behaviorist model to aid in the development of standard forms of education and to aid Professors to assess their students’ work (Bloom, Englehart, Furst, Hill, \& Krathwohl, 1956).

Bloom and the other developers believed that all students should be able to achieve maximum levels of cognitive ability if the proper path was followed. The history of the Taxonomy and the perspective of Benjamin Bloom are critical voices even now in education in West Virginia. As teachers around the state are required to use the taxonomy to classify lesson plans, it is critical for researchers to continue to investigate how the Taxonomy is used and to consider its role in formative and summative assessments.

\section{Benjamin Bloom: A Profile}

Benjamin Bloom, a behavioral psychologist at the University of Chicago, wrote extensively on the process of education. He is most well-known for the educational taxonomy that shares his name, but his work extends well beyond the Taxonomy to include extensive consideration of the process of education, the goals of education, and the role of assessment in education.

Bloom completed his doctoral dissertation at the University of Chicago in 1943 and continued to research and write about education through the end of his life in 1989 (Anderson, 1996). Through the progression of his writing, he remained committed to educational optimism (Eisner, 2000) meaning that he firmly believed that schools and educational institutions could impact learning ability. He bluntly stated that if schools were unable to do this, then "the task of the schools is to constantly weed out and 
eliminate the poorer learners while encouraging the better learners to get as much education as possible" (Bloom, 1978. p. 564). He rejected this perspective and worked to identify the criteria that would be needed in schools for all students to succeed.

A former student of Bloom's, Elliot Eisner, described Bloom as offering, "his students a model of an inquiring scholar, someone who embraced the idea that education as a process was an effort to realize human potential; indeed, even more, it was an effort designed to make potential possible. Education was an exercise in optimism" (Eisner, 2000. p. 388). Bloom believed in setting goals, constructing behavioral plans, and in assessing students. But he believed in the ability of all students to meet goals and argued it was the responsibility of schools to meet the educational need of every student (Bloom, 1978). The process of goal setting was to develop a societal agreement about the nature and content of education and the assessment was to see how well teachers have succeeded in bringing students towards those goals (Bloom, 1978).

In the early 1940s, Benjamin Bloom studied at the University of Chicago under Ralph Tyler (Anderson, 1996). His dissertation was titled, "The Relationship between Educational Objectives and Examinations Designed to Measure Achievement in General Education Courses at the College Level" (Bloom, 1943). With this project, Bloom began to research topics that would provide some of the intellectual backings for the Taxonomy that bears his name. After studying at the University of Chicago, he became a professor at the institution and never left.

Beginning in 1952, Bloom along with 34 educators, psychologists and school examiners began to meet to "provide an overarching classification system for test questions" (Booker, 2007. p. 349). In 1956, the group published one volume of a 
proposed three-volume collection with the goal of describing education in taxonomic terms. The system that Bloom and others developed initially divided learning into three major domains. The three domains were the psychomotor, affective and cognitive.

Taxonomic Domains. The first domain that the group of educators addressed was the cognitive domain. The cognitive domain is the type of knowledge that is related to knowledge that a person's mind learns. It has been described as simple and elegant, keeping the taxonomy to six categories (Wineburg \& Schneider, 2010). The second domain that the educators addressed was the affective domain. The affective domain taxonomy was written but has been little referenced and was not widely distributed. This taxonomy addressed the way that students learn through feeling and emotion.

The Taxonomy of the psychomotor domain was never written. The goal of the psychomotor taxonomy was to address how students learn through movement and their bodies. The first and most famous text was the "Taxonomy of educational objectives: Handbook I, the cognitive domain" (Walberg \& Haertel, 1992; Seddon, 1978; Bloom, et al., 1956). The cognitive domain is the taxonomy that many people in education are familiar with, and it is often believed to define the breadth of educational practice. Simply put if students demonstrate proficiency at the highest level of Bloom's Taxonomy, then "education" has been achieved (Anderson, 2002).

The Taxonomy further categorized learning by organizing learning verbs in six ascending categories of process, which are Knowledge, Comprehension, Application, Analysis, Synthesis and Evaluation (Bloom, et al., 1956). For the educators involved in the development of this Taxonomy, all cognitive learning could be placed along this 
scale. Some of these categories are further defined in the Taxonomy to more precisely label learning.

The subcategories of the Taxonomy were structured in an ascending process and the categories have been labeled as higher order and lower order thinking skills (Eber \& Parker, 2007). Lower order thinking was composed of three categories: knowledge, comprehension and application. Higher order thinking was composed of analysis, synthesis and evaluation (Forehand, 2005). These categories were believed to represent a linear process of learning with all students beginning with the development of knowledge and moving through the Taxonomy towards evaluation.

Bloom and the other educators published their Taxonomy to help assess student learning. The group was concerned with the assessment of learning of university students and the Taxonomy was designed to retroactively categorize the learning of students by assessing examination questions along the sequence of the Taxonomy (Eisner, 2000). By placing the correctly answered questions along the taxonomic scale, the educators believed that they could categorize the cognitive level achieved by each student.

Each of the categories defined in the Taxonomy provided increasingly specific levels of ways of understanding and using information. Bloom's Taxonomy further classified learning through subcategories. These subcategories are not widely used, but the six major categories have become ubiquitous in education for defining learning. The category of Knowledge was divided into "knowledge of specifics", "knowledge of ways and means of dealing with specifics", and "knowledge of universals and abstractions in a field". Comprehension was separated into categories of "translation", "interpretation", 
and "extrapolation". Analysis was divided into the "analysis of elements", "analysis of relationships", and "analysis of organizational principles". Synthesis includes "production of a unique communication", "production of a plan or proposed set of operations" and "derivation of a set of abstract relations". Evaluation is divided into "evaluation in terms of internal evidence" and "judgments in terms of external criteria" (Bloom et al., 1956). Application was not divided into subcategories. Each of the subcategories was thought to represent a level of intellectual progress that must be mastered before the learner is able to move onto the next level (Bloom, 1978) making the Taxonomy consistent with Bloom's later interest and writings on mastery learning.

Intended use of Bloom's Taxonomy. For Bloom the psychologist, learning is a mastery process whereby students achieve the levels of cognitive mastery in an ascending process. The goal of learning is to develop mastery of each level and Bloom, years later, argued that this mastery should be pictured as "over time we have developed our walking to a point where it works well without conscious attention" (Bloom, 1986. p. 72). This is a description of learning that has been mastered. The material that students are to learn is to be so well learned that it becomes an automatic process such as walking.

Each of the taxonomy's lower levels must be reached and mastered so that they become automatic functions. This allows learners to attempt and perform increasingly complex tasks. This is the action that the Taxonomy attempts to describe, remembering that it only defines the cognitive process without addressing the psychomotor or the affective domains of learning. As developed, the Taxonomy was a tool to retroactively categorize what students had learned. 
Bloom assumed and argued that all of education can be broken down into components, which can then define successful learning and this success is required at early levels of education in order to progress to subsequent learning tasks (Resnick, 1977). The original goal was to create a common language for university assessors to determine how much their students are learning.

Current use of Bloom's Taxonomy. The original goal of the developers of Bloom's Taxonomy stands in contrast to the common usage to the Taxonomy in current times. The current usage is primarily in the K-12 environment and it is used for planning, objectives, and assessments. Many educators have no historical context for the Taxonomy and little understanding of the breadth of what Bloom believed that education should be. However, the failure to understand the history and context of Bloom's Taxonomy creates an imbalance in the use of the Taxonomy. While calling for higher order thinking, Bloom believed that knowledge was the basis for all thinking and learning and thus should never be minimized or discounted (Booker, 2007). Reading Benjamin Bloom's writings demonstrates his deep respect for lower order thinking and he believed that a great deal of time and attention should be paid to developing knowledge and comprehension skills.

As the Taxonomy has become commonly used in the K-12 environment, the Taxonomy's relative values have not shifted. There is little questioning of whether the division of cognition into higher order or lower order levels is good for students. The Taxonomy is used more extensively as a device for planning rather than assessment so teachers are required to plan to have students work at higher levels of thinking. 
Wineburg \& Schneider (2010) argue that in social studies, this system of education is upside down. They found that when high school students who have been taught to think abstractly and in the higher order domains are confronted with a new piece of historical text, they miss facts and leap to conclusions. They argue that for the historian, knowledge is of high value and that history graduate students must be reeducated to identify knowledge before they are taught to draw conclusions.

Bloom recognized that knowledge was the basis for all education. The problem with the Taxonomy may not be in its construction but in its use. Practitioners who use the Taxonomy in this way fail to grasp that the lower orders of thinking are appropriate and even desired at younger ages and grades, as Bloom understood education. What Bloom argued 10 years before the publication of the Taxonomy was

"if progress is to be made in the field of education, teachers must see their job clearly. They must know their own purposes and goals, they must know when they achieve these goals, and they must know where and why they fail. To do this, they must set up their objectives, measure initial status of students with respect to these objectives, teach, measure final status of students, analyze results to determine success and failure; then they must repeat the cycle over and over again, revising objectives, revising instructional procedures, revising measurement devicesproviding a continuous program of education improvement. To strive to achieve certain objectives, the teacher himself must cherish these goalsthey must be his in every sense of the word- and they must be stated, not to convince others, but to furnish working guides for the total learning process" (Bloom, 1944. p. 140).

Bloom provides to educators the appropriate method by which the Taxonomy should be used and how standards and assessment benefit students. The Taxonomy allowed professors to understand what level of cognition their students had achieved. It had narrow design parameters and provided helpful, but limited, information. 
However, culturally, great value is placed on the advanced. The relative value of what education provides to individuals is a societal question and one that many educators participate in. Education as a cultural goal must have benchmarks for success and a terminus by which the success of the system can be assessed (Eisner, 2001). In the American educational system, good teachers know that they are responsible for defining goals and helping their students reach them. Bloom believed that all students have the ability to learn what schools have to teach given sufficient time and attention (Bloom, 1978; Bloom 1977; Resnick, 1977; Bloom, 1974a; Bloom 1974b; Bloom 1972). There is no rushing this process.

\section{Taxonomy and Assessment}

Bloom's perspective on education shaped the development of the Taxonomy. Mastery and time are not addressed in the Taxonomy itself. The Taxonomy simply creates levels by which students' outcomes can be understood. These levels were created to categorize examination questions given to college students during the 1950s. The measurements were gathered in exams given to students at the completion of a course of study. Individual departments within the University setting designed these assessments and the process of organizing the results taxonomically was to encourage the professors to consider the outcomes that their program had achieved.

However, in the decades since the Taxonomy was written, standardized exams have become commonly used in the K-12 setting (Burroughs, Groce, \& Webeck, 2005; Berube, 2004). Politicians and others use standardized exams to determine success and failure of groups. They are used to establish commonalities of success and failures. 
Since the results of tests can be arranged taxonomically, educators have begun to use the Taxonomy as a planning tool.

As K-12 educators began to use Bloom's Taxonomy, the usage of the Taxonomy was expanded as educators recognized that each of the categories offered a prescription of skills for students. Education of students can now be systematically described through language, specifically verbs, which enable educators to categorize their lessons and goals while monitoring student achievement in terms of the Taxonomy. Naturally, as educators saw the value, so too did other stakeholders. They began to recognize that a Taxonomic approach to education would allow for learners and learning to be classified along the same scale (Anderson, 2002).

Bloom's Taxonomy inherently provides value levels for knowledge, though Bloom did not believe that a given type of knowing was more valuable than another. He did wish that educators would engage in "the systematic ordering of our basic knowledge in such a way that what is known and true can be acted on, while what is superstition, fad, and myth can be recognized as such and used only when there is nothing else to support us in our frustration and despair" (Bloom, 1972, p. 334). Curriculum and pedagogy should be organized in such a way that the practice of educators is understandable, communicable and practical. The Taxonomy serves as one way in which these goals may be approachable.

Systems structurally place value. In American education, value has long been debated. With the vast quantity of what could be taught to students, society must make decisions about what should be taught and Bloom's Taxonomy made the act of defining value easy without facing the challenges of making the decisions using other criteria 
such as curriculum or pedagogy. The Taxonomy, in that sense, seems to be valueneutral and objective. It allows decisions to be based on actions and not on context as if this is culturally more neutral.

\section{Cognitive education above all others}

The history of education is marked with discussion of educational value and practice. William Schubert reports that Herbert Spencer, in 1861, asked what knowledge was of most value. Society has reconstructed what is valued in education repetitively. Schubert points out that the educational system that emphasizes cognition limits the education and fails to address the affective forms of learning such as "needing, experiencing, doing, being, becoming, overcoming, sharing, contributing, and wonder" (Schubert, 2009. p. 23). Schubert's list approaches the affective domain as much as Bloom's Taxonomy addresses the cognitive domain. Adopting any taxonomic approach to education that stresses one area as more valued than others creates difficulties for the process of educators. Bloom and the team of educators that he worked with identified but failed to execute this balance through the affective and psychomotor domains.

Current discussions in education value the cognitive domain through the use of taxonomic and standard approaches to education while educational researchers tend to be more interested in identifying the affective domain. Many educational theorists will argue that education without the consideration of the affective and psychomotor domains is a partial education. Merryfield \& Subedi (2006) argue in this vein saying, "through the integration of global knowledge and cross-cultural experiences, students develop perceptual skills in empathy, open-mindedness, and perspective consciousness, including the ability to explain an event or issue from multiple perspectives" (p. 284). 
Multiple perspectives may also be described as other ways of knowing and these traits are found in the affective domain.

Cognitive outcomes are important but limited in terms of the scope of education. Bloom's Taxonomy was written to address the cognitive domain, but additional questions emerge in education about a singular taxonomic approach to education. Fear of values-based education may cause teachers to flee from higher order Bloom's activities. Analysis, synthesis and evaluation require the transmission of cultural values. Darling-Hammond (2006) argues that some teachers believe that higher order skills, "necessarily involve indoctrination of beliefs. They are rightfully wary of coercing young students into believing certain things and they don't see a workable alternative to inculcating values claims" (p. 268). They see these skills as threatening the neutrality of the curriculum and their position as conveyer of information.

The Taxonomy is used to defend teaching students knowledge that is valueneutral but as stakeholders give lip service to valuing higher order thinking, the Taxonomy also functions in another way. Teachers are able to take the Taxonomy and quantify what they teach. The Taxonomy may also fuel the "belief about the nature of thinking skills that says that education can be methodology-rich and yet content-free or content-light" (Booker, 2007. pp. 351-352). By depending upon methodology while neglecting or minimizing content, teachers can defend their work to society while avoiding addressing the curricular debates around content. It is critical for society that we consider what students learn and where they learn in (Anderson, 2002). This can be analyzed through alignment of content with standards in a Taxonomic approach to education. This tension emerges in social studies education very clearly. 
Bloom's Taxonomy provides a structure by which assessment for cognitive development may be completed. It appropriately defines cognitive goals for educators and levels of assessment focused on students, "within a larger curricular framework and oriented toward valued goals" (Mathison \& Fragnoli, 2006. p. 207). Education does have value-laden goals and society contests the relative values to these goals. Identifying and articulating these goals is critical to the success of preparing students for adulthood.

Educators who teach students to learn beyond lower order ways of thinking open themselves to the charge of partisanship and indoctrination if the educational climate fails to support them in allowing students to develop skills of questioning and evaluation. Pointedly, Evaluation, as per Bloom's Taxonomy, requires students to develop the ability to assess relative value (Hills, 2004). There is an inherent necessity in the educational process for students to develop these skills. However,

"in much of our professional socialization, teachers of all grades learn that we are supposed to remain neutral conveyors of information. Teachers who want to explore complex political and social issues, especially issues on which they have strong views, risk accusations of being too political, of indoctrinating students, or in today's political parlance, of pushing political correctness" (Kohli, 2000. p. 28).

Kohli clearly articulates that the cost of teaching advanced skills in an unfavorable environment may lead to partisan charges of inculcating particular values.

Bloom's Taxonomy defines the highest cognitive functions as the evaluation and synthesis of material. By applying the Taxonomy to teacher's work, some argue that the teacher's perspective is made explicit. As the curriculum is analyzed through any taxonomy, teacher's decision-making process may be revealed. Teachers use language to describe what they teach and what the student outcomes should be. By structuring 
lessons with this language, education is thought to be protected from "hidden" values.

This sounds subversive and disturbing as if society is out to get teachers and teachers are out to indoctrinate students (Nelson \& Pang, 2006). The idea of revealing the "hidden" curriculum undermines the teacher's professional training and responsibilities.

\section{Bloom's Taxonomy in Higher Education}

When Bloom's Taxonomy is applied at the collegiate level it is not by way of assessment but through planning. This raises a question: does every lesson by a teacher result in a measurable response from the student? Booker (2007), a university professor, was instructed to create statements of learning for his classes that used action verbs, none of which could be at the Knowledge Level as it was deemed to be "too low" for college. This was surprising to him, as he firmly believed that he was to be teaching his students knowledge and higher thinking skills. His critique of the Taxonomy as a planning tool was the work of education happens at all levels of the Taxonomy and to speak as though a professor should not be planning on adding to a student's knowledge demonstrates a lack of understanding of the classroom at all levels.

Sharing this critique and similar administrative directives, Doughty (2006), reported that he was instructed that "words such as 'understand' are essentially useless because 'passive' terms 'do not convey what the student should be doing'" (p. 10). He rejected the notion that the education that he offers to his students results in a measurable action as he says, "I am stumped when it comes to describing what happens when students 'do' wisdom" (p. 19).

Booker adds to this claim, "Bloom's Taxonomy has been used to devalue basic skills education and has promoted 'higher order thinking' at its expense" (Booker, 2007. 
p. 348). Basic skills have value as creating the groundwork that students can then use for higher order thinking. When teachers are responsible for justifying every lesson with student action and the hidden curriculum becomes the center of educational inquiry, all events in the classroom must be described. This description requires teachers to justify every lesson as if education were a physics problem where every action has an equal and opposite reaction.

The application of Bloom's Taxonomy may have created a broader notion that by controlling inputs educators can control outputs with respect to students. Scientifically Based Educational Reform (SBER) claims that it seeks to standardize teachers, curriculum and outcomes among diverse students who cannot be standardized and whose experiences cannot be controlled (Mathison, Ross \& Vinson, 2006). While Bloom's Taxonomy worked on developing a standardizing language for education, SBER and No Child Left Behind (NCLB) have taken the standardization to a higher level and demonstrate that standardization is not necessarily an educational strength (Love, 2009).

This hidden curriculum made public is increasingly critical in the face of modern educational trends. The current push of No Child Left Behind (Anderson, 2009) and the application of SBER have left education with the requirement to state what the goals of education are and for teachers to align every lesson to these goals describing the action of the students. For social studies education, goals may be nebulous and depend upon the political climate. Thornton (2005) argues that "in theory, the goals of particular courses, such as U.S. history, are based on these broader aims in turn, the specific objectives of units of instruction and lessons, which normally teachers devise, are 
supposed to be derived from course goals" (p. 45). The goals of social studies have to be broader than the goals of the individual courses.

\section{Student Achievement}

Bloom's Taxonomy was developed as a tool for teachers to use to assess student learning. Yet, the Taxonomy is increasingly used to develop curriculum standards, as it formatively plans curriculum that students will interact with (Noble, 2004). The matching of assessment and planning is an important component of education, but it presupposes that students begin with a common level of knowledge and experiences (Eisner, 1995).

As students do not begin formal schooling with identical experiences, using a single progression that assumes a given starting point is inherently flawed. As a planning tool, the Taxonomy begins to look like a rubric. James A. Hills (2004) considered just this by "juxtapos(ing) Bloom's cognitive taxonomy as a rubric with any subject matter rubric. Advancing along the cognitive continuum thereby becomes the aim of the system" (p. 58). Rubrics demonstrate given levels of achievement and are scored by advancing in a given direction to a pre-determined goal. If the Taxonomy is a rubric, then education is achieved by students when they reach the highest level.

This process of assigning students to given levels of cognition. Bloom was bothered by this use of the Taxonomy. In a biographical sketch of Benjamin Bloom, Anderson wrote, "tests and other forms of evaluation are still used primarily to classify and sort students rather than to help educators better understand students so that they, in turn, can provide appropriate instruction of high quality" (Anderson, 1996. p. 83). This demonstrates a challenge that Bloom's Taxonomy presents. Is it a tool that can turn any 
subject matter into a rubric or is it a way to assess what students know and enable teachers to more effectively instruct their students? Part of the answer for this lies in the use of the Taxonomy as a method by which curriculum standards are developed and students are assessed.

Testing measures and curriculum standards depend upon language for assessment. Curriculum standards use language to layout expectations for teachers and tests assess the learning of students (Anderson, 2005). This method of assessment has conflicting narratives. For many, standardized tests are a poor assessment of student for methodological reasons (Anderson, 2009). However, Bloom (1944) argued that "if progress is to be made in the field of education, teachers must...know their own purposes and goals, they must know when they achieve these goals, and they must know where and why they fail" (p. 140). Assessment is a critical component of education and, for Bloom, it empowers teachers to improve the education that they provide to students. The process of assessment is powerful for teachers, as Mathison and Fragnoli (2006) argue, "assessment for learning helps the teacher to create the scaffolding that enables more and better student understanding of what is being taught" (p. 201). This process of scaffolding empowers teachers to most effectively prepare students for the future. In 1944, Bloom demonstrates his commitment to assessment as he believed that through assessment, "test experts and teachers should be successful in mapping out the range of objectives in each course of instruction now offered in our educational institutions and in stating them in such terms as to offer guidance for all who state or select them" (Bloom, 1944. p. 141). 
Bloom's Taxonomy classified learning through language, specifically action verbs. Education hinges on language and by classifying learning in this way, teachers, assessors and stake holders can share a commonality of language that enables them to communicate (Krathwohl, 2002; Bloom, 1972). The system was developed during an era in which students were expected to learn through direct instruction; thus the work of the teacher needed to be constructed in such a way as to maximize student success (Krathwohl, 2002). Educators believed that through the instruction of teachers, students would learn and the Taxonomy would quantify how much they had learned not by asking for a regurgitation of facts (knowledge) but by analyzing the language used as it reflected cognitive processes.

This depth of analysis of assessment seem to have been abandoned in favor of simple knowledge based exams. In a 2007 report, Crocco and Costigan found that teachers experienced increasing limits on pedagogy and curriculum as they had to prepare students for factual exams. By conducting more than 200 focus group interviews of teachers with fewer than five years of experience, they found that teachers reported increasing instances of standardized approaches to teaching (Crocco \& Costigan, 2007). This standardization, which began in the early $19^{\text {th }}$ century both in knowledge and organizational forms, left the teachers feeling as though they were unable to develop as teachers and unable to learn to make critical decisions for their classrooms. Teacher's frustration led them to feel pressured to cover vast amounts of material, driven by the testing model that the state follows. The work that teachers found they were expected to do was to prepare students for a basic cognitive exam. 
For Crocco and Costigan, the highly standardized system led the teachers to teach what was assessed and to view their classroom not as a community but as a generic group of learners. For these teachers, standardization stood opposite of community. This is not to say that they believed that assessment was the problem, but rather the standardization of assessment across unique populations and communities led to an inability to tailor the curriculum to meet the needs of their particular classrooms.

Good teachers know that they are responsible for defining goals and helping their students reach them. The public educational system in the United States requires education to be outcome dependent (Burroughs, Groce, \& Webeck, 2005) and uses standard measurements to assess the results. The outcomes should be fixed but the time and attention should be flexible based on the needs of individual students.

\section{Bloom's Taxonomy and Social Studies}

Social Studies education has had an internal history of controversy. Biesta (2006) describes this struggle as a competition between to narratives about the content of social studies when she argues that, "once upon a time- modern time- there lived a subject. This subject was seen as the autonomous, pre-social, and trans-historic source of truth and rationality and of its own identity" (p. 33). This image of social studies conflicts with the reality that Biesta then presents. Social studies education has never been value-free and trans-historical. It is fundamentally concerned with how society views itself and the world in which it operates. It is inherently civic and ever evolving as society changes and the community's values shift.

The relationship between the school as the place of education and the school as a social organization for students is indisputable. Students are active participants in their 
school community and the cost of failing to engage students as civically-minded members of this community is great (Stiff-Williams, 2010). As civics falls into the formal domain of social studies, it is critical to consider how civic-mindedness and Bloom's Taxonomy intersect or diverge from each other as disciplines. Social studies is concerned with developing deep thinkers who are civically active. Simultaneous with this, education is increasingly driven by standards, which are informed, in part, by Bloom's Taxonomy. These standards aid educators in a carefully assessing their practice and student progress (Stiff-Williams, 2010).

Students live in situations that are inherently civic and communal as they spend much time with their peers in a social space. The cognitive component of education that is heavily valued by standards addresses little of this common way of life and it is up to educators to address the affective skills that students need to be strong and effective citizens (Stiff-Williams, 2010; Biesta, 2006). Benjamin Bloom recognized this fact but ultimately failed to draw equal attention needed to affective education as he did to cognitive education.

The lack of publicity to the affective domain of learning has led some to heavily criticize Bloom's Taxonomy. According to some, Bloom's Taxonomy "has contributed to a society of exploited producers, compliant consumers and submissive citizens" (Doughty, 2006. p. 2). This reflects the roots of the Taxonomy in Behaviorism where the goal of education may function as a mechanism of control. The cognitive Taxonomy, when viewed and used in isolation has led some educators to push back against the perceived silence on other ways of knowing and learning. Doughty (2006) goes on to argue that the use of the Taxonomy may allow for education to be, 
"transform(ed) from a dialogue into the personal acquisition of pre-digested, prepackaged and pre-determined chunks of knowledge or individual competencies" (p. 2). This shift from a dialogue, which is inherently social and civic, to the imparting of cognitive data is quite problematic for civic education. Civics should be taught in a manner that is civically-minded and not through poor pedagogy that separates content from pedagogy.

This separation has been the consideration of Diana Hess for many years as she considers the way in which students learn through talking. Diana Hess (2009a) argues that the way in which students learn is directly tied to level of work that they are engaged in. She has studied the way students engage in political talk and has identified that students who engage in high-quality, knowledge rich debate learn more. She says that the process of articulation is a key component of student learning and she argues that through debate "individuals will become better informed- quite simply, they will know and understand more. People who are lucky enough to have had experience with high-quality political talk often recognize that they are learning- both from what they hear and what they say" (pp. 17-18). For her, student outcomes are dependent upon the ability of students to articulate their point of view in respectful but divergent ways so that they are able to shape their opinions and be impacted by the opinions of knowledgeable peers and instructors.

\section{Curriculum}

For students, the primary way in which they gain formal cognitive knowledge is through the textbook. The textbook is selected as one that meets the criteria set forward by the state standards for a given course. It is, therefore, tied to the Taxonomic 
approach to education as it is the medium by which the teacher is to help the student advance through cognitive growth.

In social studies, the cognitive aspect of learning easily trumps other ways of teaching and knowing, particularly through the presentation of knowledge in textbooks and classical pedagogical styles of lecture. "Textbooks are steeped in a fact-based, chronological presentation of history that is disconnected from and irrelevant to the lives of the students who use them" (Marker, 2006. p. 87). If Marker is correct, then textbooks and the presentation of history stand opposed to civic ways of living, as civic knowledge and practice are directly linked to and relevant for students.

Bloom articulated a similar issue in 1977 when he said "the curriculum and textbook makers and the teachers first attempt to organize learning tasks by subjects or fields of content, then to arrange them in a sequential or logical order" (Bloom, 1977. p. 194). The Taxonomy informs standards; standards inform curriculum choices. The increasing trend in education is to look at education as a fixed progression from one point to another and to describe and address this progression in a cognitive manner (Eisner, 2001).

Standardization, therefore, must neglect significant individual notions of students and communities. Students are increasingly aware of conflicting narratives about the past and thus driven to ask new questions (Vinson, 2006). Whelan (2006) argues, "in the increasingly interrelated complexities of our modern, global existence, the more things change the more things change more. Thus, any effort to standardize the content of a history-centered curriculum, no matter how well intentioned, assumes, but erroneously so, that all students will always need to ask the same questions of the past" 
(p. 44). Standardization must ignore competing narratives, as they do not lend themselves to simple assessment across a large sample.

This standardization may lead to social studies being taught as a story of resolved conflicts. One clear example of this silence may be found in women's history or that of other minority groups. Crocco (2006) argues this point that women's history is taught as a knowledge area that does not deserve higher levels of analysis because the work or equality has been achieved. It is a historic fact as presented by textbooks. By using the language of Bloom's Taxonomy, teachers can avoid controversy, they can avoid analysis and they can avoid uncomfortable discussions. Students are not asked to develop their own opinions or their own values. By teaching the issue as closed (Hess, 2009b) students and teachers can avoid difficult conversations (Hess, 2011) and what students "know" may be easily seen and assessed. It is possible to consider standards as closed issues, as they present the expectations for a course as fixed and non-negotiable.

This is a negative and grim analysis of the intersection of standardization and social studies. Social studies is concerned with preparing students to be citizens and to equip them with the knowledge, skills and attitudes that will inspire them to be actively engaged in their community (NCSS, 2010). This exercise is "inevitably a moral enterprise" (Darling, 2006. p. 267). It is also messy. In contrast to this negative view, it is critical that social studies teachers recognize ways in which standardization, assessment and a taxonomic approach to education may be helpful.

Bloom's Taxonomy provides social studies teachers with a framework within which they can evaluate both their practice and student progress. If Bloom is correct and all students can reach basic competency levels given enough time and attention, then 
his work is critical for teachers to consider (Resnick, 1977). This leaves the crafting of standards and assessment to educators who should have clearly articulated goals for their students.

Bloom's Taxonomy can promote reflective teaching and learning practice. It can empower educators to promote the learning methods of Dewey and Thornton (2005) as they identify foundational knowledge and connect it to broad concepts and themes (Marino \& Bolgatz, 2010). This opens the door for educators to engage in authentic practices that enable students to grow into citizens with the skills and practices to think deeply and engage in meaningful civic activities.

\section{The Teacher}

Thus far the taxonomic approach to modern civic education has been explored as has the development of and use of standards in school systems. Both of these function to broadly impact the education that all students receive, but there is an interpreter who takes these documents and uses them. This is the teacher who plans instruction on the basis of course requirements and assessment plans by the school. The teacher takes the curriculum and standards and applies them to the students in their classroom.

Social studies teachers are the gatekeepers of knowledge and practice in their classroom (Gerwin \& Visone, 2006; Mann, 1989). They are the ultimate decisionmakers about the curricular and pedagogical choices that are made in their classroom communities. As social studies teachers are called by their national organization, NCSS, to be responsible for teaching civic-mindedness to their students, it is critical to consider their roles of decision-maker and practitioner in their classrooms (NCSS, 2010; Noonan, 2010; Splitter, 2010; Vinson, 2006; Patrick, 2003; Hahn, 2001b). 
In this age of accountability and testing, many find that social studies is frequently pushed aside, particularly civic dispositions which take a backseat to knowledge as teachers focus on information that can be assessed on standardized tests (Cohen, Pickeral, \& Levine, 2010; Misco \& Shiveley, 2010; Abrams, Pedulla, \& Madaus, 2003).

With the rise in required standardized assessment tools, the curriculum offered to students is narrowing. Even with this, teachers report high levels of comfort with civic content (Torney-Purta, Barber, \& Richardson, 2005). According to Drake (2001), standardization has led many teachers to see learning in very discrete components that do not relate to each other and are heavily weighted towards the knowledge domain of cognition. While teachers are confident in the knowledge of civic education, there remains no comprehensive set of actions or dispositions for them to teach (Buchanan, 2007).

The space in which teachers work is critical to their success and understandings of civic education, and the cultural milieu shapes the reality of teaching practice more than we may recognize (Andrabi, Bau, Das, \& Khwaja 2010; Laughlin \& Nganga, 2008; Torney-Purta, Barber, \& Richardson, 2005; Giroux, 2000). The 1999 IEA Civic Education study found that teachers in the United States believed that they were well prepared and capable of teaching civic knowledge (Torney-Purta, Barber, \& Richardson, 2005; Hahn, 2001b). In this, the taxonomic and standard approach to education has done what Benjamin Bloom feared when he said, "the availability of the taxonomy might tend to abort the thinking and planning of teachers in regard to curriculum, particularly if teachers merely selected what they believed to be desirable objectives 
from the list provided in the taxonomy" (Bloom, et al., 1956. p. 5). The literature shows that many are concerned with the cognitive limits on content due the rise in standards, assessment and a taxonomic understanding of learning.

The relationship of teachers to Bloom's Taxonomy is a question of who is the master. Does the Taxonomy dictate practice or does the teacher? If the teacher teaches a given cognitive level because that is the appropriate level for her student, then the teacher is using the Taxonomy as a tool. If they are teaching the cognitive level because they are told to teach a given level and do not consider the appropriateness for their students, then the Taxonomy is dictating practice, which is an inappropriate use of the Taxonomy. Bloom's Taxonomy may aid teachers in recognizing their pedagogical process as part of the critical experience that teachers provide to students (Bloom et al., 1956). The pedagogy of teachers and curriculum approved by society are tied to each other. What teachers teach and how they teach it can both be described by Bloom's Taxonomy. Teachers make curricular and pedagogical choices that can be understood in terms of standard learning experiences. The challenge is to discover if standardization of process helps the teacher, the students, or the system.

Dettmer (2006) clearly identifies ways in which taxonomies are helpful in the classroom. She identifies flexible learning objectives that allow teachers to create individual pedagogical approaches and curricular choices to maximize student success. She argues that gifted education and work in multiple intelligence theories have strengthen the taxonomic approach to education. This has occurred by forcing educators to engage richly in higher order thinking while simultaneously drawing much needed attention to the psycho-motor domain and affective domain. 
Planning and evaluation have a critical place in the classroom. Teachers who use Bloom's Taxonomy in their planning and evaluation must recognize that their students may learn on multiple levels simultaneously and that the learning may be individually dependent (Gardner, 2000). "While there are many factors influencing whether or not students learn how to discuss highly controversial issues effectively in classrooms, the single most important factor is the quality of teachers' practice" (Hess, 2009a. p. 53). Teachers can use tools from Bloom's Taxonomy to evaluate their own practice and to critically consider their curricular and pedagogical process. However, if teachers plan rigidly along the taxonomic scale, then the work of leading a productive discussion may be seriously compromised.

In a 2007 study by Bümen, Turkish teachers are challenged to begin the practice of day to day planning, which is not part of normative education practice in that culture. The study investigated how teachers could be equipped with Bloom's Taxonomy to increase their daily planning. Teachers were instructed to use the Taxonomy to plan and assess their lessons. Bümen says, "the process of stating objectives, planning and guiding instruction leads to sharper, more clearly defined assessment and a stronger connection of assessment to both objectives and instruction (Bümen, 2007. p. 441). The usage of this Taxonomy in Turkey resembles the common use in America. Teachers do use the Taxonomy for assessment purposes but they also use it to plan their lessons. This planning is for whole group instruction and not to track the individual educational development of students.

Following this current use, teachers have responded by arguing that students learn on multiple levels in a single lesson. This critical evaluation of the educational 
process reflects the current changes in understanding how students learn. Currently, educators believe that students can learn on multiple levels of Bloom's Taxonomy simultaneously (Booker, 2007). There is general recognition that students need to be challenged on multiple levels during the same lessons. Unfortunately, "knowledge construction (should be) by students rather than complete reliance on someone else's completed act of thought" (Thornton, 2005. p. 82).

This multiplicity of processes interrupts the original goal of Bloom's Taxonomy as Whelan (2006) argues, "in most cases, students studying history are merely expected to 'consume' the conclusions of others, and not 'produce' any knowledge or meaning for themselves" (p. 41). This presentation of knowledge does not allow students to connect or experience the material in a manner in which they can genuinely construct knowledge and move through the various levels of Bloom's Taxonomy.

\section{Teacher dispositions}

Teachers play a powerful and critical role in providing civic exposure and tools to students. Through modeling and advocating, teachers are able to provide students with a picture of what an engaged civic actor may look like through their own practice in their classroom. The dispositions that they teach and model set the stage for student engagement in the community (Osguthorpe, 2008; Schussler, Bercaw, \& Stooksberry, 2008). Teachers often seem to act without awareness that students are observing more than what they say, but also what they do. They provide an example to students of societal norms in both social behavior and intellectual contemplations.

If social studies, and specifically civics teachers, are going to permeate their students with civic dispositions, they must model these dispositions. However, many 
teachers see their primary role as transmitting societal norms to students without disrupting society (Ross, 2000). The dispositions that are valued in the classroom are those that do not disrupt society or the classroom. Teachers seek student behavior to be that which makes for an orderly classroom and thus orderly society, but this presumes the teacher values order over change and calmness over disruption. In a society that is plagued with problems, this reluctance to challenge students to move toward civicminded practice and democratic ideals creates a dynamic in which they are accepting of society, and do not possess tools to recognize and address existing problems.

Within all of this, the public faces a challenge in defining the role of the teacher. The teacher is an employee of the state and thus of society, however, society has left teachers with conflicting aims. Teachers are to teach civics to an orderly classroom and to generate quantifiable assessment. Yet, in a broader argument, teachers need to negotiate with society to form their position "as public intellectuals and teaching as a central dynamic of expanding democratic social relations within and across national and transnational terrains" (Giroux, 2000. p. 93). The conflict is that it is hard to quantify, assess and be free of disruption in a classroom that is engaged in discussion and formation of civic dispositions and the practice of civic action. The very civic notion of participation and change requires some disruption, which may resemble disorder in the classroom.

\section{Conclusion}

As civic education is one of the competing goals for education, the structure of the class is one that faces scrutiny and depends upon socially recognized documents. Civic education is shaped by the community in which it is being taught, the teacher and 
state documents. All of these items have been impacted by educational documents, most particularly Bloom's Taxonomy in an era in which standardization and assessment are emphasized. In civic education, the guiding, standardizing documents are published by the state. These documents are shaped by Bloom's Taxonomy and NCSS. This research considers how these two documents have shaped civic education through standards and through the work of the teacher.

Civic education in West Virginia has been defined as critical to the success of education in the state. It is the capstone social studies class and by defining the goals and structure of the class, educators are given guidance as to the type of class that the students are to participate in. By considering the way in which goals are structured by Bloom's Taxonomy, the researcher presents civic education in its educational milieu. Bloom's Taxonomy was constructed to consider student outcomes but has become a commonly used planning tool for states.

The organization of goals along a continuum presents a critical component of education: that educators have a roadmap along which they travel with students. In that Bloom's Taxonomy is commonly used and is reflected in the work of West Virginia teachers, it is an appropriate document for research and consideration. This educational roadmap is helpful for teachers and stakeholders in education as they create a common understanding of a course, even as the ultimate goals and directions may be contested. Without goals and assessment, discussion is stifled.

To facilitate a common understanding, it is critical to investigate how the state standards are used by a teacher and how underlying academic sources are framing the civic mission in West Virginia's schools. 


\section{Chapter 3}

\section{Methods and Procedures}

This study uses a mixed methodology employing qualitative tools of open-ended interviews, informal interviews and classroom observations with quantitative analysis of state standards using Bloom's Taxonomy as a framework in which to consider both the state standards for $12^{\text {th }}$ grade civic course and teacher generated lesson plans. By narrowing the research focus to the NCSS definition of civic education, the teacher, civics course and standards may be evaluated in two forms. The first is whether the state standards align to the NCSS definition of civic education. The second is to consider at what cognitive level the teacher and standards present material to students. The civics course, teacher and standards are evaluated by comparing them with the NCSS definition of civics and by considering the cognitive level at which material is designed and presented.

The textual analysis began by assessing the alignment of the state standards with the NCSS civic definition and by analyzing the level of Bloom's cognitive taxonomy. The same outline is then applied to the case study subject's lesson plans. These two separate analyses are then paired with a qualitative analysis of the teacher's translation of standards and lesson plans into the interactive process of educating students. The qualitative observations, discussions and analyses provide the framework, comprehension and perspective of the teacher, which facilitates closer inspection of how the teacher approaches her work and provides context by which the quantitative analysis may be interpreted. 
In order to appropriately prepare future citizens, it is critical within this analysis that the teacher and the state be held up to the standard issued by NCSS which argues that standards "provide a framework for professional deliberation and planning about what should occur in a social studies program in grades pre-K through 12" (NCSS, 2010. p. 3). In that the standards are the structure under which teachers create lessons and execute the curriculum, states use the standards to provide a clear framework that is in keeping with the goals of education. For social studies, this goal is to prepare civically-minded citizens.

West Virginia approached the necessity of educating citizens by adding a fourth social studies requirement for high school graduation. These standards for $12^{\text {th }}$ grade civics need to be considered in light of the cognitive level and NCSS definition for civic education. NCSS provides a definition; Bloom provides a framework; the standards provide the plan; the teacher acts as the executor. The synthesis of these factors function together to prepare students to be engaged citizens within their community.

In the American educational system, states mandate the content of students' education through standards that describe the courses that students are to take. NCSS (1994) argues "the importance of social studies ensures that policymakers, educators, parents, and citizens of all kinds will want to know what students should be taught, how they will be taught, and how student achievement will be evaluated" (p. viii). For some stakeholders, standards and course descriptions that elucidate the goals of civics are synonymous with the goals of a government course. However, this is not a universally held perspective, and some states have opted to require a course in civic education that is distinct from government courses. 
The distinction between the two types of courses is frequently argued to be the difference between political knowledge and community knowledge, action and beliefs (Bos, Williamson, Sullivan, Gonzales, \& Avery, 2007; NCSS, 2010). Therefore, the selection of a course is intentional and articulates a particular vision for what the course should entail. This choice reflects the goals that the individual states have for social studies education (Journell, 2010).

The researcher believes that state standards represent an intentional choice related to the goals and content of the civics course and that the standards that have been developed are designed to aid teachers in planning pedagogy and curriculum. The standards provide teachers with a framework in which to understand how to meet societies' goals for education. The framework is responsible for presenting guidelines that enable teachers to achieve the goals of the state. The researcher also believes that these documents lean toward the knowledge domain of cognitive learning. This trend to emphasize the cognitive domain is seen in the literature (Altoff, 2008) and demonstrates the central need to consider the role that Bloom's cognitive taxonomy plays in education.

Employing a mixed research methodology enables the researcher to address the textual analysis and to provide context within a West Virginia civics teacher's understanding and application of the state documents. This qualitative study depends on rich data and careful analysis of the data and as Merriam (2009) states, developing an "understanding the meaning people have constructed, that is, how people make sense of their world and the experiences they have in the world" (p. 13). Characterizing this "sense" is critical for answering four major questions: how teachers approach teaching, 
why they teach, how they view the material they teach, and how they view their students.

The situational context of rural Appalachia is underrepresented in the body of civics research. Appalachia has unique cultural dynamics that should be studied to investigate how schools and communities intersect and this research addresses that silence in a small way. The social context is critical to interpreting the qualitative results and it is the social context of rural West Virginia that provides an important perspective on how civic education functions in a racially, but not culturally, homogenous, socioeconomically disadvantaged region.

\section{Theoretical Framework}

This study was conceptualized using grounded theory to compare and contrast teaching methods, styles, dispositions, purposes, and pedagogy as discovered through the typical case sampling and document analysis. Grounded theory is a theoretical methodology described in 1967 by Glaser and Strauss (Merriam, 2009). The goal of grounded theory is for the researcher to be the primary collector of the data.

Additionally, the researcher is responsible for constructing meaning from the data and continuously combing the data and the research questions. In grounded theory, it is critical for the researcher to develop and rich and deep data source from which to draw conclusions. Without this data, the researcher is unable to draw meaningful connections, or connections that create theory to describe what had been observed (Merriam, 2009; Yin, 2009; Patton, 2002).

The heart of the process of grounded theory lies in constant comparison. Conclusions are drawn out of the data and as they emerge, they are 
evaluated by the data to triangulate the validity of the data. The triangulation involves using the different data sources to confirm the conclusions. This process is ongoing throughout data collection to ensure that similarities and differences are considered while categories for analysis are being coded. The study moved through basic description, to conceptual ordering, to theorizing (Patton, 2002. p. 490). It was designed to allow emerging themes regarding teaching practices to develop by using the analysis of consistent and constant comparison.

Merriam (2009) argues that the methodology that streams from grounded theory has shifted over time in keeping with the adaptive nature of the theory to reflect other qualitative methods. Specifically, the methodology draws on the perspective of postmodernism (p. 31). This research project makes use of the postmodern perspective, particularly by using practices from critical theory to compliment and inform the development of grounded theory in this study. As the researcher approaches the analysis of documents as distinct but complimentary analysis to the case study data, the pairing of critical theory with grounded theory is appropriate in this circumstance.

Critical theory inherently values the location of the research as an intrinsic component of analysis. As such, the theoretical framework makes use of critical theory. Critical theory considers the context of research as imperative to the interpretation (Merriam, 2009). This research investigates the community as critical to the understanding of civic education. Critical theory considers issues of the construction of knowledge, which can be seen in the construction of standards. Critical theory is concerned with challenging the data and changing the perspective of society on the research data source (Merriam, 2009; Patton, 2002). In this circumstance, critical theory 
will be applied to state documents that shape the content and structure of civic education in West Virginia.

\section{Methodology}

This study used a mixed methodology combining Bloom's Taxonomy and the civic definition offered by NCSS to evaluate WV state standards and the work of a practicing civics teacher. The textual analysis of the WV $12^{\text {th }}$ grade civics standards qualitatively assessed what the standards communicate to the teacher and how Bloom's Taxonomy and NCSS are incorporated. The quantitative analysis evaluates the frequency of themes and language as defined by NCSS and Bloom's Taxonomy. Textual analyses are paired with quantitative and qualitative analyses of a civics teacher's lesson plans and a qualitative assessment of practical application employed by the civics teacher. By pairing two research techniques, the researcher hopes to present results that represent the intricacies of civic education in West Virginia.

The research questions may be more fully answered as the research conclusions are strengthened through triangulation (Patton, 2002). Merriam further explores this idea by identifying four methods by which triangulation can be used (Merriam, 2009. p. 215). These methods include using "multiple methods, multiple sources of data, multiple investigators, or multiple theories to confirm emerging findings" (p. 215). The researcher in this study has identified multiple theories of critical theory and grounded theory as well as using multiple sources of data and multiple research methods in considering both textual analysis and a case study participant.

The observations of the case study were developed over time to include various civics classes and over the duration of a school year so as to represent the broad practice 
that took place in the classroom over time. The observation allowed the research to better understand the classroom setting, to be able to contextualize both what the teacher said and did in a particular classroom, and to ascribe meaning to the teacher's actions and statements during an interview. Namely, the observations function as a method of triangulating the content of the interviews (Patton, 2002).

\section{Research Questions}

The purpose of this research was to examine how West Virginia's CSO's for civic education conform to the definition of civic education presented by NCSS. The analysis then considers how the language of the state standards for civic education uses Bloom's Taxonomy. After these two questions are addressed, it is critical to investigate the use of the standards in a classroom. This qualitative case study offers a picture of one application of the standards in a classroom and to consider how one teacher uses the standards. The researchers used specific questions to code and categorize the documents and guiding research questions to frame this study with the case study.

The document analysis considered the following questions.

1. What is the frequency with which the WV $12^{\text {th }}$ grade civic Standards meet the three components of civic education (actions, dispositions, and knowledge)?

2. How does the $\mathrm{WV} 12^{\text {th }}$ grade civic Course Description align with the NCSS definition of civic education?

3. How do the WV $12^{\text {th }}$ grade civic Performance Standards align with the NCSS definition of civic education? 
4. How do the WV $12^{\text {th }}$ grade civic Standards align with the NCSS definition of civic education (NCSS, 2010)?

5. Using Bloom's Taxonomy as a framework, how do the West Virginia $12^{\text {th }}$ Grade Civic Standards demonstrate cognitive learning?

The guiding questions for the case study analysis of a West Virginia $12^{\text {th }}$ grade civic teacher are as follows:

1. How do you view the community of your school?

2. How do you define civic education?

3. How do you assess civic education?

4. How do lesson plans and state documents inform your pedagogy?

5. How does the classification of lessons on the basis of Bloom's Taxonomy impact your planning and implementation of classroom practice?

These questions were constructed to be manageable for the scope of the project, advancing the research on West Virginia's CSO's and investigating the interplay of civic education, with the professional standards and literature.

\section{Sampling method}

Typical case sampling was used to select the participant for the case study. Typical case sampling involves selecting a participant on the basis of their "the sample is illustrative not definitive" (Patton, 2002. 236). This illustrative case was selected to answer the research questions fully. The teacher and community were selected because it is typical of West Virginia. This sampling is purposeful and was done before the data 
was collected, as the context of the classroom and teacher shaped both the data and the questions that were developed and emerged from the data as it was collected (Merriam, 2009).

\section{Case Study}

The research strategy of applying the quantitative data to a single case is based in the portrayal of one teacher's experience operationalizing the documents that are being considered (Yin, 2002). Documents do not exist in a vacuum and they do not apply themselves. Education, in America, is fundamentally concerned with the application of material in a relational context of teacher and student. Case studies allow for a careful and deep consideration of how the application of documents may play out in a classroom.

The case study allows for the researcher to deeply consider the relationship between teacher and student and teacher and documents. By systematically and comprehensively investigating these relationships, researchers may gain a richer understanding of what motivates a teacher and their educational perspectives.

Yin (2002) argues that the case study is appropriate for:

1. Investigating the situational professional knowledge, which is highly complex.

2. Investigating multiple sources of data, which are sensitive to context.

3. Studying teacher's knowledge and perspective as it is personal and rooted in their experience.

The researcher chose to use a case study approach to investigate the "why's" and "how's" of civic education in a particular context as it was the most appropriate and deepest way to answer the research questions. 
The Institutional Review Board of West Virginia University approved the study. The participant was assured that the data would be secured and a pseudonym would be used. The teacher was informed that their participation was voluntary and they could end their participation at any time.

\section{Data Collection}

Data was gathered through semi-structured interviews, emails, informal conversations, and class observations. Each interview was semi-structured, recorded, and transcribed. The transcriptions were analyzed for core consistencies (Patton, 2002) and compared with other sources of data. These consistencies were problematized, and divergent themes were considered across the data. The researcher spent substantive time with the case study participant, observing multiple classes over the course of two years, communicating informally with the teacher and formally interviewing them. The relationship between the researcher and subject allowed for a level of professional rapport to develop and allowed the researcher access to the thoughts and personal perspective of the subject.

The teacher was interviewed three times, extensively with each formal interview lasting roughly an hour. She was observed upwards of 25 times, and engaged in far more informal conversations and emails. These narratives and observations were carefully coded for themes, convergence, and divergence in keeping with qualitative research practice (Patton, 2002). These interviews provided a major source of data and they allowed for other source material to support or challenge the teachers' personal descriptions. In answering the research questions, the subject offered a strong personal perspective on civic education, its value and pedagogical approach. The teacher had a 
deep love of teaching and their personal narrative shaped their perspective and pedagogical approach to the subject matter. A deeply committed civic teacher, the subject identified strongly with the community in which they taught and had a relationship with many of the families in the community. This engagement shaped their perspective on the value and teaching of civics.

\section{Content Analysis Procedures}

\section{Using the NCSS Definition}

A single professional text allows the researcher to develop a common standard by which to evaluate the state documents. This definition allows for commonality of critique to be applied to all civics courses. The civic definition of NCSS allows the researchers to evaluate if the WV civics standards have developed a course that meets the common definition of a civics course. The National Council of Social Studies is the professional organization that guides the practice of social studies teachers around the nation and is the common organization for offering guidance to both states and teachers as to the appropriate practice of social studies education. This standard can then be qualitatively applied to the practice of a civics teacher. The case study participant's practice and lesson plans may also be evaluated on the basis of their compliance with NCSS.

\section{Using Bloom's Taxonomy}

The choice of Bloom's Taxonomy was made by the researcher due to continued use of the cognitive taxonomy by West Virginia's teachers. All lesson plans are scaled to Bloom's Taxonomy and teachers employ the taxonomy to categorize their lessons. The lesson plans are submitted to the school administration as a way to maintain 
accountability for the teachers. They are the formal document that describes what teachers are doing in the classroom and what experiences students will have. Both the lesson plans and the standards will be evaluated using Bloom's Taxonomy to uncover and investigate the ways in which the standards require levels of cognitive process.

The analysis of these data is clarified by applying Bloom's Taxonomy to the language. The Taxonomy provides a way for researchers to categorize and understand the way language is used to require increasingly complex levels of thought (Wen-Chih \& Ming-Shun, 2009). Bloom's taxonomy allows the researchers to consider the role in which language empowers/requires teachers to teach dispositions and behaviors. The question emerges from the research: how do you teach dispositions and behaviors? Dispositions and behaviors are communicated through the standards and yet the teaching of attitudes and actions are conflict-ladened practices depending on the perspective of the community. Critical theory allows for the analysis of standards that reflects the politically and socially constructed and debated standard for education.

\section{Coding}

This study used the electronically published state standards found on the West Virginia Department of Education's website, which are published for teachers. The relevant documents were downloaded from the state's website for the 2011-2012 school year. The state standards were written in 2004 and thus the teacher was well-familiar with them and had had time to interpret them and develop lessons to fully address the standards.

The research questions considered what the state standards communicate in keeping with critical theory defined by Merriam (2004). There is a qualitative textual 
analysis and a quantitative portion that considers frequency of themes and language. The civic definition provided by NCSS allows the researcher to evaluate if state course meets a common standard of civic education. Using a single professional text allows the researcher to have a definition that is external to the governmental school standards. The NCSS definition allows for a consideration of the standards to evaluate if they are written to achieve the goals the state has identified.

The standards that were considered were the $12^{\text {th }}$ Grade Civics standards. The standards consider four separate areas. They are divided into Citizenship, Civics, Economics and Geography. For the purposes of this study, Citizenship and Civics standards were considered. The standards are additionally divided into three sets of descriptors. The three sections are as follows: a major standard with four descriptors, specific performance standards, and finally the content standard (CSOs). The research will consider how the teacher uses these sections in planning lessons.

While the NCSS definition provides a clear standard to which the state documents and teacher's lesson plans can be compared, Bloom's Taxonomy allows the researcher to critically consider the specific language within the standards and lesson plans. The Taxonomy enables the specific requirements to be considered and categorized. By applying this methodology to each document, the documents can then be compared for convergence and divergence. This analysis allows the researcher to consider the broader picture of civic education in the state and to substantively investigate how the standards achieve the NCSS goals of educating students for civic life (Krathwohl, 2002). 
Bloom's taxonomy allows the researchers to consider the role in which language impacts how teachers are instructed to teach dispositions and behaviors. Elliot Eisner (1991) articulated the issue clearly that "children need opportunities not only to acquire the skills of impression, but also the skills of expression" (p. 16). Bloom's Taxonomy provides a language through which the researchers can consider both the skills of impression and expression. "Taxonomy gives us two ways in which the learning target can be raised" (Raths, 2002. p. 235). Raths continues that teachers can "consider objects that emphasize metacognitive knowledge. One of the primary benefits of metacognitive knowledge is that it 'connects' students to academic learning...they gain knowledge of subjects in which they are and are not interested" (Raths, 2002. p. 235). This connection between the classroom and student life is a critical and definitive component of civic education.

Additionally, it defends high-order skills that are increasingly vital in the current state of technological development. A critical question emerged from this research: how do standards guide teachers towards attitudes and skills? This answer is best addressed through using a critique of the standards themselves to see if states have found ways to do this through the development of higher-order thinking and practices in the classroom. By pairing qualitative and quantitative analysis, the researcher presents results that represent the intricacies of the standards and the practice of civic education in West Virginia. 


\section{Coding the Standards}

The $12^{\text {th }}$ grade West Virginia civics standards were coded in three major categories. First they were coded on the basis of the NCSS definition of civic education. Each standard was categorized on the basis of the verbs used to describe what students would do. The standards were categorized as either meeting the definition of knowledge, disposition or action. This is an analysis of the NCSS standards.

The standards were the categorized in two ways using Bloom's Taxonomy. They are coded on the basis of the first verb in each standard. Critical theory argues that knowledge is a statement of power and the researcher believes the position offers a value statement. However, to offer a complete analysis, the researcher additionally coded each standard to represent each of the verbs used in the individual standard. This three-fold evaluation offers an initial answer to the research question and provides an answer to the alignment of the state's course development to the professional definition of civic education.

\section{Coding the Lesson Plans}

The lesson plans were coded by of the verbs used by the teacher to describe the students' work. Each of the lessons was also coded on the basis of the civic definition of NCSS. Lessons could be coded in more than one category. West Virginia mandates that the teachers categorize their lessons using a system that depends upon Bloom's Taxonomy. The researcher used this system as an additional method of coding. The state's system is an ABCD coding system, which makes use of the higher and lower order cognitive skills developed by Bloom's Taxonomy. The teacher categorizes each lesson: this is an important component of triangulation of the observations. The way 
that the teacher categorizes the lesson plans should reflect they way they teach the lessons and how they view civic education. These components offer validity to the research questions.

\section{Coding Handouts and Exams}

The handouts and exams that the researcher received from the teacher and observed the implementation of were also coded using Bloom's taxonomy and the definition of civic education offered by NCSS. Additionally, they were analyzed using textual analysis to consider how language communicates meeting to students. This process is critical for the triangulation of data and provides a written perspective on civic education as developed by the teacher. The teacher writes the exams and constructs the handouts herself. She does not use material produced by a curriculum company. The teacher also does not use a textbook often. Thus, the handouts and exams present another way in which the teacher interacts with and provides information to students.

\section{Coding the Observations}

The observations were coded on the basis of what the teacher did and how she interacted with students. The subject often spoke to the researcher during class about what she was doing, so these interactions are coded separately from the interactions with the students. The pedagogical choices of the teacher were coded to represent how they met the definition of civic education offered by NCSS and coded to represent the presentation of material on the basis of Bloom's Taxonomy. This process was evaluated and reevaluated throughout the data gathering process. In keeping with grounded theory and critical analysis, this process was ongoing and continuously reevaluated during the data gathering. After an initial coding, the researcher returned to 
the research questions and re-interviewed the teacher to address issues that emerged throughout the initial analysis.

\section{Analyzing Interviews}

The three formal interviews were coded for internal consistency and divergence, though they represented very different discussions. The researcher explored issues of pedagogy, curriculum and student practice. The teacher discussed these matters in both formal and informal contexts with the researcher. The interviews provide the perspective of the teacher as they conscientiously consider their own practice.

By assessing a broad number of data points, the researcher hopes to fully answer the research questions with appropriate depth of analysis. The mixed methodology allows for greater depth of analysis and ensures proper triangulation of the data, offering a clear understanding of the practice of civic education in West Virginia. Additionally, it addresses the cognitive levels at which both the teacher and the state view as definitive for success in civic education. This cognitive level is paired with the formal NCSS definition of civic education. The theoretical framework and methodology inform the study and allow for the development of answers to the research questions.

\section{Conclusions}

The qualitative methodology was adopted as it most effectively answered the research questions. By using Grounded Theory, the research developed and analyzed a rich data source in a typical case study participant. This participant was interviewed, observed and communicated with at length, so that the research was able to enrich the pool of information from which to answer the research questions. The questions were 
addressed and refined throughout the study as the data directed the researcher to meaningful lines of inquiry.

To contextualize the case study participant, it was imperative to consider the intellectual framework from which the participant operated. This framework was found in the documents produced by West Virginia and informed by NCSS and Bloom's Taxonomy. The relationship between these documents was explored using critical theory, a methodological approach that is rooted in qualitative analysis and is paired with grounded theory through a post-modern perspective. Critical theory enabled the research to draw qualitative conclusions that emphasized power and to problematize the findings and relationships.

The methodology was selected as that which was most appropriate to the research questions and the data that was gathered. Qualitative analysis depends upon thoughtful data collection and careful consideration of the findings. The conclusions refer to the data and the multiple and extensive passes over and through the information provided to the researcher by the case study participant. 


\section{Chapter 4}

\section{Findings}

\section{Introduction}

The researcher separated the analysis into two separate considerations. This was done to facilitate deep analysis and the ability to consider the textual analysis as distinct from the case study. The textual analysis was then applied to the case study as a framework in which to understand the case study participant's decisions, practices, and understandings. The documents were considered both as distinct constructs and as interacting systems by which education for the case study participant is shaped. By understanding and analyzing them both directly and indirectly, the researcher hopes to present a balanced, thoughtful and deep analysis of both the documents and the practice of the case study participant.

The critical results include the validating of the document selection on the basis of those texts that the case study participant uses in lesson planning, assessment, and conversation. The use of these documents by the participant varies with respect to the published intent of the documents and they primarily serve an administrative function. The documents, additionally, provide a point of communication between the administration and the teacher but not to the students. Rarely do these documents under consideration interact directly with the students, as once again the teacher is shown to mediate the content of a course to the students. The researcher begins with the analysis of the documents as a way in which to structure and frame the experiences of the case study participant. 


\section{The Textual Analysis}

The document analysis began with the West Virginia state standards for $12^{\text {th }}$ grade social studies to consider the fundamental development of the course on civic education (WVDOE, 2005). The analysis was conducted along two separate lines in order to answer the research questions. The textual questions that guided the analysis were:

1. What is the frequency with which the WV $12^{\text {th }}$ grade civic Standards meet the three components of civic education (actions, dispositions, and knowledge)?

2. How does the WV $12^{\text {th }}$ grade civic Course Description align with the NCSS definition of civic education?

3. How do the WV $12^{\text {th }}$ grade civic Performance Standards align with the NCSS definition of civic education?

4. How do the WV $12^{\text {th }}$ grade civic Standards align with the NCSS definition of civic education (NCSS, 2010)?

5. Using Bloom's Taxonomy as a framework, how do the West Virginia $12^{\text {th }}$ Grade Civic Standards demonstrate cognitive learning?

The analysis begins with the development of the place that West Virginia civic education has in the national educational schema. This context enables the researcher to carefully interpret some findings in light of the national understanding of civic education. From this context, the research questions are then approached. 


\section{Context}

As of the 2011-12 school year, West Virginia became one of nine states that mandated a class in civic education for high school graduation (See Table 1). Of the nine, three states require a year-long class and six states require a semester-long class. Each of the mandated courses that are a year-long has a multi-discipline focus. No state offers a pure, year-long consideration of civic education. From this, it is possible to infer that the content of civic education is generally considered to be manageable in less than a year.

West Virginia's course, titled Civics for the $21^{\text {st }}$ Century, was adopted in 2004. The class of 2008 was the first in West Virginia that was required to take civics for graduation. The CSO's for Civics for the $21^{\text {st }}$ Century requires instruction in four domains: citizenship, civics, personal finance and geography (WVDOE, 2005).

Personal finance and geography diverge from the civic content area and may demonstrate that, much like the other eight states that require a course in civic education to graduate, the course fills a variety of roles within the educational scope and sequence (Table 1).

The nine states that require a course in civic education are not easily characterized as a group. They represent diverse geographic, economic and political circumstances. Many of the states have standards that were revised after 2001, which may indicate that the No Child Left Behind (NCLB) legislation did force many states to revisit their standards, however revision does not necessitate more effective education. It does indicate that current educators and politicians are invested in the current standards through the work of revision. 
Other states may teach civic education through integrating it throughout social studies courses. These nine states prioritize civic education by naming and requiring courses in civic education. As one of these states, West Virginia has valued civic education by naming and requiring a high school course of all its students.

Table 1

States Mandating Civic Education

\begin{tabular}{|l|l|l|l|}
\hline State & Title & Length & Year Adopted \\
\hline Arkansas & Civics for One Semester & Semester & 2006 \\
\hline Connecticut & Civics & Semester & 2009 \\
\hline Delaware & Integrated Civics and Geography & Year & 1995 \\
\hline Louisiana & One semester of Civics or AP & Semester & 2008 \\
& Government & Sivics & Semester \\
\hline Michigan & Government and Citizenship & Year & 2006 \\
\hline Minnesota & US and NH government/civics & Semester & 2006 \\
\hline New Hampshire & Civics/Economics & Semester & 2000 \\
\hline North Carolina & Civics for the 21st Century & Year & 2004 \\
\hline West Virginia & &
\end{tabular}

By recognizing the states that teach civic education, the lack of uniformity becomes clear. These are states that differ with respect to population and political measures. They span a vast area of the country. One thing that they have in common is a high school requirement for civic education as a distinct area of academic inquiry. These nine states have different titles for the class, the length of time the course lasts differs and the adoption of these courses varies. Table 1 presents a snapshot of civic education in the United States and the states that require the class. Other states may require civic content to be embedded into their social studies educational plan, but these nine states require a class. 


\section{The Standards}

West Virginia developed state standards for all courses. The $12^{\text {th }}$ grade social studies course Civics for the $21^{\text {st }}$ Century, is divided into four topics and each topic is divided into three sections. The research analysis begins with a consideration of these sections. The four topics that are considered are Citizenship, Civics, Financial Literacy, and Geography. Each of these components has three separate sections of Course Description, Performance Descriptors and Content Standards. The Course Description offers a broad understanding of the course, the Performance Descriptors allow the teacher to categorize at what level of achievement individual students are working and the Content Standards offer day-to-day descriptions of what students are to be doing in the class. The Content Standards are required to be attached to every lesson plan that the teachers submit to the school administration. Neither the Course Description nor the Performance Descriptors are required to be used or assessed, directly.

For Civics for the $21^{\text {st }}$ Century, the CSOs cover four major topics from social studies. These sub-topics are as follows: civics, citizenship, economics and geography. This study considered the civics and citizenship topics, as they are the two categories relevant to the research questions. For each of these sections, there are four "student will..." statements in the Course Description, separate Performance Descriptors and Content Standards, which contain primary and secondary verb descriptions.

The analysis of each of these sections is first through the application of the definition of civic education offered by NCSS. NCSS defines civic education as "the knowledge, intellectual processes, and democratic dispositions required of students to be 
active and engaged participants in public life" (NCSS, 2010. p. 9). This definition offers three major separate components that must be addressed:

1. Knowledge and intellectual processes

2. Democratic dispositions

3. Action and engagement

These three components are a theme that permeates the literature around civic education (Hess, 2011; Cohen, Pickeral \& Levine, 2010; Misco \& Shiveley, 2010; Kahne \& Sports, 2008; Bos, Williamson, Sullivan, Gonzales, \& Avery, 2007; Buchanan, 2007; Feldman, Pasek, Romer \& Jamieson, 2007; Boston, Pearson \& Halperin, 2005; Noddings, 2005; Hahn, 2001b). The knowledge of civic functions and practices, the dispositions toward civic life and the action of a citizen are mutually required and balanced in a well-developed civic course. None of the individual strands function to produce a strong citizen in isolation.

It is common, in education, to refer to the state standards and in West Virginia the Content Standards and Objectives are referred to in short hand as CSOs. However, what people seem to be referencing to are the numbered standards that are in the third section. The Course Description and Performance Descriptors are not commonly discussed or referenced. The standards open with a Course Description, which offers eight statements of what students should be able to do or know by the end of the course. The Performance Descriptors offer a way by which student achievement may be classified. The Standards offer a list of specific items that are to be taught by the teacher and these are listed on the lesson plans of teachers. The Standards are, perhaps, the most critical to consider with respect to classroom practice, though no more critical 
to consider than the other sections in considering the way in which the state views the course.

\section{Civic CSOs and NCSS}

Grounded theory argues that validity of data is achieved through revisiting data from various perspectives. The West Virginia $12^{\text {th }}$ grade civics standards seek to prepare students to be future citizens as per the NCSS definition of civic education. The civic definition offers three categories by which civic education can be defined. The first question looks broadly at the three components. The next three questions investigate the various components of the state standards and the fifth question considers Bloom's Taxonomy.

Bloom's Taxonomy becomes critical as it is linked to the Knowledge category of the NCSS definition of civic education. As a cognitive taxonomy, it clearly is tied to the Knowledge category rather than the Disposition or Action category. As the case study participant is required to categorize every civics lesson plan along Bloom's Taxonomy, the emphasis on the Knowledge category is not surprising. Therefore, the relationship is a critical to consider in this research project.

\section{Research Question 1:}

\section{What is the frequency in which the WV $12^{\text {th }}$ grade civics standards meet the three components of civic education (actions, dispositions, and knowledge)?}

The civics teachers in West Virginia are given a list of thirty-nine separate standards, ten of which are categorized as "Citizenship" and twenty-nine of which are categorized as "Civics". Each bullet point begins with a verb, which for this research project will be called the "Primary Verb". Many of the bulleted points have subsequent 
verbs as the standard represents a multi-step process. Table 2 lists the frequency with which the verbs appear in the CSOs. The thirty-nine standards include eighty-one distinct actions that students are "to do" in order for the teacher to fully cover the standards. There are sixteen distinct verbs in the Primary Verb category and thirty-five distinct verbs throughout all of the Standards.

Of the Primary Verbs, thirty-five of the requirements fall into the Knowledge category, three of them are Action verb and one of them is a Dispositional verb. There are eight Action verbs from the total, one Dispositional verb and seventy-two verbs in the Knowledge category. This further demonstrates an imbalance between the three categories, yet it is interesting that the single Dispositional verb occurs in the Primary Verb slot. It does not appear more in the secondary or additional positions.

The Action verbs increase when the Standards are fully analyzed. This may be because it is recognized that for action to take place, students need knowledge. They need to be paired together and thus it is reasonable to combine in a single requirement both the knowledge and the active requirement in order to meet the standard. The additional action verbs are paired with knowledge verbs to create a two-step process for completion. The multi-step process that is imbedded in the Standards raises a question: Do teachers fulfill all components of an individual standard when they connect it to their lesson plan or do they fill one component of it? The answer to this question has significant implications for the structure and shape of the Civics course. 
Table 2

Verbs of Standards for Citizenship and Civics at the $12^{\text {th }}$ Grade Level

\begin{tabular}{|c|c|c|c|c|c|}
\hline Standards & Primary Verb & All Verbs & Knowledge & Disposition & Action \\
\hline Analyze & 6 & 8 & $\mathrm{X}$ & & \\
\hline Apply & & 1 & $\mathrm{X}$ & & \\
\hline Articulate & & 1 & $\mathrm{X}$ & & \\
\hline Assess & 2 & 3 & $\mathrm{X}$ & & \\
\hline Cite & & 1 & $X$ & & \\
\hline Compare (and Contrast) & 2 & 3 & $\mathrm{X}$ & & \\
\hline \begin{tabular}{|l|l|} 
Create \\
\end{tabular} & & 1 & & & $\mathrm{X}$ \\
\hline Debate & & 1 & $\mathrm{X}$ & & \\
\hline Defend & & 4 & $\mathrm{X}$ & & \\
\hline Demonstrate & 2 & 3 & $\mathrm{X}$ & & $\mathrm{X}$ \\
\hline Describe & & 1 & $\mathrm{X}$ & & \\
\hline Develop & 1 & 1 & & $\mathrm{X}$ & \\
\hline Differentiate & 2 & 2 & $\mathrm{X}$ & & \\
\hline Evaluate & 2 & 9 & $\mathrm{X}$ & & \\
\hline Examine & 9 & 12 & $\mathrm{X}$ & & \\
\hline Explain & 2 & 3 & $\mathrm{X}$ & & \\
\hline Formulate a Proposal & & 2 & $\mathrm{X}$ & & \\
\hline Give Examples & & 1 & $\mathrm{X}$ & & \\
\hline Identify & 3 & 3 & $\mathrm{X}$ & & \\
\hline Illustrate & 1 & 1 & $\mathrm{X}$ & & \\
\hline Influence & & 1 & & & $\mathrm{X}$ \\
\hline Interpret & & 1 & $\mathrm{X}$ & & \\
\hline Monitor & & 1 & $\mathrm{X}$ & & \\
\hline Outline & 1 & 2 & $\mathrm{X}$ & & \\
\hline Participate & & 1 & & & $\mathrm{X}$ \\
\hline Predict & & 1 & $\mathrm{X}$ & & \\
\hline Prepare a Summary & & 1 & $\mathrm{X}$ & & \\
\hline Recognize & 2 & 2 & $\mathrm{X}$ & & \\
\hline Relate & & 2 & $\mathrm{X}$ & & \\
\hline Research & & 1 & $\mathrm{X}$ & & \\
\hline Summarize & & 1 & $\mathrm{X}$ & & \\
\hline Support & 1 & 1 & $\mathrm{X}$ & & \\
\hline Take & & 3 & $X$ & & \\
\hline Trace & 1 & 1 & $X$ & & \\
\hline Use & 1 & 2 & $\mathrm{X}$ & & $\mathrm{X}$ \\
\hline Total & 39 & 81 & & & \\
\hline
\end{tabular}


Table 2 lists all of the verbs used in the state Standards, demonstrating the separate categories of the "Primary Verbs" and "All Verbs". The activities required by the Standards are diverse and many separate intellectual activities are mandated. Reading these different verbs, indicates that the state may wish to have the students to engage in many different learning activities. Another perspective is that the state uses a variety of words while expecting students to engage in very few activities, namely cognitive learning functions.

The analysis thus far has considered the correlations between the Content Standards and Objectives written by West Virginia for $12^{\text {th }}$ Grade Social Studies in so far as they address Civic and Citizenship competencies. The analysis concludes that the documents do reflect the definition of civic education produced by NCSS and the CSOs broadly consider the knowledge, action and dispositions of civic education. However, the distribution of these characteristics is heavily weighted towards the knowledge strand and a few explanations for this imbalance has been considered, though it remains shrouded as to the thinking of the State in the construction of the documents.

Proportionally, the Course Description and Performance Descriptors appear to be more balanced than the Standards. However, the Standards are the only section of the CSOs whose use is mandated in many schools. The document is relevant in classroom research as it is used by a teacher and that question will be addressed in the second section of this research paper. 


\section{Research Question 2:}

\section{How does the WV $12^{\text {th }}$ grade civic Course Description alignment with the NCSS definition of civic education?}

The Course Description offers simple "student will..." statements that are designed to summarize the content of the course. There are four such statements in both the Citizenship and Civics sections of the Civics for the $21^{\text {st }}$ Century course. These statements represent what the students should have learned throughout the course. Each of the standards begins with a "students will" and then a verb. These verbs can be categorized into both NCSS's definition of civic education and Bloom's Taxonomy. In categorizing the verbs, the researcher found that considering the statements in the three sections of the CSOs, the Knowledge category was over represented compared to Dispositions and Actions (See Table 4).

Each subsection, Civics and Citizenship, offered four statements defining what students should be able to do by the end of the course. The students are to be able to recognize, characterize, develop, demonstrate, examine, research (x2) and compare (WVDOE, 2004). These seven verbs describe the action related to the knowledge content in the course. Six of the actions are related to personal knowledge.

The dispositional verb is where students are to "develop and explain civic dispositions" (WVDOE, 2004) and the action verb is where students are to "demonstrate participatory skills" (WVDOE, 2004). The wording begs the question as to the difference between "demonstrating participatory skills" and simply participating in civic life. The remaining verbs are focused in the knowledge or cognitive domain. The Citizenship category uses the word "dispositions" twice however, one of the instances 
says, "students will recognize and evaluate civic dispositions" (WVDOE, 2005). This depersonalizes dispositions as if it is enough for students to recognize when others have civic dispositions, but they themselves are not asked or required to develop dispositions of citizenship.

More interestingly, the reference to action and disposition both falls in the Citizenship category and not in the Civics category. The state articulates a value for action and dispositions by its citizens but these are part of Citizenship education, which is distinct from Civic education as laid out in the state standards. The four statements in the Course Description under Civics emphasize knowledge and are sub-labeled as "Purposes of Government, Ideals of United States Democracy, United States Government and Politics, and United States Government and World Affairs" (WVDOE, 2005). Understanding these four parenthetical statements places the action of the "Student will" firmly into the category of knowledge.

Action and dispositions do have a place in the course, as defined by the West Virginia government. The question of what the state understands "civic" content to be is still open. The overarching emphasis is on the Knowledge domain in the Content Standard, however continues to raise questions as to how well the state has sought alignment with NCSS's vision of civic education. 


\section{Research Question 3:}

How do the WV $12^{\text {th }}$ grade civic Performance Descriptors alignment with the NCSS definition of civic education?

The Performance Descriptors offer a rubric by which the teacher can categorize the student's operational level. This rubric includes categories of Novice, Partial Mastery, Mastery, Above Mastery and Distinguished (WVDOE, 2005). This section of the Standards recognizes that students work at individual levels and offers to teachers a structure whereby they are able to categorize student outcomes.

The "Distinguished" Performance Descriptors represent nine cognitive or knowledge practices and two action statements (See Table 3). Four of the Performance Descriptors at the distinguished level require students to summarize what they know. They are also asked to critique, judge, research, evaluate and justify. These are all skills related to cognition and knowledge. There are two statements that require the students to act as they are to "initiate ways to work with others" and "interact with other citizens" (WVDOE, 2004). Each of the action verbs occurs within the "Citizenship" domain and not the "Civic" domain.

For the remaining categories, the two action standards shift to understanding or assessing other people's interaction and service. The only remaining action requirement is in the "Mastery" level where students need to "work with others" (WVDOE, 2005). There are no Performance Descriptors that allow for the assessment of dispositions and three that assess action (See Table 3). 
Table 3

Performance Descriptor Verbs

\begin{tabular}{|c|c|c|c|c|c|}
\hline & Distinguished & $\begin{array}{l}\text { Above } \\
\text { Mastery }\end{array}$ & Mastery & $\begin{array}{l}\text { Partial } \\
\text { Mastery }\end{array}$ & Novice \\
\hline \multirow[t]{5}{*}{ Citizenship } & Justify & Assess & Explain & Identify & Define \\
\hline & Initiate & Assess & Work with & $\begin{array}{l}\text { Give } \\
\text { Examples }\end{array}$ & Recognize \\
\hline & Evaluate & Summarize & Select & $\begin{array}{l}\text { Give } \\
\text { Examples }\end{array}$ & Name \\
\hline & Research & Investigate & Examine & $\begin{array}{l}\text { Give } \\
\text { Examples }\end{array}$ & Tell \\
\hline & Interact & Evaluate & Analyze & Study & Define \\
\hline \multirow[t]{6}{*}{ Civics } & Critique & Analyze & Interpret & Explain & Identify \\
\hline & Summarize & Differentiate & Outline & Describe & List \\
\hline & Judge & Research & Analyze & Compare & Describe \\
\hline & Summarize & Evaluate & Examine & Identify & Recognize \\
\hline & Summarize & Evaluate & Explain & Examine & Name \\
\hline & Summarize & Assess & Debate & Discuss & Identify \\
\hline
\end{tabular}

Of the categories within the Standards, Citizenship and Civics provide the content and the state describes what students should be doing in each of these categories on a scale of five points. Of the fifty-five standards, there are thirty distinct verbs. "Summarize" occurs five time and only in the "Distinguished" and "Above Mastery" categories. The verbs that are repeated only vary across a single category. If it occurs in "Distinguished", it occurs no lower than "Above Mastery". If it occurs in "Partial Mastery", it may occur in "Novice" or "Mastery" but no higher or lower. Reading across the levels, the progression seems to be defined by verbs, very clearly. 
Table 4

Performance Descriptors by the Numbers

\begin{tabular}{|l|l|l|l|l|l|}
\hline Verb & Frequency & Location & Knowledge & Disposition & Action \\
\hline Analyze & 3 & AM, M & X & & \\
\hline Assess & 3 & AM & X & & \\
\hline Compare & 1 & PM & X & & \\
\hline Critique & 1 & D & X & & \\
\hline Debate & 1 & M & X & & \\
\hline Define & 2 & N & X & & \\
\hline Describe & 2 & PM, N & X & & \\
\hline Differentiate & 1 & AM & X & & \\
\hline Discuss & 1 & PM & X & & \\
\hline Evaluate & 4 & $\mathrm{D}, \mathrm{AM}$ & $\mathrm{X}$ & & \\
\hline Examine & 3 & $\mathrm{M}, \mathrm{PM}$ & $\mathrm{X}$ & & \\
\hline Explain & 3 & $\mathrm{M}, \mathrm{PM}$ & $\mathrm{X}$ & & \\
\hline Give Examples & 3 & $\mathrm{PM}$ & $\mathrm{X}$ & & \\
\hline Identify & 4 & $\mathrm{PM}, \mathrm{N}$ & $\mathrm{X}$ & & \\
\hline Initiate & 1 & $\mathrm{D}$ & & & \\
\hline Interact & 1 & $\mathrm{D}$ & & $\mathrm{X}$ \\
\hline Interpret & 1 & $\mathrm{M}$ & $\mathrm{X}$ & & \\
\hline Investigate & 1 & $\mathrm{AM}$ & $\mathrm{X}$ & & \\
\hline Judge & 1 & $\mathrm{D}$ & $\mathrm{X}$ & & \\
\hline Justify & 1 & $\mathrm{D}$ & $\mathrm{X}$ & & \\
\hline List & 1 & $\mathrm{~N}$ & $\mathrm{X}$ & & \\
\hline Name & 2 & $\mathrm{~N}$ & $\mathrm{X}$ & & \\
\hline Outline & 1 & $\mathrm{M}$ & $\mathrm{X}$ & & \\
\hline Recognize & 2 & $\mathrm{~N}$ & $\mathrm{X}$ & & \\
\hline Research & 2 & $\mathrm{D}, \mathrm{AM}$ & $\mathrm{X}$ & & \\
\hline Select & 1 & $\mathrm{M}$ & $\mathrm{X}$ & & \\
\hline Study & 1 & $\mathrm{PM}$ & $\mathrm{X}$ & & \\
\hline Summarize & 5 & $\mathrm{D}, \mathrm{AM}$ & $\mathrm{X}$ & & \\
\hline Tell & 1 & $\mathrm{~N}$ & $\mathrm{X}$ & & \\
\hline Work with & 1 & $\mathrm{M}$ & & & \\
\hline & & & & & \\
\hline
\end{tabular}

Table 4 describes all of the verbs used in the Performance Descriptors. Each of the verbs is categorized on the basis of how many times it appears, in which categories it appears and whether it was coded by the researcher as a falling into the NCSS categories of Knowledge, Dispositions, or Action. 
The Performance Descriptors are simple and straightforward sentences but they are not formally used in lesson planning or assessment. The breadth of verbs indicates that the authors value a variety of skills or are trying to identify multiple ways of assessing students. However, it may be that the heavy emphasis on assessment of what students know, may indicate a common set of skills rather than true multifaceted assessment strategy.

As the use of the Performance Descriptors is not explained, it leaves it up to teachers or the reader to interpret how they may be used. As they are published as part of the Content Standards and Objectives, it may be that they are written for all stakeholders to have a broad sense of what students should be able to do at the end of the course. Additionally, they could be used by a teacher to create their assessment strategies. The clearest use of them is for teachers to review them to help them develop an overarching sense of how effective their teaching is. What is less clear is how they are actually to be used as they are published by the state but there is no requirement for teachers to use them in their assessment or evaluation. This does leave the question as to the intended purpose of the Performance Descriptors.

\section{Research Question 4:}

\section{How do the WV $12^{\text {th }}$ grade civic Standards alignment with the NCSS definition of civic education (NCSS, 2010)?}

The final section of the standards is the CSO's, which are the Standards and may be the most commonly used section by teachers. In some West Virginia school districts, lesson plans must be correlated to the Standards every day (Interview, 2012). Teachers are required in many schools to submit lesson plans to their school administration and 
each lesson must meet some Standards (Interview, 2012). The Standards are designed to create a shared experience for students and teachers around the state. They are the common guiding requirements that schools use to shape and structure classes and thus education.

The Standards are a series of statements, that begin with a verb and describe what a teacher is to teach. They are arranged into subcategories that describe and shape the course. Frequently a single standard includes additional verbs making the completion of the standard a multi-step process. The primary verbs of the Standards represent thirty-five knowledge verbs, one dispositional verb and three action verbs. These statements describe what teachers are to teach and what students are to do on a daily basis. The teachers in WV are required to list the CSOs that they are addressing on every lesson plan in contrast to the Course Descriptions or Performance Descriptors. Therefore the Standards are, perhaps, the most critical to consider with respect to classroom practice.

The researcher began the evaluation process by dividing the analysis into two sections. Each standard has a primary verb that is the first action that is expected by the student. Many of the Standards have more than one verb in the statement. For each lesson, the teacher selects the Standards that her lesson meets. The lesson is written to achieve the Standard in the manner that the teacher views as important and effective. Ideally the teacher assigns all of the Standards throughout the duration of the course.

The Standards may be considered in terms of the primary requirement and the total requirement. The first verb listed is considered to be the "Primary Verb" (see Table 6). This reflects the researcher's perspective that the first verb is frequently of the 
most concern. This is in keeping with a critical theory that indicates that the position of language in these documents represents a given level of importance or value (Watson \& Watson, 2011). The consideration then moved to all of the verbs in the Standards.

The Standards are listed on lesson plans and this tends to be the way in which teachers represent alignment of the class to the state's expectations. If the teacher aligns her lessons proportionally to the Standards, there is a clear over representation of the knowledge domain in the course as experienced by students (See Table 4). This does not represent a lack of alignment of the course with the NCSS definition. In fact, the Standards do require both action and dispositional development. The state makes it clear that it requires attention to students' dispositions, going so far as using the language of dispositions. The state also requires action. The alignment is there but not with equitable balance between the three sections.

This raises the question: is the lack of equity a practical problem or an ideological problem? Put another way: does West Virginia value civic knowledge more than dispositions and action or are there other reasons for the imbalance? One possible explanation is that it is easier to compose or assess the knowledge domain as it lends itself to classroom instruction and assessment. Action frequently requires the students to demonstrate a behavior or practice outside of the classroom and dispositions may be perceived as more challenging to articulate and assess.

The Standards do stop short of mandating civic action, and they do not require specific attitudes or dispositions. Namely, it is possible for students to graduate with high marks in 12 th grade social studies without completing any civic action. The state calls for the development of dispositions and asks students to "demonstrate participatory 
skills characteristic of involved citizens; research and analyze public policy, monitor arguments and developments; and devise methods to influence public policy decisions" (WVDOE, 2004). This requires students to complete a great deal of involvement in the political process through their class.

This methodological approach to civic education emphasizes the role of government while potential minimizing the role of the student in their community. Namely, the action and dispositions of the Standards are related to government. The students are not required to do anything in their local community and the documents enable them to engage in the political process without attaching their reputation to this work in a public way. The disconnection, additionally, is reflected as the dispositional requirements are listed under the category of "Citizenship" Standards and not "Civic" Standards (WVDOE, 2004). The strand of the Standards titled "Civics" focus exclusively on knowledge (WVDOE, 2004).

West Virginia does not explain the difference between citizenship and civics but they function as mutually exclusive categories in the CSOs. NCSS certainly considers civics to be the academic domain concerned with the development of citizenship, but WV seems to have distinct academic practices in mind. The Standards separate out the practices of citizenship from those of civics (WVDOE, 2004). "Citizenship" requires action and dispositional development, however the "Civic" Standards do not emphasize this position. The "Civics" Standards reflect an emphasis on the knowledge component of the discipline. Bringing all of this to bear, it seems to be clear that West Virginia took the call for action and dispositional development in their students seriously. 
Proportional distribution of requirements has not be achieved or, perhaps, even attempted.

The language that is used in the Standards is critical to understanding how teachers form lesson plans. The Standards begin with the statement "students will" (WVDOE, 2004). Following that statement, there is a bulleted list of actions that describe what students will do. Each of these items is coded based on the topic under which it falls. Table 5 demonstrates the frequency by which the various components of the state documents fall into the three categories defined by NCSS.

Table 5

States and NCSS

\begin{tabular}{|l|l|l|l|}
\hline NCSS Definition & Course Description & $\begin{array}{l}\text { Performance } \\
\text { Descriptors }\end{array}$ & $\begin{array}{l}\text { Primary Verb of } \\
\text { Standards }\end{array}$ \\
\hline Knowledge & 6 & 55 & 35 \\
\hline Dispositions & 1 & 0 & 1 \\
\hline Actions & 1 & 3 & 3 \\
\hline
\end{tabular}

\section{Civic CSOs and Bloom's Taxonomy}

As the CSOs have been analyzed for their congruence with the NCSS definition of civic education, it is now critical to the research questions, to consider how they align with Bloom's Taxonomy. Bloom's Taxonomy offers six overarching categories that organize learning into a progressive cognitive schema. Cognitive learning begins with Knowledge and then moves through Comprehension, Application, Analysis, Synthesis and finally Evaluation (Bloom et. al., 1956). It is a progressive developmental process whereby a teacher is able to guide a student through learning.

This systematic approach to cognition was developed by Bloom and his team of researchers using behavior psychology as the intellectual framework from which they developed their theory. The framework is now ubiquitous in educational circles and the 
intellectual underpinnings are rarely questions in the K12 setting, though there are clear voices arguing that it is antiquated. Regardless of the debate, Bloom's Taxonomy offers a framework that classifies verbs into a hierarchical process and this process is still used regularly in the WV classroom, as the research shall demonstrate.

The Taxonomy, as it was originally conceptualized but not executed, viewed academic progress or learning as a three-fold state in which students would progress through the Cognitive, Psychomotor and Affective Domains. As seen in this paper, the Psychomotor Taxonomy was never written; the Affective Taxonomy was written but has been little referenced in research or academic literature and is out of print. The Cognitive Domain was published and has been highly influential in education. The three-fold understanding of cognition reflected in Bloom's Taxonomy's, corresponds to the definition of civic education offered by NCSS.

As NCSS defines civic education in terms of action, disposition and knowledge, it may be seen that the two frameworks reflect each other. Cognition equates to knowledge. Psychomotor equates to action, and affective to dispositions. However, as the Psychomotor and Affective domains have not heavily influenced education, the verbs in the Standards must be organized across the Cognitive Domain.

As was seen above, very few of the Standards required action or dispositional development in students. Therefore, the next level of analysis is to see how the verbs are organized across the Cognitive domain. 


\section{Research Question 5:}

\section{Using Bloom's Taxonomy as a framework, how do the West Virginia $12^{\text {th }}$ Grade}

\section{Civic Standards demonstrate cognitive learning?}

The West Virginia Civic Standards are statements that address and define what teachers will teach in the mandatory $12^{\text {th }}$ grade social studies class. By organizing these verbs across the Cognitive domain, the researcher hopes to present how the state of West Virginia understands the cognitive requirements of students on the verge of completing high school.

The major finding of this section was that the consideration of the primary verbs included five of the six levels of Bloom's Taxonomy and the secondary verbs represented all of the levels. The category of "Analysis" was more prevalent than the other categories both for the Primary Verb and for All Verbs. (See Table 6). By relying heavily on the Analysis Category, the Standards emphasize higher order thinking.

Table 6

Bloom's Taxonomy and State Standards

\begin{tabular}{|c|c|c|c|c|c|c|}
\hline Taxonomy & Knowledge & Comprehension & Application & Analysis & Synthesis & Evaluation \\
\hline $\begin{array}{l}\text { Primary } \\
\text { Verbs }\end{array}$ & $\begin{array}{l}\text { Identify, } \\
\text { Recognize, } \\
\text { Outline }\end{array}$ & $\begin{array}{l}\text { Explain, } \\
\text { Demonstrate }\end{array}$ & $\begin{array}{l}\text { Develop, } \\
\text { Use, Trace }\end{array}$ & $\begin{array}{l}\text { Analyze, } \\
\text { Compare, } \\
\text { Differentiate, } \\
\text { Examine, } \\
\text { Support, } \\
\text { Illustrate } \\
\end{array}$ & & $\begin{array}{l}\text { Assess, } \\
\text { Evaluate }\end{array}$ \\
\hline Number & 6 & 4 & 3 & 22 & 0 & 4 \\
\hline All Verbs & $\begin{array}{l}\text { Differentiate, } \\
\text { Identify, } \\
\text { Monitor, } \\
\text { Recognize, } \\
\text { Research }\end{array}$ & $\begin{array}{l}\text { Articulate, Cite, } \\
\text { Defend, } \\
\text { Demonstrate, } \\
\text { Describe, } \\
\text { Explain, Give } \\
\text { Examples, } \\
\text { Prepare a } \\
\text { Summary }\end{array}$ & $\begin{array}{l}\text { Apply, } \\
\text { Debate, } \\
\text { Develop, } \\
\text { Formulate a } \\
\text { Proposal, } \\
\text { Participate, } \\
\text { Trace, Use }\end{array}$ & $\begin{array}{l}\text { Analyze, } \\
\text { Compare and } \\
\text { Contrast, } \\
\text { Examine, } \\
\text { Influence, } \\
\text { Interpret, } \\
\text { Outline, } \\
\text { Predict, } \\
\text { Relate, } \\
\text { Support, Take }\end{array}$ & $\begin{array}{l}\text { Create, } \\
\text { Illustrate, } \\
\text { Summarize }\end{array}$ & $\begin{array}{l}\text { Assess, } \\
\text { Evaluate }\end{array}$ \\
\hline Number & 9 & 15 & 9 & 34 & 3 & 12 \\
\hline
\end{tabular}


Table 6 demonstrates how the all of the verbs in the State Standards are organized into the categories of Bloom's Taxonomy and the frequency with which the verbs occur. By considering the verbs in these categories, it presents a clear picture of how the verbs were coded based on the definitions of the verbs.

The significant number of verbs that fell into the Analysis category may represent a few practical and ideological issues. Analysis is considered to be part of the Taxonomy concerned with higher order thinking. West Virginia directly mandates the use and educational value of higher order skills. It may be assumed that students already have a basis of knowledge from which to work as previous social studies courses have addressed the development of the American State from a historical perspective. It is possible that the assumption has been made that students have the knowledge necessary that will allow them to move into the higher order cognitive tasks.

Another perspective, however, is that the words that fall into the category of "Analysis" represent documents and reading skills. If the state wants students to read about a person, a document, a problem or a Supreme Court Case, then they call for the analysis of said item. The question really becomes, at this point, how does a teacher use the Analysis category. Of the thirty-nine standards in the Civics and Citizenship categories, twenty-two of the primary verbs fall into the "Analysis" category. The primary verb of "analyze" is used six times and "examine" is used nine times (Table 6).

The topics that are analyzed are the Great Debate, the Bill of Rights, the Constitution, the role of citizens, and the interaction among nation states (WVDOE, 2004). The first three categories represent four separate CSOs. Students are to examine the rights of citizens, "the characteristics of citizen's rights", the Declaration of 
Independence (as well as factors and individuals that were influential to that document), Supreme Court Cases, US Constitutional Government values, the Two- Party system, special interest groups, environmental issues, and intellectual and participatory skills of a citizen (WVDOE, 2004). Under the Analysis category, seven of the twenty-two verbs are directly linked to document analysis.

Analysis is further seen as a primary skill in that when all of the verbs are considered, the other categories increased significantly, and represent a larger proportion of the total. Analysis went from twenty-two to thirty-four. Comprehension went from four to fifteen. Knowledge went from six to nine. Application went from three to nine. Synthesis went from zero to three and Evaluation went from four to twelve. Broadly, the lower order skills expanded from thirteen to thirty-three, which is an increase from $33.33 \%$ of the Standards to $40.24 \%$ of the Standards. Higher order thinking skills comprised twenty-six of the primary verbs, which is $66.67 \%$ of the Standards to fortynine of the verbs or $59.76 \%$ of the Standards. The Standards do emphasize higher order thinking skills in the Standards and this emphasis continues in the classroom where teachers are required to categorize every lesson as higher or lower order thinking skills.

The overarching analysis demonstrates that the state has written the Standards in a way that emphasizes Higher Order thinking skills. This emphasis will be seen in the case study participant, whose experience with state mandates reflects a desire to graduate students who are equipped with higher order skills in keeping with their emphasis on $21^{\text {st }}$ Century Skills (WVDOE, 2005). 


\section{The Teacher}

The analysis of the technical documents guiding civic education in West Virginia is relevant in the specific context of the classroom. It is critical in the context to evaluate how the documents are understood, operationalized and interpreted by a classroom teacher. By selecting a typical case to study, the researcher hopes to demonstrate how the documents are used in a single, particular case (Patton, 2002).

The data was gathered through classroom observations, formal interviews, informal discussions, and emails over a three-year period of time. Throughout the study, the case study and researcher developed a relationship of trust and professional respect that enabled the researcher to develop a rich body of data from which to interpret classroom practice and the use of state standard documents.

This section of the research project was guided by the following questions:

1. How do you view the community of your school?

2. How do you define civic education?

3. How do you assess civic education?

4. How do your lesson plans and state documents inform your pedagogy?

5. How does the classification of lessons on the basis of Bloom's Taxonomy impact your planning and implementation of classroom practice?

The questions are constructed to paint a picture of depth and nuance. The first question contextualizes the teacher in her school. Questions two and three directly address the teacher's perspective on the content of civic education. The final two questions address the documents that guide civic education and how the teacher uses and 
understands these documents. The questions create a picture of civic education as seen by a typical teacher in a typical West Virginia community. The case study participant was assured that this research was IRB approved and that the identity of the teacher would remain confidential. The researcher assigned the participant the pseudonym of Ms. Smith.

The study reveals some encouraging and positive traits of civic education in West Virginia. Ms. Smith is deeply committed to her students and highly values civic education. The overriding conclusions include that students are expected to demonstrate knowledge as that is what teachers can practically do in the classroom and that the lack of dispositional and action-based standards reflect the stress on teachers who face an overwhelming amount of content, students who lack basic knowledge and consistent literacy weakness among students.

\section{Ms. Smith}

Ms. Smith grew up in West Virginia and attended college in the state. She reports being a mediocre high school student with little interest in school and no interest in social studies. Her high school was in a rural area in the state and her high school had roughly 450 students in grades 6-12 (Interview, 2012). She and her family's lives where intrinsically woven into the local community school. Yet, her she has no distinct memory from a social studies class (Interview, 2010). There was nothing remarkable about her high school experience and she graduated and went on to college.

Enrolled in a local college, she intended somewhat indifferently to major in education and says, "teaching English seemed like it might be ok" (Interview, 2012). As she began to take classes, she said, "I had a horrible English teacher who made me hate 
the idea of teaching English" (Interview, 2012). While considering her future, she had to take a history course. During this class, the professor changed her educational trajectory. He turned history from a recitation of facts as she had always experienced it, into a gripping narrative. "He (the professor) presented the information in a way that I never heard before. He was the first one to tie it all together" (Interview, 2010).

Ms. Smith was stunned to see that history connected to politics and economics. The professor tied history to current events and specifically to the lives of his students. This narrative pedagogical approach hooked Ms. Smith, and she became convinced that social studies was fascinating. This diverged from her high school experience and Ms. Smith decided that she needed to become a social studies teacher (Interview, 2012). To be a social studies teacher, Ms. Smith became committed to the narrative pedagogy and the need to connect her content to the lives of her students. This connection is particularly critical in civic education where the content that students are learning are inherently tied to their experiences in their community and the ability to impact their world. This practice is a widely used research perspective (Merriam, 2009; Patton, 2002). Patton (2002) argues that narrative analysis "can illuminate the life and culture that created it" (p. 133).

Upon completion of her undergraduate degree, Ms. Smith was recruited to teach high school social studies in Maryland. The high school had over 2200 students, which was a huge shift from the small rural high school that she had attended. She taught a variety of history and social studies classes including classes on the American political system. These courses affirmed her love of her content but the size of her classes made it difficult to know the students well enough to help connect the material to their lives. 
During this period of time, she continued training in education, completing a Master's Degree in Social Studies Education as well as an administration certificate, which would qualify her to apply for a principal position in the future.

While in Maryland, Ms. Smith continued to refine her pedagogical approach and develop a deeper understanding of her content area. After five years, she was tired of class sizes of over thirty-five students. The volume of students led her to feel as though she lacked a connection to the community and the students. A job opened at her high school alma mater for social studies and she immediately applied. She had always loved her hometown and worked hard to convey to her former principal both her passion for social studies and her pedagogical strengths (Interview, 2012). However, she laughs about her deep attachment to her community. The students are part of her community; their parents are part of her community; her family is part of her community.

If teaching civics was solely dependent upon being a member of the community and having a deep understanding of the needs of the community, then Ms. Smith seems perfect. She possess the personal qualifications to teach civics, however, she had no training in civic education. In fact, Ms. Smith does not articulate a difference between the political courses that she taught in Maryland and the course in civic education (Interview 2012). She reports that the first year that she taught civic education, she learned a great deal through trial and error, but she found that the content grew on her (Interview, 2012). However, she felt that the Civic Curriculum and CSO's fail to do justice to the material generally covered in a Government course (Interview, 2012). She believes that there should be CSO's that address the message of legislation and notes a lack of rigor in the knowledge-based Standards (Interview, 2012). 
Ms. Smith's classroom has no windows and no visible computers. A stack of civics textbooks sits in the back of the classroom on the floor. There are no bookcases. She has a computer on her desk connected to a project and a smart board. The room is sparse and with cinderblock walls, there are cords running around the walls or across the floor. In a case there are a classroom set of laptops that the students use every few weeks in the classroom. The walls are dingy blue and in the back of the classroom a large poster of a nuclear bomb detonation hangs. The other walls are at times bare or filled with student artwork and posters. The desks are old molded plastic with rickety, worn-out metal shelves under the chairs. This is the antithesis of a modern, sleek classroom.

The focus of the class is the students and teachers. The lack of technology and books do not impede Ms. Smith. The computers are too precious to allow the students to use daily. The process of getting them in and out of the locked cabinet, identifying which student has which machine and getting the students logged onto the internet can easily take up to 10 minutes of a 40 minute class. Ms. Smith generates her own material using the CSOs as a guideline, the lives of her students as a reference point and the Internet for reading material, games and handouts. The textbooks are helpful for reviewing content that has already been taught or reinforcing lessons and the students are comfortable picking up a book if they need more information or want a reference. Primarily, if Ms. Smith wants the students to read a document, she prints it off of the Internet and makes copies (Observation, 2012). She generates most of her curriculum, as the textbooks are both inadequate to teach the students the Standards and out of date 
with respect to current political and social issues (Interview, 2012). This practice of construction demonstrates the value and power that the state standards have.

\section{Case Study Question 1:}

\section{How do you view the community of your school?}

Ms. Smith now teaches in rural West Virginia, in the small mining community in which she grew up. The town has fewer than two hundred residents and the school serves around 500 students in grades 6-12 (US Census Bureau, 2011b). The students are drawn from a collection of similar small towns from the region. Ms. Smith sees the community in which the students live as the primary source of information for civic education (Interview, 2012). The students' lives and experiences are the strongest and most valuable curriculum material. Her classroom recognizes the individual narratives that are in the room and she frequently draws on her personal knowledge of her students to teach a lesson. These connections span car ownership, to political interests, to raccoon pelts (Observations, 2012).

Many times, the researcher watched her call on a particular student to direct their attention to something she believes to be of interest to them. During the primary season of 2012, she often pointed out specific issues to specific students. She would inquire of them particular information that she knew that would have. This demonstrates her perspective that her students are a community of learners. Ms. Smith individualized her instruction based on the individuals in the classroom. Teaching the same lesson in back to back class periods often revealed slightly different emphasis that reflected the identity of the students in her room (Observations, 2012). 
When asked about her community, Ms. Smith interrupted the questions by saying, "I love it. I love teaching here and being here. It's home" (Interview, 2010). The home that she was describing seemed to transcend the school and encompass the local town. Teaching in her hometown was the dream she never had. She wanted to leave when she graduated from high school, but when the opportunity to return "home" presented itself to her as an adult, she jumped at the opportunity (Interview, 2012). The interview for her job was with her high school principal and she prepared a careful portfolio. She said, "The principal looked through every paper and read all of my lesson plans. I worked hard on that portfolio of teaching because I wanted this job badly" (Interview, 2010).

Her work took on a different meaning when she returned home because the students remind her of her own intellectual journey in a very immediate and personal way. Coming back to her high school alma mater was fascinating because she was not brought back due to a love of the school. She had no memories of high school social studies, but a great fondness for the broader community. Her lack of memories from high school social studies adds an intensity to her desire to convey the critical nature of civic content to her students (Interview, 2012). Ms. Smith pedagogical practice is heavily influenced by her experience in college. She continues to practice the art of connection and her knowledge of the community is a critical component of the content that she teaches. These students reflect her own self-image. The students reflect her childhood. They reflect her education.

She uses the pedagogy that inspired her intellect and interest in history and politics. As she gets a voice in educating the next generation of her community, 
convincing them to see their lives as deeply tied to history and governments is a critical responsibility. The perspective she takes seems to be that if she talks to them enough, they, too, will see the connection. Her pedagogy matches the Standards, which emphasize knowledge. Her perspective downplays the roll of community action and dispositional development that is critical to civic education.

\section{Case Study Question 2:}

\section{How do you define civic education?}

Through the literature and the state documents, it may be seen that civic education has a debated and contested definition. West Virginia selected to call their $12^{\text {th }}$ grade social studies course "Civics for the $21^{\text {st }}$ Century". In the documents, it does not clearly define what civic education is, but it uses language of government knowledge and a community awareness to frame and shape the course. The case study participant defines civic education in a very particular way. Ms. Smith says that civics is "the basic structure and functions of the United States government. It also has sections on criminal and civil law and personal finance. Civics classes should make students active, informed, and responsible citizens" (Interview, 2012).

This definition emphasizes the knowledge of the government. The statement of citizenship follows the idea that the focus is on the United States' government. Citizenship, for Ms. Smith, is rooted in an American citizenship rather than a global or local identity. This is a very particular identity and yet the knowledge, rooted in this identity, is designed to create a citizen. This approach creates American citizens rather than a democratic citizen as described by John Dewey (Dewey, 2004). 
Ms. Smith also describes the civic education as requiring knowledge of the "basic structure and function". The word "basic" has different senses where it could the base knowledge that students need to become "active, informed, and responsible citizens". It could also imply "basic" as contrast with "advanced". Therefore this definition provides Ms. Smith with justification to teach in the methods that she values.

For Ms. Smith, the pedagogical approach that she is most comfortable with and most allows her to meet her internal expectations of civic education is a narrative pedagogical approach. This approach is teacher intensive and requires the teacher to be a strong story-teller. Ms. Smith uses her connections to the community as fodder for her classroom practice. From her perspective this approach offers to her students her own method of engagement with social studies.

Using a narrative pedagogical approach, Ms. Smith models a process of making connections between the knowledge of the content and the experiences of her students (Observation, 2012). She asks questions of her students that require them to draw on their own experiences outside of the classroom (Observation, 2012). By questioning her students about their experiences, she verbalizes her own awareness of their lives in the community and asks them to see the content of civics as connected to their lives outside of the classroom. This is the key to civic education, for Ms. Smith. The heart of civic education is the knowledge of the government as it is applied to the daily lives of her students.

She sees and argues that the students' positions in the community are key components of both her pedagogy and her content. Her love of the community allows her access into the experiences of her students, which maximizes what she teaches and, 
hopefully, what they learn. This method of instruction and assessment allows Ms. Smith to monitor her student's progress and understanding of the content, while she continues to build her own connection to the community. She may ask them about school events such as baseball games and elections, or bring in the experiences of her students as welders or taxidermists.

This methodology of questioning reflects the Socratic method of education where she asks the students to construct understanding on the basis of asking questions. By answering questions, the students demonstrate what they know and how they connect the knowledge to their experiences. The students also extend their knowledge by answering questions from their life experiences rather than from a textbook.

The questions Ms. Smith varied across Bloom's Taxonomy as they asked students if they had knowledge of topics, experience in various topics and opinions of various topics (Observations, 2012). This questioning strategy is paired with active learning practices where students are to construct projects that demonstrate their knowledge (Observations, 2012; Observation, 2011; Observation, 2010). The researcher observed multiple lessons in which students constructed art projects, board games, review games and interactive projects.

One such activity was to have students run for president. Teams of students worked as a campaign team where one student functioned as the candidate and the others worked to fill other roles in the campaign. They developed platforms and commercials. They hung up posters and handed out pamphlets. The whole school was able to vote in the election. The students had debates and presented platforms to define their political and social agendas. This project allowed the students to demonstrate a 
great deal of background knowledge. They used the knowledge to pursuade other students to vote. The platforms, however, reflected the school culture and community rather than broader issues related to society. The project was fascinating and the students were inspired and impassioned. It raises the question as to where is the break down between students being passionate about changing their school and being passionate about changing their world. They are clearly passionate about their school life. Why are they not passionate about their community life?

Pedagogy and Community. According to Ms. Smith, the projects and questioning strategies create a sense of community in the classroom. The pedagogical choices increase the meaning of the relationships in the classroom and allow students to teach each other (Interview, 2012). Ms. Smith is an active leader in the classroom, but a critical component of assessment in her classroom is to allow the students to work together and construct and demonstrate knowledge and beliefs about civic education.

For Ms. Smith, everyday life is a civic act. She returned to this school because of the community and sees civic engagement as a connective experience. She experienced the most transformative education as a conversation, and it is this that she tries to replicate with her students. As she connects to them as individual, she pushes them to see their knowledge of civics as linked to their experiences. In her classroom, the researcher watched her discuss the community with her students and discuss their roles as members of that community.

In the creation of community, the experiences of her students outside of the classroom become a critical source of material for the class. Through narrative pedagogy and questioning, she uses the students' experiences of volunteering at various 
community events as part of the curriculum. She uses narrative presentation of material to connect her content to the lives and experiences of her students, teaching through story-telling (Observation, 2012). She reports that her students talk about volunteering at the local soup kitchen, at the library in reading programs and in various churches (Interview, 2010). The effectiveness of this teaching strategy is supported by Hahn and the IEA Civic Education survey (Hahn, 2001b). This study found that students who volunteer or participate in extra-curricular activities or athletics had higher levels of civic awareness than students who did not take part in these activities. The report would suggest that these students who engage in community activities would be more engaged in civic class. This reflects Ms. Smith's experience that the students are interested in being active and serving their community (Interview, 2010).

However, many students are not engaged in the class, despite what Ms. Smith does to attempt to engage them. She does believe that the students are ultimately responsible for their education. How much is there responsibility is a question. She feels as though she continuously evaluates her pedagogy and content but her underlying style remains the same. She reports having students in the classroom who are illiterate having reached $12^{\text {th }}$ grade (Interview, 2010). "Whose responsibility is it to teach a $12^{\text {th }}$ grader how to read?” Ms. Smith asks, rhetorically (Interview, 2010). How do you engage students in learning when for 12 years they have been passed along without mastering basic skills?

By using the students' experiences as part of the information upon which to draw her connection, Ms. Smith has seen that her students are increasingly interested in bringing their lives into the classroom and making the connections that she views as so 
valuable. Her preparation to teach civics has come from personal knowledge and her own commitment to the community, yet her instincts and experience have taught her that students' interests is made powerful and effective through connection. Her identity as a member of the community informs her practice and she believes that her community values her. It is a reciprocal relationship.

However, many in the community love the school but do not value education, according to Ms. Smith (Interview, 2010). Sports and identity are very important to them, but the school's math or literacy scores are not. She has students who tell her that their fathers got a job with a high school diploma, so as long as they do that much work, they will be fine (Interview, 2010). Personally, Ms. Smith feels that the parents of her students support her but not her educational requirements. They care about her but they do not seem to value education. She feels strongly that the community values teachers and support her as a leader in her classroom (Interview, 2010). This tension puts Ms. Smith out on a limb in trying to insist that her students do academic work. As with everything, some parents minimize education and others do not. The conversation, however, impacts how all students perform in her class.

The Balance of Standards. From the tension with the community that is both a help and hindrance to her, Ms. Smith faces additional tension as she seeks to understand and operationalize the standards and curriculum. The struggle that Ms. Smith faces is that she feels confronted with "the information you have to memorize" (Interview, 2010). From her perspective this is the information that represents the function of the government and legal views. 
What the CSOs represent and require from her perspective are the knowledge component of civic education and, she feels “they don't even cover knowledge that well” (Interview, 2012). Every Monday, she submits her lesson plans to her principal. She is required to match her lessons to the CSOs and meets this requirement as a function of her job. However, she notes a number of weaknesses in the Standards (Interview, 2012). These weaknesses include the lack of instruction in legislative practices and the development of laws (Interview, 2012).

In order to meet the goals and standards laid out by WV, Ms. Smith feels confined by the Standards. She reports, "there are so many Standards that I have to cover" (Interview, 2012). These objectives take the vast majority of the year and as she tries to make connections through the content, she reports feeling as though the Standards interfere with teaching. Her students need to understand the broader goals of civic education and the Standards keep her from teaching her students more socially relevant lessons.

This overemphasis on standards has led, in her opinion, to a lack of connection between her students and their community. Looking at electoral politics, Ms. Smith reported that she was surprised when "it became clear how few students could identify any of the members of Congress or even the state's governor who is currently running for office" (Interview, 2010). This lack of knowledge was compounded by a lack of interest and connection by the students. They simply did not care about their elected officials nor did they see the relevance to their daily lives. By bringing in civic and political awareness, Ms. Smith has been struck by how quickly the students have 
become engaged in the election process, however, this lack of connection and interest was not isolated to a single class. She has the same scenario repeat itself year after year.

In this instance, she worked hard to bring the election into the students every day. This was true in both 2010 and 2012 (primaries) as the researcher observed her talking about the elections and the students quickly began to pay attention as demonstrated by the comments and observations that they made in the classroom.

Ms. Smith has found that a great deal of her energy must be spent on bringing into the classroom a broader level of awareness to the local, state, national and global community. As she has brought material into the classroom, the students are emulating that, bringing her ads and articles to hang on the class walls that spark discussion and a growing awareness of politics (Interview, 2012). "My students come into my $12^{\text {th }}$ grade class and many of them do not know who the state senators are, let alone the governor" (Interview, 2012). These holes in their knowledge, she takes very seriously. She begins by informally assessing what they know and she brings in current event information as part of the curriculum. She values this by taking their interests seriously and addressing these interests in the classroom.

She decorates her classroom with news material and begins classes by bringing up topics in current events. Sitting in her classroom during the political primary season of 2012, she would begin class by asking the students who won the primaries from the night before. She engaged the students in discussion of each states' primary process and the allocation of electoral votes, not as a formal lesson, but as part of a conversation. When students answered questions or brought up issues, she took them seriously, often going to the computer to look up answers. 
The more information her students have, the more clearly they are able to articulate their political ideals. She reports that "many of my students identify themselves as part of a political party but they can't tell you want that means or what they believe" (Interview, 2010). One of her goals is to help them articulate the ideologies behind the political identifications so that they can speak with more authority. She recommended to one student that he look into volunteering with the Republican party during one class (Observation, 2012) and in other classes helped other students discuss the ideologies that undergird their identification as members of the Democratic party.

By working with the students and listening to them, she actively applies the principles of combining the knowledge of civic life with the students' attitudes towards that life. From this, she seeks to encourage participation in the community. These are emotional and personal issues that she feels responsible for helping her students to articulate. Helping students understand and verbalize their own political dispositions is a valuable part of what she hopes her students will gain from their civics class.

\section{Case Study Question 3:}

\section{How do you assess civic education?}

With her narrative pedagogical approach, Ms. Smith practices continual assessment in her classroom as she looks for the students to verbalize the connection between content and their lives. This is the definition of learning that she uses to assess the effectiveness of her teaching. Like the teacher she emulates, she listens to her students and works to build connections between content and their lives. This frequently looks like story-telling. With few or no notes in front of her, she stands in front of the 
classroom and begins to tell a story. At times, this is assisted by a power point presentation and many questions. The informal assessment is often concerned less with knowledge and more with disposition or action verbs. She asks the students "have you ever done __ or how do you feel about ___."

This process of assessment is in keeping with ideals of civic education. She saves knowledge-based assessment for formal summative assessment that often takes the form of an exam. In order to monitor progress, she says, "I use formative and summative assessment to monitor all my students and make sure that they are making progress" (Interview, 2012). This raises the question of value, as it seems that her formal assessment perpetuates the idea that knowledge is the definition of academic success where action, experience and perception are only of informal value. Considering the tests that Ms. Smith provided to the researcher, the type of question was restricted to knowledge-based answers. The students were not asked about their experiences, actions or disposition in formal assessments.

Ms. Smith had a different perspective on the limits she faced teaching, and that was the curriculum the county selected. There are only two chapters dedicated to topics beyond government knowledge, and she felt she was constrained to teach the textbook as it was presented to her. However, she saw her students as active community members that have a strong connection to the small town in which they live. She said, "this is our home. We've grown up here; our families have grown up here...a lot of them are very active in school communities or outside either through their churches, or food pantry" (Interview, 2010). This sense of civic education allows students to 
demonstrate their knowledge in an alternate way, though its not part of the grade they earn in the class.

Noonan (2010) argues that as teachers address "the skills of emotional learning, including social awareness, self-awareness, and participation" (pp. 2-3) students are increasingly aware of their own civic competencies. In keeping with the state's ultimate goal of preparing future citizens, this connection between what students experience and

what they know and believe is critical to the success of the course. Ms. Smith's teaching addresses the heart of civic education as she identifies the civic participation of her students in a community that they are aware of. By using the narrative approach to her lessons, she hopes to maximize these lessons and allow students to connect the content to their lives in a meaningful and productive way.

The students' experiences in the community and their beliefs related to political and social issues are involved in the classroom. They are a critical part of the narrative that forms and structures the curriculum. However, when it comes to formal assessments, they are lacking. The grade that is ultimately assigned at the end of the course are shaped by exams which the researcher analyzed and represented only knowledge-based questions.

\section{Case Study Question 4:}

\section{How do your lesson plans and state documents inform your pedagogy?}

Ms. Smith sees components of the CSOs as a critical guide in the development of the civics course. The Standards form the basis for her instruction yet they are also a source of frustration to Ms. Smith. She says, "they (state officials) say that my lessons are to conform to the Standards and my students should know how the United States' 
government functions, however, they don't give me a single standard to discuss the passage of legislation. Either I have to teach topics that are not included in the Standards or I have to ignore the Standards" (Interview, 2012).

Ms. Smith reports trying to move beyond the Standards, yet this is a struggle. The Standards assume that students have a given background knowledge that she finds to be inconsistent (Interview, 2010). They also assume that students have an understanding of how the United States Government functions. However, the scope and sequence of social studies education in West Virginia has the students studying United States History in $10^{\text {th }}$ grade so that they have not studied the topic for a full year when they enter the civics classroom (WVDOE, 2004).

In order to teach the Standards and from Ms. Smith's perspective the course, the students need a great deal of remediation. Between remediating and meeting the Standards, Ms. Smith feels as though she does not have adequate time to explore topics that interest her students. The Standards are not a starting point, but a finishing point. The students in Ms. Smith's classroom do not possess enough functional knowledge of topics such as "how a bill becomes a law". As many of the Standards reflect very specific goals, Ms. Smith reports feeling as though they are too specific and that the students are not prepared to meet them.

In practice, she emphasizes knowledge while trying to connect it to the lives of her students. In observations from Fall 2011 and Spring 2012, the researcher watched her use narrative to help the students see how civic content connects to their lives. She said, "I try to make those leaps as often as I can and model that for my students so that they learn" (Interview, 2010). The knowledge, from her perspective, is foundational. 
She makes the connections but focuses on knowledge rather than dispositional and behavioral practices.

The Standards have limits to their usefulness however; she uses them to guide her planning. The other components of the state documents of the Course Description and the Performance Descriptors are even less useful. She says that she reviews the Course Description with her students every year in order to give them the road map of where they are going (Interview, 2012). "I review it at the beginning of the year, but don't use it for planning at all," she says (Interview, 2012). She wants her students to begin the course with the end in view. This helps keep the course from being bogged down in minutia.

The Performance Descriptors are another issue. These she reviews by herself but does not use with her students (Interview, 2012). She says, "I don't really have any specific performance descriptors. I know my classes and the students. I look at lots of different things to determine if they are mastering CSOs" (Interview, 2012). She does, however, say that she has her own performance descriptors that she develops (Interview, 2012). These are formative and summative assessment techniques that she uses to assess her students as individuals who learn at different rates and begin with different abilities and knowledge (Interview, 2012). This approach is more organic and in keeping with her teaching style. She speaks of her job as teaching students and not teaching a curriculum, yet she still acts as though she is constrained by the Standards.

By keeping her focus on her students, the Performance Descriptors seem like they could be very helpful, but they only describe where students should end up and do not view their education as a process. Ms. Smith focuses more on the process and 
individual journey that each student is taking. She assesses them as individuals and tries to keep her focus there.

\section{Case Study Question 5:}

\section{How does the classification of lessons on the basis of Bloom's Taxonomy impact your planning and implementation of classroom practice?}

The individual nature of her assessment lends itself to the use of Bloom's

Taxonomy. As Ms. Smith works to assess her students as individuals, she makes use of Bloom's Taxonomy. However, like her use of the Standards, her use of Bloom's Taxonomy reflects a required component of her lesson plans and its use is anything but as an individual assessment or planning tool.

A required component of Ms. Smith's lesson plan for every class period, every day is Bloom's Taxonomy. Every lesson that she writes, she is required to classify as falling into either higher or lower order thinking skills. The process of classification is to attempt to have teachers focus on higher order thinking skills (Interview, 2012). Ms. Smith reports attempting to focus on the higher order skills in her civics class, but the analysis of the lesson plans indicates that her planning tends towards skills of comprehension, which is in the lower order skills.

The state's goal as reported by Ms. Smith is to have the students develop higher order skills, but she does not see her students as having adequate background in lower order skills in order to reach higher order skills in even a majority of the lessons. The process of developing cognitive skills is still developing and her planning emphasizes meeting the needs of her students where they are and not where the state would like them to be. 
The planning tool seems inadequate for the state's purposes, because it is unclear that there is any attempted to analyze the lesson plans of teachers across the year. Ms. Smith reported that she believed most of her lessons were in the higher order skills (Interview, 2012). She also reported that her classification represented what she taught. The researcher observed lessons and found that her classification of the lessons was accurate representations of what happened in the classroom.

Ms. Smith did not think that the classification process along Bloom's Taxonomy was particularly helpful in terms of her planning, however, she did believe that it encouraged her to be reflective in her own practice. She liked doing it for herself but did not think anyone else ever looks at it (Interview, 2012). Reflective teaching practice is critical for Ms. Smith and she not only plans carefully, but she participates in video conferencing to receive feedback on her teaching from other teachers (Interview, 2012).

The conferencing is particularly important for assessment of her students. She says that while she uses both formative and summative assessment techniques, having an additional critical eye helps her catch blind spots in her teaching. She says that the conferences allow observers to submit questions to her that enable her to better, "monitor my teaching and what the students know/don't know/or have forgotten" (Interview, 2012). All of this leads her to attempt to be more self-aware and aware of her students. By combining the use of Bloom's Taxonomy with the conferencing, she feels that she offers her students a highly adapted course, that meets as many of their needs and interests as she can while being constrained by West Virginia's mandate. 


\section{ABCD Chart}

The lesson plans used during the 2011-2012 school year by the case study participant reflect the county's policy of categorizing every lesson on what is called an ABCD Chart. The chart, as seen in Table 7, allows the teacher to indicate if the lesson operates in a higher or lower order cognitive domain while simultaneously determining how the student is to use the lesson.

Table 7

$A B C D$ Chart

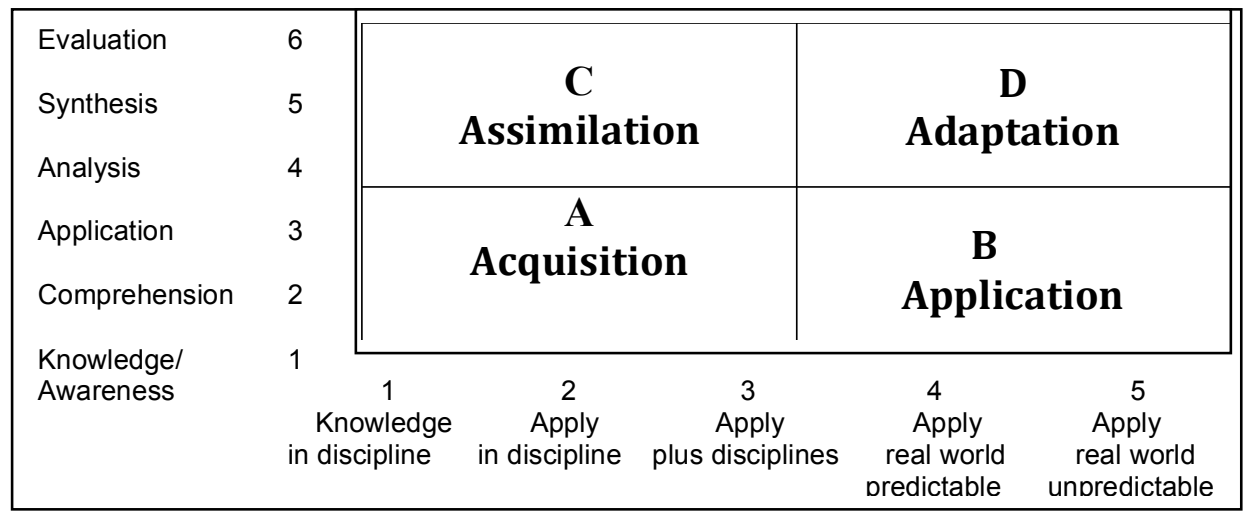

Table 7 is the chart that Ms. Smith is required to categorize all lessons along. It represents two separate decisions. The lessons are categorized as falling into one of the categories: either A, B, C, or D. The chart was provided to the researcher by the teacher on her lesson plans. She includes the chart on her weekly lesson plan sheet and categorizes all lessons as falling into one of the four boxes.

All of the lessons submitted by Ms. Smith made use of this chart and lessons are categorized on two axis (Table 7). One decision that the teacher makes is whether the lesson represents a higher order cognitive skill or lower order cognitive skill. The second decision is whether the lesson occurs with real world application or in discipline specific application. The desires seems to be for students to begin by acquiring 
knowledge of a discipline and move towards the ability to adapt the information for real world circumstances. The movement throughout a child's education in West Virginia begins with a general orientation around quadrant $\mathrm{A}$ and to end with a general orientation around D. The State, however, does not publish information about the use of this chart.

The quadrants are labeled as A: Acquisition, B: Application, C: Assimilation, D: Adaptation. Acquisition and Application are associated with lower order skills and Assimilation and Adaptation are associated with higher order skills. Acquisition and Assimilation occur in the content specific schema and Application and Adaptation occur in the real world.

To consider the lesson plans developed by the case study participant, the first step was to consider which quadrants she identified in her lesson plans. Each lesson was labeled by the week in which it was taught and the day of the week that it occurred. For example, a lesson planned for the third day of the second week is labeled 2.3. Each of the lessons was coded in this way and then the lesson was organized into the ABCD chart (See Table 8).

Table 8 ABCD Chart Organized by Lesson

\begin{tabular}{|l|l|}
\hline \multicolumn{1}{|c|}{ C: Assimilation } & \multicolumn{1}{|c|}{ D: Adaptation } \\
$2.3,2.5,3.1,4.1,5.4,5.5,6.3,6.4,9.2,9.5$, & $2.4,4,2,10.2,10.3,12.2,12.3,12.4,14.4$, \\
$11.2,11.3,13.1,15.3,15.5,16.5,17.1$, & $15.1,19.4,19.5,20.1,28.4$ \\
$\begin{array}{l}17.2,21.5,22.5,24.2,24.3,24.5,25.3, \\
25.5,26.4,28.3\end{array}$ & \multicolumn{1}{|c|}{ B: Application } \\
\hline \multicolumn{1}{|c|}{ A: Acquisition } & \multicolumn{1}{|c|}{ B: } \\
$2.2,3.2,3.4,6.5,10.1,10.4,11.1,12.1$, & $2.1,3.3,4.3,4.4,4.5,5.1,5.2,5.3,6.1,6.2$, \\
$14.1,14.2,16.1,16.2,18.1,19.1,19.2$, & $8.1,8.2,8.3,8.4,8.5,9.1,9.3,9.4,11.4$, \\
$19.3,20.2,20.3,20.4,21.1,21.2,21.3$, & $11.5,13.2,13.3,13.4,13.5,14.3,14.5$, \\
$21.4,22.1,22.2,22.3,22.4,24.1,24.4$, & $15.2,15.4,16.3,16.4,18.2,18.3,18.4$, \\
$25.1,25.2,26.1$ & $25.4,26.2,26.3,26.5,28.1,28.2$ \\
\hline
\end{tabular}


Table 8 demonstrates the coding of the teacher's lesson plans. Each lesson was coded in the following way: week.day. The first number represents the week that the lesson occurred in and the second number represents the day in which lesson was planned. By coding the individual lessons this way, the researcher is able to present the frequency in which each quadrant occurs. From the lesson plans provided by the case study participant represents 28 of the 36 weeks of school. During those weeks, there were 111 days of instruction. Of those days, thirty-two lessons fell into A: Acquisition, thirty-nine fell into B: Application, twenty-seven fell into C: Assimilation and thirteen fell into D: Adaptation.

Table 9

Analysis of $A B C D$ Chart

\begin{tabular}{|l|l|l|}
\hline Category & Number & Percentage \\
\hline A: Acquisition & 32 & $28.82 \%$ \\
\hline B: Application & 39 & $35.14 \%$ \\
\hline C: Assimilation & 27 & $24.32 \%$ \\
\hline D: Adaptation & 13 & $11.71 \%$ \\
\hline
\end{tabular}

Table 9 presents the raw number and the percentage at which each quadrant of the $A B C D$ Chart occurs. Each of the categories is represented throughout the course. Their frequency is noted above, with category B: Application representing the highest percentage of lessons at $35.14 \%$ of all the lessons. Category D: Adaptation represents the lowest percentage of the lessons at $11.71 \%$.

Considering the lessons in another way, it is important to look across the chart in both directions. Table 10 demonstrates that $63.96 \%$ of the lessons fell into the lower 
order cognitive thinking as described by the case study participant. The higher order thinking skills were planned in $36.03 \%$ of the lessons. There is more even distribution of the location of the cognitive process as $53.14 \%$ addressed discipline specific content whereas $46.85 \%$ of the lessons addressed real world concerns.

Table 10

Analysis of ABCD Chart 2

\begin{tabular}{|l|l|l|l|}
\hline Lower Order & Higher Order & In Discipline & In Life \\
\hline A/B & C/D & A/C & B/D \\
\hline $63.96 \%$ & $36.03 \%$ & $53.14 \%$ & $46.85 \%$ \\
\hline
\end{tabular}

Table 10 presents the percentage of lessons when considered both along the row and column on the $A B C D$ Chart. This analysis reveals a good level of balance between the locations, yet an imbalance in cognitive level. As the lessons are not categorized on the basis of the Taxonomy specifically, the use of this structure must be compared to the WV CSOs. According to the case study participant, the goal was to have as many lessons as possible in the higher order thinking quadrants. In that just over a third of the lessons fell into the higher order thinking quadrants, the reality of the teaching is that the students were receiving lessons that were more concerned with lower order thinking skills. This was confirmed by observation where many of the lessons the researcher observed were concerned with knowledge and comprehension tasks.

Combining these percentages in a single analysis, it becomes clear that while the Standards include two-thirds higher order thinking and one-third lower order thinking, the lessons that the teacher devised reversed those proportions (See Table 11). The West Virginia Standards for civic education uses higher order verbs to require teachers to emphasize those cognitive skills that they believe represent cognitive advancement. The reality of the classroom is that Ms. Smith uses the higher order skills as a much lower 
percentage of the classroom practice. The researcher observed that this was frequently due to the need of the students. Ms. Smith need to use knowledge based presentation in order for students to follow along.

Table 11

$A B C D$ Chart and the Standards

\begin{tabular}{|l|l|l|l|l|}
\hline & Bloom's Level & ABCD & Number & Percentage \\
\hline CSOs Primary Verbs & Lower Order & $\mathrm{A} / \mathrm{B}$ & 13 & $33.33 \%$ \\
\hline CSOs Primary Verbs & Higher Order & $\mathrm{C} / \mathrm{D}$ & 26 & $66.67 \%$ \\
\hline CSOs All Verbs & Lower Order & $\mathrm{A} / \mathrm{B}$ & 33 & $40.24 \%$ \\
\hline CSOs All Verbs & Higher Order & $\mathrm{C} / \mathrm{D}$ & 49 & $59.76 \%$ \\
\hline Lesson Plans & Lower Order & $\mathrm{A} / \mathrm{B}$ & 71 & $63.96 \%$ \\
\hline Lesson Plans & Higher Order & $\mathrm{C} / \mathrm{D}$ & 40 & $36.03 \%$ \\
\hline
\end{tabular}

Table 11 presents a combination of the data from West Virginia State Standards (WV DOE, 2005) and the lesson plans from Ms. Smith as it applies to the relative frequency. This comparison demonstrates that there are a number of disconnections between what is intended and what is executed. The State values civic education and requires the class. They require teachers to conform their lessons to the Standards. They seem to expect teachers to teach higher order thinking skills while recognizing that this is a process that is ongoing in a child's education.

Ms. Smith analyzes her lessons to teach the state requirements however she acknowledges that she needs to remediate many of the required topics. She also is required to and complies with ranking her lessons along Bloom's Taxonomy. She assesses her students on the basis of how they feel and what they do with respect to civic education. However, her lesson plans reflect lower order thinking skills as an emphasis and formal assessment is confined to knowledge based questions.

Where her students end up on Bloom's Taxonomy is individual and ongoing, so her goal is to help them master the content of Civic education and become more aware 
of and engaged in their community. Depending upon their individual interests and strengths, she judges success on an individual level and monitors her own pedagogical and curricular advancement as a function of an ongoing process in which she continues to be engaged. Like many good educators, she continues to reinvent her lessons and looks for growth in herself and her students every year.

The state documents and Bloom's Taxonomy are critical parts of Ms. Smith's planning and documentation, but the most critical component of her curriculum and pedagogy are her students. She claims to teach students not a curriculum and course description. She wants her students to do well and appreciates the guidance from the state but she actively looks for ways to strengthen the course for her students and the weaknesses of the course documents. Her goal is to serve her students and the curriculum, CSO's, and lesson plans all must serve that end.

\section{Conclusion}

Ms. Smith represents a typical civics teacher who loves her community and has a vision of herself as a civic actor. In her classroom, she emphasizes the knowledge component of civic education, which she seeks to connect to her students' lives through a narrative pedagogy. She uses the state documents as she is required to but otherwise seems to view them as an annoyance that fail to meet the needs of the students in her classroom. She ignores the Performance Descriptors and Course Description. The Standards are required with her lesson plans and she complies with that requirement. She is also required to categorize her lessons along Bloom's Taxonomy.

The West Virginia $12^{\text {th }}$ grade civics standards heavily emphasize the Knowledge component of civic education and this confirms the emphasis on Bloom's Taxonomy by 
the school system. Bloom's Taxonomy is a cognitive progression of learning. This connects the Taxonomy to the NCSS definition of civic education. The emphasis on cognitive education is not a bad emphasis but when it is the exclusive emphasis, it represents an imbalance in West Virginia civic education. 


\section{Chapter 5}

\section{Conclusions \& Recommendations}

\section{Introduction}

The relationship between standards and classroom practice has been described as reminiscent of the Gordian Knot. In mythology, the person who was able to unravel the Gordian Know would conquer the world. Alexander the Great drew his sword and slashed through the knot, untangling the knot in an unexpected way. West Virginia adopted a Civics course to prepare students to be active and engaged citizens in their communities, but then wrote standards that convey little engagement and a great deal of cognitive knowledge. Considered in a classroom, the complications of the standards and requirements frustrate a teacher who wants to both meet the educational needs of her students and appropriately teach the material required by the state. As these two desires seem to fail to match up, she is left frustrated and conflicted as to her ultimate responsibility.

This research papers explored the relationship between three sets of documents in the context of a Typical Case. The documents were Bloom's Taxonomy (Bloom et al., 1956), West Virginia's Content Standards and Objectives that describe the Civics for the $21^{\text {st }}$ Century course (WV DOE, 2005; WV DOE, 2004) and the definition of Civic education offered by the National Council of Social Studies (NCSS, 2010). These documents have been considered in both the theoretical and operational sense. The theoretical consideration depended upon how the documents speak to and inform each other whereas the operation consideration was done through a case study analysis. 
The researcher answered specific research questions divided into the theoretical domain and the operational domain, using two complimentary theoretical frameworks (Watson \& Watson, 2011). The documents were analyzed using critical theory. The value of critical theory is that it allows the researcher to consider the language of the documents as culturally constructed and thus as a representation of values and power (Patton, 2002).

The typical case was analyzed by using grounded theory. Grounded theory relies on continually revisiting a rich data source to confirm the analysis of the data (Patton, 2002). The document analysis was completed to present a rich understanding of the documents that the state of West Virginia gives to teachers. These documents shape the course as it is presented to students. They describe what teachers are to "do" over the course of an academic class. After completing the document analysis, a case study participant was selected on the basis of being a typical case (Patton, 2002), and her practical use of these documents was then analyzed. Grounded theory was used to combine the critically analyzed document to the work of the case study participant.

The documents were a rich data source, and it was possible to consider the use of language and the components of the state documents, which teachers are required to use. West Virginia publishes three separate components to describe a course. They use the Course Description, Performance Descriptors, and Standards. The researcher also considered each of these subsections. West Virginia mandates that teachers demonstrate compliance to the Standards but not to the Course Description or the Performance Descriptors. Critical theory enables the researcher to explore this imbalance. This ambiguity directs teachers to value certain components and requirements over others. 
The research questions allowed for deep analysis and meaningful conclusions. Both methodological approaches yielded results that were complimentary but not completely perspicuous. From the research questions, several clear conclusions emerge, some questions remain cloudy and, other questions must be raised. The ten research questions, which were investigated and analyzed at length, were created to explore the relationships of the Taxonomy, the state documents and a case study participant. The operational data that was gathered included lengthy interviews, emails and observations of a $12^{\text {th }}$ grade West Virginia social studies teacher.

\section{The Documents}

The five questions that address the theoretical domain of the research were as follows:

1. What is the frequency in which the WV $12^{\text {th }}$ grade civics Standards meet the three components of civic education (actions, dispositions, and knowledge)?

2. Does the WV $12^{\text {th }}$ grade civic Course Description alignment with the NCSS definition of civic education?

3. Does the WV $12^{\text {th }}$ grade civic Performance Standards alignment with the NCSS definition of civic education?

4. Do the WV $12^{\text {th }}$ grade civic Standards alignment with the NCSS definition of civic education (NCSS, 2010)?

5. Using Bloom's Taxonomy as a framework, how do the West Virginia $12^{\text {th }}$ Grade Civic Standards demonstrate cognitive learning?

The three major components of the West Virginia state documents include the Course Description, the Performance Standards and the Standards (WVDOE, 2005). 
These documents were analyzed with respect to the NCSS definition of civic education (NCSS, 2010) and Bloom's Taxonomy (Bloom et al., 1956). Each of the three components reflected the NCSS definition of civic education but without parity of emphasis. It is unclear if the state documents reflect an intentional balance between knowledge of, disposition towards and action directed toward civic education (NCSS, 2010).

\section{NCSS and West Virginia Civic Education}

Equality between the three strands may not be valued or desired by stakeholders in education. NCSS does not address the three strands in terms of the amount of time or expectations between the three categories. It calls for the three strands. It does not explore the time dedicated to each. Therefore, West Virginia's documents may be viewed as in keeping with NCSS's definition. By using critical theory, the researcher considered the structure and development of the state documents. Considering the position of verbs and the categories that the state requires, allows conclusions to be drawn and the theory supports drawing conclusions from the structure undergirding the course plans.

The state requires teachers to use parts of the state documents and not other parts. The state requires teachers to submit their compliance to the Standards but not the Course Description or Performance Descriptors. How the teacher meets the Standards is up to the individual teacher. The analysis of the state documents and the use of these documents by a classroom teacher demonstrates that the state documents have both a very powerful place in the classroom and simultaneously, minimally impact the work of the teacher. The Standards, and specifically, the primary verb in the Standards, dictate 
and guide the teacher in pedagogical and curricular education practice. The Course Description and Performance Descriptors are virtually unused by the teacher.

In the analysis of the state documents, it became clear that as the state has taken into account the NCSS definition of civic education. As the definition contains culturally valued and contested language of dispositions and action, it is not surprising that the state emphasizes Knowledge in frequency. Rothstein (2009) argues that it is critical that we engage in dispositional and action standards, but simultaneous recognizes that this is a conflicted area in our society. This conflict is reminiscent of the discussion that John Dewey engaged it. How do we build a democratic society if we do not engage students in discussions of beliefs and actions about that society?

This question must be seriously addressed and in the analysis of the West Virginia class documents. In essence, in order to build a society, students must experience the creation of and participation in a democratic society. The majority of the Course Descriptions, the Performance Descriptors, and the Standards fell into the Knowledge category. If frequency demonstrates value, it would be clear that West Virginia values teaching students Knowledge related to civic content. This potential emphasis ties the analysis of the NCSS definition to Bloom's Taxonomy, which functions in the cognitive domain. This finding leaves space for various interpretations. There are more standards that are concerned with Knowledge. It is possible that the students need all of the knowledge in order the develop dispositions towards democratic society and identify actions that they should engage in out of this knowledge and belief.

It is also possible to view the findings more deeply through a lens of critical theory, which would argue that the raw numbers emphasize, knowledge to the exclusion 
of dispositions or actions. In this scenario, it could be argued that the state does not value dispositions or civic action, but rather values raw knowledge that is not contextualized in a democratic society. This argument makes use of the idea that dispositions and actions are politically and socially controversial practices that are dangerous for schools to engage in.

NCSS clearly values dispositions and actions as a component of civic education. Therefore, NCSS could be viewed as either supportive of democratic values or a subversive institution that is seeking to indoctrinate schools. Describing these polar ideological perspectives represents broad generalizations. The results of the study suggest that the state of West Virginia seems to stand between these poles.

The state uses the language of NCSS in the development of its course documents but it emphasizes knowledge without excluding dispositions and actions. Namely, it seems to seek some sense of balance but not parity. The critical perspective may see this lack of parity as the state refusing to prepare students to challenge the status quo and developed their attitudes and behaviors in a democratic society. However, the researcher believes that the data points to a more balanced perspective, perhaps informed by grounded theory, that the state would like to encourage democratic ideals while emphasizing a knowledge-rich curriculum. Namely, the state recognizes that students need knowledge from which to develop dispositions and act as members of their community.

The lack of balance leads to the consideration that the state of West Virginia is ultimately fearful of what an engaged citizenry may bring to the powers and organizational structures within the state. If the standards are to convey the culturally 
accepted practice from one generation to the other, then the standards are conveying that the role of the citizen is to accept the knowledge that the state deems is critical, not develop feelings or attitudes towards the state structures and allow the state to manage the needs within the communities.

A citizenry that is actively and passionately engaged in their community may conflict with the goals of government. The government may have a vested interest in maintaining a citizenry who believes that its only civic responsibility is to vote.

Following this logic, education can focus on the mundane, yet critical practices that the government follows rather than investigating and exploring the breadth of opportunity for citizens to shape society by engaging both their community and their government on multiple levels.

By teaching students what to know and now how to think broadly about the nature and purpose of governments, state standards function as a method of controlling citizens. They limit what students know and believe about the relationship between the individual and the state. These limitations, then, frustrate the teacher who is responsible to the state but also to the students. By overwhelming the teacher with knowledgebased standards, the state functionally leaves no room in the schedule to consider enabling students to delve into theoretical questions that are rooted in individual ideology and beliefs, or enable the teacher to allow students to experience and practice democratic service and engagement in their community. 


\section{Bloom's Taxonomy}

Using Bloom's Taxonomy, the researcher was able to analyze the verbs used to describe student actions and rate them along a continuum of cognitive function. Bloom's Taxonomy is a widely used educational tool (Polikoff, Porter \& Smithson, 2011; Dettmer, 2006; Anderson, 2002). The Taxonomy may be viewed as aiding stakeholders in education as they seek to meet increasing standardization in education. The cognitive model is echoed in the state documents. From there, the research question enabled the researcher to consider the cognitive level that the state emphasizes by categorizing the individual standards along the Taxonomic continuum.

The results were that West Virginia seems to value the cognitive activity of "Analysis" which is the fourth of six categories offered by Bloom. This category was emphasized both in considering all of the verbs used in the standards and the primary verbs used in the standards. The "Analysis" category falls into the higher order thinking skills, which the case study participant has been instructed by her administration to emphasize in her planning and teaching. "My principal insists that all of my lessons meet a CSO and he expects that I will teach lessons in the higher order domain" (Interview, 2012). As she categorizes her lesson plans along Bloom's Taxonomy and, more generally, into higher order thinking skills or lower order thinking skills.

In spite of the Standards including the highest number of verbs in the "Analysis" category, the teacher's lesson plans tended towards lower order thinking skills. This result contradicts what the teacher says as she believes that she teaches primarily in the higher order thinking domain. While she believes that she primarily teaches higher order thinking skills, she also argues that the Standards neglect to emphasize the 
knowledge that her students need (and lack). She says that she teaches the Standards but in other conversations she says that she teaches the students and not a curriculum. These are conflicting but not necessarily contradictory notions.

It is possible to teach both the students where they are in terms of knowledge and experience and the course as it is described by the state documents. In this case study, however, the teacher argues that the state has not constructed the course documents to reflect the needs of her students. The Standards fail to include "things my students need to know such as how a bill becomes a law" (Interview, 2012). It seems as though, for her, these two conflicting perspectives are contradictory.

These significant findings are tempered by a lack of clarity as to the intention of the documents. The researcher continues to consider whether the state of West Virginia was intentional in their emphasis of position and frequency as described by critical theory. The researcher also believes that the answers raise questions as to why the state uses multiple verbs in individual standards. The structure of the Standards raise the question as to what Analysis looks like. This theoretical consideration is important but the operational work of the documents is the critical work of the researcher.

\section{The Case Study Participant}

Using grounded theory, the researcher then turned to analyze the work of a case study participant who teaches the $12^{\text {th }}$ grade social studies course of civic education. This participant was selected as a typical case, which is "illustrative and not definitive" (Patton, 2002. p. 236). This teacher works at a rural West Virginia high school that has roughly 85 students in each grade. Grounded theory allows the researcher to continuously review the rich data source and evaluate and re-evaluate the findings on the 
basis of the evidence. In this research study, the data includes the teacher's lesson plans, assessment instruments, multiple classroom observations over the course of two years, and interviews with the teacher also over the course of two years.

From the data sources, the research questions were developed, answered, refined and reevaluated. The data was coded and organized to emphasize themes that emerged from the data source. Five questions emerged related to the operational function of the West Virginia documents. These are as follows and are addressed through the consideration of a typical case study of a $12^{\text {th }}$ grade social studies teacher in West Virginia.

1. How do you view the community of your school?

2. How do you define civic education?

3. How do you assess civic education?

4. How do your lesson plans and state documents inform your pedagogy?

5. How does the classification of lessons on the basis of Bloom's Taxonomy impact your planning and implementation of classroom practice?

These questions were constructed to consider how a single teacher uses state documents in their classroom and how a teacher's vision of civic education translates into classroom practice. This was done through analyzing lesson plans, tests, hand-outs, observing the teacher and interviewing the teacher as well as communicating with the teacher via email.

The teacher spoke of a deep commitment to civic education and her community. She sees civics as concerned with knowledge of the United States government as well as the development of a civic identity in her students. Her life in the community is critical 
to both her pedagogy and curricular choices. She, however, had a limited use of the state documents. They guided her practice but had little direct influence on the students. She reviews the Course Description at the outset of the year. She ignores the Performance Descriptors and only uses the Standards in her lesson plan documents. She reports that she feels that the Standards do not adequately prepare her students with civic content and they presume the students have a greater working knowledge that what, in her experience, they have. For the teacher, the Standards seem to function both as a safety net as she meets the requirements of her employer and a frustration as they do not meet the needs of her students.

The other significant issue from the perspective of the case study is that the Standards disconnect from the students is in their skill areas. The teacher says that she has found that many students do not have the literacy skills necessary to engage in many of the activities related to the highest cognitive functions that are laid out in Bloom's Taxonomy. While acknowledging these problems, her lesson plans reflect what her students need but not necessarily what she believes that they reflect.

The case study participant provided the researcher her lesson plans that were scored on the basis of higher and lower order thinking along the Bloom's Taxonomy. The analysis demonstrated that her lessons tended towards lower order skills in spite of the state's emphasis on higher order thinking and the teacher's assertion that she teaches high order skills, primarily. This evidence may demonstrate that the teacher is both meeting her needs and striving to teach at the highest order skill that she feels is appropriate. 
Based on the researcher's observations, the teacher's lesson plans accurately reflect what she does in her classroom. The levels that she marks are accurate for what she teaches. She does not inflate the level of cognitive skill that she teaches. Her perception of the scope of the level is inaccurate. She tends to teach lower order skills, though certainly not in exclusion to higher order skills. In interviews, she defines her job as teaching her students and not a curriculum or standards. She seeks to meet the standards and they guide her practice, however, she seems to begrudge them the power they have in her classroom. They put her on the defensive of her practice since the state documents do not meet, what she perceives, her students' needs to be.

This raises a serious question to the researcher. The West Virginia documents seem to require teachers to push students to a given level of cognitive learning. However, this process is fixed and does not represent the reality that this teacher perceives in her classroom. As the teacher views her role as intrinsically communal, her educational process is committed to raising future citizens. These citizens are the future of her community. Her personal commitment influences the way that she approaches civic education in the rural community. This is in keeping with research by Laughlin \& Nganga (2008) and Heilman (2004) where community and race impact education in rural settings.

So much of education seems to be controlled by state documents and curriculum choices. It is clear that the dispositions of teachers impacts the classroom (VanFossen \& Waterson, 2008). The way in which the dispositions of teachers impacts civic education is unclear and outside the scope of this research project. 
The case study teacher highly identifies with and values her community. She reports loving her community and feeling "unprofessional" when it comes to the town in which she teaches. This may imply a sense in which being a professional is being disconnected or, in NCSS language, lacking dispositions towards the community in which you teach. The teacher in this study has a strong sense of communal identity and believes that her place in the community is valuable and valued. She values her place in the community. As she teaches in a relational and narrative style, this connection is necessary but she seems to believe that it is less than professional.

These notions were not explored in this research project but are ideas that should be explored in terms of efficacy of civic education. The teacher's practice and beliefs related to classroom practice were explored, but the broader civic sense, of who the teacher is in the community, is another area of interest. As civics is concerned, the identity and connections between the individuals are important.

\section{Further Areas for Investigation}

John Dewey (2004) argues that the goal of education is in a large part the development of democratic life among the students. This should happen in all areas of study, but civic education embodies this in a focused attempt. Civic education, according to NCSS, is to pursue the knowledge, dispositions and actions of an engaged citizenry (NCSS, 2010). In order to fully explore how this should be achieved in current classrooms, there are quite a few questions raised by this research. Some of these questions are listed below:

1. Should parity be sought in the categories of civic education offered by NCSS? 
2. Why does the state use multiple verbs in a single standard?

3. How is civic practice influenced by literacy?

4. How does civic engagement or dispositions in a teacher translate into educational practice?

5. What does the state intend when it uses the word "analysis"?

6. How does a teacher's identification with their community impact the way in which they teach civic education?

Each of these questions represents broad themes of investigation that warrant attention from researchers.

Civic education is the work of all teachers at all grade levels. It is fundamentally concerned with the development of the next generation of citizens. It needs to address how students consider their community from the classroom, to the town, their state, nation and world. It should teach them how we order community life through governments and it should emphasize what students cognitively know.

This research project was developed and executed to understand how a state writes about and directs teachers to address civic education in a very particular way. It used critical theory to investigate state documents and grounded theory to describe and analyze the work of a teacher. The researcher was interested to develop a picture of how a teacher acts as a balance between the state and the students. The researcher was also interested to see if national educational documents such as those published by NCSS and common taxonomic approaches were used in the classroom and how they shaped civic education.

Standards shape education and the minimal attention to dispositions and actions 
offers a clear picture of where the value of education lies. It is in the knowledge domain and this allows teachers and administrators to meet the standards without considering how students engage their community or what students think about their community. Through this silence, it is clear what the state ultimately values are students who are not guided or directed in actions or attitudes. With the standards structured this way, the case study participant teaches in a way that speaks to inner conflict about her role. She wants to teach her students "the stuff they need to know" but she also wants them to be responsible citizens. The reality of her classroom is that attitudes and action are discussed but not assessed, formally.

Considering the spectrum of logic, it could be that the state believes that it is not the place of the state to teach attitudes and action. It could also be that the state does not want citizens who hold strong beliefs about their community and are willing to work to see their vision become reality. Students who become active citizens may challenge the status quo, changing the existing power structure. Power structures do not generally desire to see their own structure change. An active, engaged citizenry may do just this. The researcher has offered a picture of the practice of civic education in West Virginia that balances the interest of the state and the teacher. There are competing definitions and expectations for civic education and these voices work to shape future citizens. The meaning of the findings may be contested and debated, but it is clear that the state standards shape education and the goal of these standards should be evaluated, debated and constructed by an active and engaged citizenry. 


\section{References}

Abrams, L. M., Pedulla, J. J., \& Madaus, G. F. (2003). Views from the classroom: Teachers' opinions of statewide testing programs. Theory into Practice, 42(1), 18-29. Retrieved from http://www.jstor.org/stable/1477315

Altoff, P. (2008). Citizenship must not be the last of the three "C's". Social Education, 72(7), 379.

Anderson, L. W. (1996). If you don't know who wrote it, you won't understand it: Lessons learned from Benjamin S. Bloom. Peabody Journal of Education, 71(1, Mentors and Mentoring), pp. 77-87. Retrieved from http://www.jstor.org.www.libproxy.wvu.edu/stable/1492555

Anderson, L. W. (2002). Curricular alignment: A re-examination. Theory into Practice, $41(4), 255-260$.

Anderson, L. W. (2005). Objectives, evaluation, and the improvement of education.

Studies in Educational Evaluation, 31(2-3), 102-113.

doi:10.1016/j.stueduc.2005.05.004

Anderson, L. W. (2009). Upper elementary grades bear the brunt of accountability. Phi Delta Kappan, 90(6), 413-418. Retrieved from http://search.ebscohost.com.www.libproxy.wvu.edu/login.aspx?direct=true $\& d b=e h$ $\underline{\text { h\&AN}=36352845 \& \text { site }=\text { ehost-live }}$ 
Barbour, M., Evans, M., \& Ritter, J. (2007). Situating the Georgia Performance Standards in the social studies debate: An improvement for social studies classrooms or continuing the whitewash. Journal of Social Studies Research, 31(1), 27-33. Retrieved from http://search.ebscohost.com/login.aspx?direct=true \&db=ehh\&AN=24887569\&site=e host-live

Bell, S. E. (2009). "There ain't no bond in town like there used to be": The destruction of social capital in the West Virginia coalfields. Sociological Forum, 24(3), 631-657. doi: 10.1111/j.1573-7861.2009.01123.x

Berube, C. T. (2004). Are standards preventing good teaching? Clearing House, 77(6), 264-267. Retrieved from http://search.ebscohost.com/login.aspx?direct=true\&db=ehh\&AN=13938518\&site= ehost-live

Biesta, G. (2006). Beyond learning: Democratic education for a human future. Boulder, CO: Paradigm Publishers.

Bloom, B. S. (1943). The relationship between educational objectives and examinations designed to measure achievement in general education courses at the college level. (Doctoral dissertation). Retrieved from ProQuest. (AAT 0149768)

Bloom, B. S. (1944). Some major problems in educational measurement. The Journal of Educational Research, 38(2), pp. 139-142. Retrieved from http://www.jstor.org.www.libproxy.wvu.edu/stable/27528555 
Bloom, B. S. (1972). Innocence in education. The School Review, 80(3), pp. 333-352. Retrieved from http://www.jstor.org.www.libproxy.wvu.edu/stable/1084408

Bloom, B. S. (1974a). Implications of the IEA studies for curriculum and instruction. The School Review, 82(3), pp. 413-435. Retrieved from http://www.jstor.org.www.libproxy.wvu.edu/stable/1084070

Bloom, B. S. (1974b). Time and learning. American Psychologist, 29(9), 682-688. doi:10.1037/h0037632

Bloom, B. S. (1977). Affective outcomes of school learning. The Phi Delta Kappan, 59(3), pp. 193-198. Retrieved from http://www.jstor.org.www.libproxy.wvu.edu/stable/20298896

Bloom, B. S. (1978). New views of the learner: Implications for instruction and curriculum. Educational Leadership, 35(7), 563. Retrieved from http://search.ebscohost.com.www.libproxy.wvu.edu/login.aspx?direct=true $\& \mathrm{db}=\mathrm{eh}$ $\underline{\text { h\&AN}=7730938 \& \text { site }=\text { ehost-live }}$

Bloom, B. S. (1986). 'The hands and feet of genius': Automaticity. Educational Leadership, 43(5), 70. Retrieved from http://search.ebscohost.com.www.libproxy.wvu.edu/login.aspx?direct=true $\& d b=e h$ $\underline{\text { h\&AN}=8520040 \& \text { site }=\text { ehost-live }}$

Bloom, B., Englehart, M., Furst, E., Hills, W., \& \& Krathwohl, D. (1956). Taxonomy of educational objectives: Handbook 1: Cognitive domain. New York: Longmans, Green. 
Blumberg, P. (2009). Maximizing learning through course alignment and experience with different types of knowledge. Innovative Higher Education, 34(2), 93-103. doi:10.1007/s10755-009-9095-2

Booker, M. (2007). A roof without walls: Benjamin Bloom's taxonomy and the misdirection of American education. Academic Questions, 20(4), 347-355. doi:10.1007/s12129-007-9031-9

Bos, A. L., Williamson, I., Sullivan, J. L., Gonzales, M. H., \& Avery, P. G. (2007). The price of rights: High school students' civic values and behaviors. Journal of Applied Social Psychology, 37(6), 1265-1284. doi:10.1111/j.1559-1816.2007.00212.x

Boston, B. O., Pearson, S. S. \& Halperin, S. (2005). Restoring the balance between academics and civic engagement in public schools. . Retrieved 4/26, 2011, from http:/www.aypf.org/publications/Restoring\%20the\%20Balance\%20Report.pdf

Buchanan, J. (2007). Civics education: Questions we should be answering and answers we should be questioning. The Social Educator, 25(3), 22-27.

Bümen, N. T. (2007). Effects of the original versus revised Bloom's taxonomy on lesson planning skills: A Turkish study among pre-service teachers. International Review of Education / Internationale Zeitschrift Für Erziehungswissenschaft / Revue Internationale De l'Education, 53(4), pp. 439-455. Retrieved from http://www.jstor.org.www.libproxy.wvu.edu/stable/27715401

Burroughs, S., Groce, E., \& Webeck, M. L. (2005). Social studies education in the age of testing and accountability. Educational Measurement: Issues and Practice, 24(3), 13-20. 
Butts, R. F. (1988). The moral imperative for American schools: "... inflame the civic temper...". American Journal of Education, 96(2, The Moral Life of Schools), pp. 162-194. Retrieved from http://www.jstor.org.www.libproxy.wvu.edu/stable/1085250

Carr, J.F. \& Harris, D.E. (2001). Succeeding with standards: Linking curriculum, assessments, and action planning. Alexandria, VA: Association for Supervision and Curriculum Development.

Cochran-Smith, M., \& Lytle, S.L. (2006). Troubling images of teaching in No Child Left Behind. Harvard Educational Review, 76(4), 668-697. Retrieved from http://her.hepg.org/content/56v8881368215714/fulltext.pdf

Cohen, J., Pickeral, T., \& Levine, P. (2010). The foundation for democracy: Promoting social, emotional, ethical, cognitive skills and dispositions in K-12 schools. Interamerican Journal of Education for Democracy, 3(1), 74-94.

Crocco, M. S. (2006). Gender and social education: What's the problem? In E. W. Ross (Ed.), The social studies curriculum: Purposes, problems, and possibilities (3rd ed., pp. 171-193). Albany, NY: State University of New York.

Crocco, M., \& Costigan, A. (2007). The narrowing of curriculum and pedagogy in the age of accountability: Urban educators speak out. Urban Education, 42(6), 512535. doi:10.1177/0042085907304964 
Darling, L. F. (2006). Teaching social studies as if it mattered: Young children and moral deliberation. In E. W. Ross (Ed.), The social studies curriculum: Purposes, problems, and possibilities (3rd ed., pp. 265-282). Albany, NY: State University of New York.

Darling-Hammond, L. (2000). How teacher education matters. Journal of Teacher Education, 51, 166-173. doi:10.1177/0022487100051003002

Dettmer, P. (2006). New blooms in established fields: Four domains of learning and doing. Roeper Review, 28(2), 70-78.

Dewey, J. (2004). Democracy and education: An introduction to the philosophy of education. Mineola, NY: Dover Publications.

Doppen, F., Misco, T., \& Patterson, N. (2008). The state of k-12 social studies instruction in Ohio. Social Studies Research and Practice, 3(3), 1-25.

Doughty, H. A. (2006). Blooming idiots: Educational objectives, learning taxonomies and the pedagogy of Benjamin Bloom. College Quarterly, 9(4), 1-23.

Drake, S. M. (2001, September). Castles, kings...and standards. Educational Leadership, 59(1), 38-42

Eber, P. A., \& Parker, T. S. (2007). Assessing student learning: Applying Bloom's taxonomy. Human Service Education, 27(1), 45-53. Retrieved from http://search.ebscohost.com.www.libproxy.wvu.edu/login.aspx?direct=true $\& \mathrm{db}=\mathrm{eh}$ $\underline{\text { h\&AN}=27875275 \& \text { site }=\text { ehost-live }}$

Eisner, E.W. (1995). Standards for American schools: help or hindrance? Phi Delta Kappan, 76(10), 758-763. 
Eisner, E. W. (2000). Profiles of famous educators: Benjamin Bloom 1913-1999. Prospects, 30(3), 387-395. doi:10.1007/BF02754061

Eisner, E. W. (2001). What does it mean to say a school is doing well? Phi Delta Kappan, 82(5), 367. Retrieved from http://search.ebscohost.com/login.aspx?direct=true\&db=a9h\&AN=3953106\&site $=$ ehost-live

Feldman, L., Pasek, J., Romer, D., \& Jamieson, K.H. (2007). Identifying best practices in civic education: Lessons from the student voices program. American Journal of Education, 114 (November), 75-100.

Gardner, H. (2000). The disciplined mind: Beyond facts and standardized tests, the K-12 education that every child deserves. New York: Penguin Putnam Inc.

Gerwin, D. \& Visone, F. (2006). The freedom to teach: Contrasting history teaching in elective and state-tested courses. Theory and Research in Social Education, 34(2), 259-282.

Giroux, H. (2000). Democratic education and popular culture. In D. Hursh \& E. W. Ross (Eds.), Democratic social education: social studies for social change (8596). New York, NY: Falmer Press.

Good, A.J., Heafner, T., Rock, T., O’Connor, K., Passe, J., Waring, S., \& Byrd, S. (2010). The De-Emphasis on Social Studies in Elementary Schools: Teacher Candidate Perspective. Current Issues in Education, 13(4). Retrieved from http://cie.asu.edu/ 
Guskey, T. R. (2007). Closing achievement gaps: Revisiting Benjamin S. Bloom's "learning for mastery". Journal of Advanced Academics, 19(1), 8-31. Retrieved from

http://search.ebscohost.com.www.libproxy.wvu.edu/login.aspx?direct=true $\& d b=$ ehh\&AN=30045658\&site $=$ ehost-live

Hahn, C. (2001a). Democratic understanding: Cross-national perspectives. Theory into Practice, 40(1), 14-22.

Hahn, C., (2001b). Civic knowledge, attitudes, and experiences of ninth graders in the United States: Results from the IEA civic education study. ERIC Digest.

Heilman, E. E. (2004). Hoosiers, hicks, and hayseeds: The controversial place of marginalized ethnic whites in multicultural education. Equity \& Excellence in Education, 37(1), 67-79. doi:10.1080/10665680490422124

Hertzberg, H. W. (1981). Social studies reform, 1880-1980. Boulder, Colorado: Social Science Education Consortium.

Hess, D. (2009a). Controversy in the classroom: The democratic power of discussion. New York: Routledge.

Hess, D. (2009b). Moving beyond celebration: Challenging curricular orthodoxy in the teaching of brown and its legacies. Teachers College Record, 107(9), 2046-2067.

Hess, D. (2011). Discussions that drive democracy. Educational Leadership, 69(1), 69-

73. Retrieved from http://search.ebscohost.com.www.libproxy.wvu.edu/login.aspx?direct=true\&db= $\underline{\text { ehh\&AN }=65235671 \& \text { site }=\text { ehost-live }}$ 
Hess, D., \& Posselt, J. (2002). How high school students experience and learn from the discussion of controversial public issues. Journal of Curriculum \& Supervision, 17(4), 283. Retrieved from

http://search.ebscohost.com/login.aspx?direct $=$ true $\& d b=a 9 h \& A N=6938059 \&$ site $=$ ehost-live

Hills, J. A. (2004). Better teaching with Deming and Bloom. Quality Progress, 37(3), 57-57-64. Retrieved from http://search.proquest.com.www.libproxy.wvu.edu/docview/214757479?accounti $\underline{d}=2837$

Hinde, E. (2008). Civic education in the NCLB era: The contested mission of elementary and middle schools. Journal of Curriculum and Instruction, 2(1), 7486.

Hutchens, M.J., \& Eveland Jr., W.P. (2009). Circle working paper \#65: The long-term impact of high school civics curricula on political knowledge, democratic attitudes and civic behavior: A multi-level model of direct and mediated effects through communication. The Center for Information \& Research on Civic Learning \& Engagement.

Hymel, S., Schonert-Reichl, K. A., \& Miller, L. D. (2006). Reading, 'riting, 'rithmetic and relationships: Considering the social side of education. Exceptionality Education Canada, 16(3), 1-44.

Journell, W. (2010). Standardizing citizenship: The potential influence of state curriculum standards on the civic development of adolescents. Political Science \& Politics, 43(2), 351-358. doi:10.1017/S1049096510000272 
Kahne, J. \& Sporte, S. (2008). Developing citizens: The impact of civic learning opportunities on students' commitment to civic participation. American Educational Research Journal, 45(3), 738-766. doi:10.3102/0002831208316951

Kohli, W. (2000). Teaching in the danger zone: Democracy and difference. In D. W. Hursh, \& E. W. Ross (Eds.), Democratic social education: Social studies for social change (pp. 23-42). New York, NY: Falmer Press.

Krathwohl, D. R. (2002). A revision of Bloom's taxonomy: An overview. Theory into Practice, 41(4, Revising Bloom's Taxonomy), pp. 212-218. Retrieved from http://www.jstor.org.www.libproxy.wvu.edu/stable/1477405

Krugman, P. (2005). For richer. In H. Shapiro, \& D. Purpel (Eds.), Critical social issues in American education: Democracy and meaning in a globalizing world (3rd ed., pp. 7-22). Mahwah, NJ: Lawrence Erlbaum Associates.

Kunzman, R. (2006). Grappling with the good: Talking about religion and morality in public schools. Albany: State University of New York Press.

Laughlin, P. \& Nganga, L. (2008). Interdisciplinary ways of knowing: A collaborative teacher education project for culturally responsive pedagogy in rural white America. Spaces for Difference: An Interdisciplinary Journal, 1(2). Retrieved from: http://escholarship.org/uc/item/6t08f2m4

Lipscomb, A. A., \& Bergh, A. E. (Eds.). (1820). The writings of Thomas Jefferson. Washington, DC: Thomas Jefferson Memorial Association of the United States. 
Love, B. (2009). The inclusion of Bloom's taxonomy in state learning standards: A content analysis. Ph.D. dissertation, Southern Illinois University at Carbondale, United States -- Illinois. Retrieved April 27, 2011, from Dissertations \& Theses: Full Text.(Publication No. AAT 3358737).

Mann, H. (1989). On the art of teaching. Bedford, MA: Applewood Books.

Marino, M., \& Bolgatz, J. (2010). Weaving a fabric of world history? An analysis of U.S. state high school world history standards. Theory and Research in Social Education, 38(3), 366-394.

Marker, P. (2006). The future is now: Social studies in the world of 2056. In E. W. Ross (Ed.), The social studies curriculum: Purposes, problems, and possibilities (3rd ed., pp. 77-96). Albany, NY: State University of New York.

Mathison, S., \& Fragnoli, K. (2006). Struggling for good assessment in social studies education. In E. W. Ross (Ed.), The social studies curriculum: Purposes, problems, and possibilities (3rd ed., pp. 197-215). Albany, NY: State University of New York.

Mathison, S., Ross, E. W., \& Vinson, K. D. (2006). Defining the social studies curriculum: Influence of and resistance to curriculum standards and testing in social studies. In E. W. Ross (Ed.), The social studies curriculum: Purposes, problems and possibilities (3rd ed., pp. 99-114). Albany, NY: State University of New York.

Merriam, S. B. (2009). Qualitative research: A guide to design and implementation. San Francisco, CA: Jossey-Bass. 
Merryfield, M., \& Subedi, B. (2006). Decolonizing the mind for world-centered global education. In E. W. Ross (Ed.), The social studies curriculum: Purposes, problems, and possibilities (3rd ed., pp. 283-295). Albany, NY: State University of New York.

Misco, T., \& Shiveley, J. (2010). Seeing the forest through the trees: Some renewed thinking on dispositions specific to social studies education. The Social Studies, $101,121-126$.

Moon, R., \& Koo, J. (2011). Global citizenship and human rights: A longitudinal analysis of social studies and ethics textbooks in the Republic of Korea. Comparative Education Review, 55(4), 574-599.

National Council for the Social Studies (Ed.). (2010). A framework for teaching, learning, and assessment. Silver Spring, MD: National Council for the Social Studies.

National Council for the Social Studies. (1994). Expectations of excellence: Curriculum standards for social studies. National Council for the Social Studies, Silver Springs, MD.

Nelson, J., \& Pang, V. O. (2006). Racism, prejudice, and the social studies curriculum. In E. W. Ross (Ed.), The social studies curriculum: Purposes, problems, and possibilities (3rd ed., pp. 115-135). Albany, NY: State University of New York.

Niemi, R., \& Smith, J. (2001). Enrollments in high school government classes: Are we short-changing both citizenship and political science training? PS: Political Science and Politics, 34(2), 281-287. 
Noble, T. (2004, November 1). Integrating the revised Bloom's taxonomy with multiple intelligences: A planning tool for curriculum differentiations. Teachers College Record, 106(1), 193-211.

Noddings, N. (1998). Philosophy of education. Boulder, CO: Westview Press.

Noddings, N. (2005). Educating citizens for global awareness. New York, NY: Teachers College Press.

Noffke, S. (2000). Identity, community, and democracy in the 'new social order'. In D. W. Hursh, \& E. W. Ross (Eds.), Democratic social education: Social studies for social change (pp. 73-84). New York, NY: Falmer Press.

Noonan, J. M., (2010). Re-imagining teacher professional development and citizenship education: Lessons for import from Colombia. Presented at the 54th Annual Meeting of the Comparative and International Education Society.

Orlich, D. C. (2011). Educational standards--caveat emptor. Kappa Delta Pi Record, 47(2), 52-57. Retrieved from http://search.ebscohost.com/login.aspx?direct=true\&db=ehh\&AN=57154720\&si $\underline{\text { te}}=$ ehost-live

Osguthorpe, R. D. (2008). On the reasons we want teachers of good dispositions and moral character. Journal of Teacher Education, 59(4), 288-299.

Parker, W. C. (1996). "Advanced" ideas about democracy: Toward a pluralist conception of citizenship education . Teachers College Record, 98(1), 104-125.

Parker, W. C. (2006). Public discourses in schools: Purposes, problems, possibilities. Educational Researcher, 35(8), pp. 11-18. Retrieved from http://www.jstor.org/stable/4124788 
Patrick, J. J. (1999). Concepts at the core of education for democratic citizenship. In C. Bahmueller, \& J. Patrick (Eds.), Principles and practices of education for democratic citizenship (pp. 1-40). Bloominton, IN: ERIC Adjunct Clearinghouse for Interantional Civic Education.

Patrick, J. J. (2003). Essential elements of education for democracy: What are they and why should they be at the core of the curriculum in schools? Paper presented in Sarajevo, Bosnia and Herzegovina

Patton, Michael. (2002). Qualitative evaluation and research methods $3^{\text {rd }}$ Ed. London: Sage Publications.

Polikoff, M. S., Porter, A. C., \& Smithson, J. (2011). How well aligned are state assessments of student achievement with state content standards? American Educational Research Journal, 48(4), 965-995. doi:10.3102/0002831211410684

Rapoport, A. (2009). A forgotten concept: Global citizenship education and state social studies standards. Journal of Social Studies Research, 33(1), 91-112. Retrieved from

http://search.ebscohost.com/login.aspx?direct=true\&db=ehh\&AN=48461393\&si $\underline{\text { te}}=$ ehost-live

Raths, J. (2002). Improving instruction. Theory into Practice, 41(4), 233. Retrieved from http://search.ebscohost.com/login.aspx?direct=true\&db=ehh\&AN=8550724\&site $=$ ehost-live 
Reimers, F., \& Cardenas, S. (2010). Youth civic engagement in Mexico. In L. R. Sherrod, J. Torney-Purta \& C. A. Flanagan (Eds.), Handbook of research on civic engagement in youth. Hoboken, NJ, USA.: John Wiley \& Sons, Inc. doi:10.1002/978070767603.ch6

Resnick, L. B. (1977). Review: Assuming that everyone can learn everything, will some learn less? The School Review, 85(3), pp. 445-452. Retrieved from http://www.jstor.org.www.libproxy.wvu.edu/stable/1084787

Ross, E. W. (2006). The struggle for the social studies curriculum. In E. W. Ross (Ed.), The social studies curriculum: Purposes, problems, and possibilities (3rd ed., pp. 17-37). Albany, NY: SUNY Press.

Ross, E. W. (2000). Redrawing the lines: The case against traditional social studies instruction. In D. Hursh \& E. W. Ross (Eds.), Democratic social education: social studies for social change (43-64). New York, NY: Falmer Press.

Rothstein, R. (January 23, 2009). Getting accountability right. Education Week

Schubert, W. (2009). What is worthwhile: From knowing and needing to being and sharing. Journal of Curriculum and Pedagogy, 6(1), 22-40.

Schussler, D. L., Bercaw, L. A., \& Stooksberry, L. M. (2008) The fabric of teacher candidate dispositions: What case studies reveal about teacher thinking. Action in Teacher Education, 29(4), 39-52.

Seddon, G. M. (1978). The properties of Bloom's taxonomy of educational objectives for the cognitive domain. Review of Educational Research, 48(2), pp. 303-323. Retrieved from http://www.jstor.org.www.libproxy.wvu.edu/stable/1170087 
Splitter, L. J., (2010). Dispositions in education: Nonentities worth talking about. Educational Theory, 60(2), 203-230.

Stiff-Williams, H. (2010). Widening the lens to teach character education alongside standards curriculum. Clearing House, 83(4), 115-120. doi:10.1080/00098651003653030

Thornton, S. (2005). Teaching social studies that matters: Curriculum for active learning. New York, NY: Teachers College Press.

Torney-Purta, J., Barber, C., \& Richardson, W. (2005). How Teachers' Preparation relates to Students' Civic Knowledge and Engagement in the United States: Analysis from the IEA Civic Education Study? Retrieved from www.civicyouth.org

Urban \& Wagoner (2009) American education: A history $4^{\text {th }}$ edition. New York: NY. Routledge.

Vander Veldt, M. \& Ponder, J. (2010). Implementing social action curriculum in an elementary classroom: Reflections from the journey. Social Studies Research and Practice, 5(1), 45-57.

VanFossen, P. \& Waterson, R. A. (2008). "It is just easier to do what you did before...": An update on Internet use in secondary social studies classrooms in Indiana. Theory and Research in Social Education, 36(2), 124-152.

Vinson, K. D. (1999). National curriculum standards and social studies education: Dewey, Freire, Foucault, and the construction of a radical critique. Theory \& Research in Social Education, 27(3), 296-328. Retrieved from 
http://search.ebscohost.com/login.aspx?direct=true $\& d b=e h h \& A N=36242183 \&$ si

te $=$ ehost-live

Vinson, K. (2006). Oppression, anti-oppression, and citizenship education. In E. W. Ross (Ed.), The social studies curriculum: Purposes, problems and possibilities (3rd ed., pp. 51-76). Albany, NY: State University of New York.

Walberg, H. J., \& Haertel, G. D. (1992). Educational psychology's first century. Journal of Educational Psychology, 84(1), 6-19. doi:10.1037/0022-0663.84.1.6

Watson, S., \& Watson, W. (2011). Critical, emancipatory, and pluralistic research for education: A review of critical systems theory. Journal of Thought, 46(3), 63-77.

Wen-Chih, C., \& Ming-Shun, C. (2009). Automatic applying Bloom's taxonomy to classify and analysis the cognition level of English question items. Pervasive Computing, 727-734. doi:10.1109/JCPC.2009.5420087

Westheimer, J., \& Kahne, J. (2004). What kind of citizen? the politics of educating for democracy. American Educational Research Journal, 41(2), pp. 237-269.

Retrieved from http://www.jstor.org/stable/3699366

Whelan, M. (2006). Teaching history: A constructivist approach. In E. W. Ross (Ed.), The social studies curriculum: Purposes, problems, and possibilities (3rd ed., pp. 37-49). Albany, NY: State University of New York Press.

Wineburg, S., \& Schneider, J. (2009). Was Bloom's Taxonomy pointed in the wrong direction?. Phi Delta Kappan, 91(4), 56-61.

Yin, R.K. (2002). Case study research: Design and Methods. Beverly Hills: Sage Publication 
Zarret, N., \& Eccles, J. (2009). The role of family and community in extracurricular activity participation: A developmental approach to promoting youth participation in positive activities during the high school years. In L. Shumow (Ed.), Promising practice for family and community involvement during the high school (pp. 27-58) United States: Information Age Publishing Inc. 


\section{Electronic Resources}

Andrabi, T., Bau, N., Das, J., \& Khwaja, A. I. (2010). Bad public schools are public bads: Civic values and test-scores in public and private schools. Retrieved from http://popcenter.uchicago.edu/pdf/Bad\%20Public\%20Schools\%20are\%20Public \%20Bads.pdf

Annie E Casey Foundation. (2012). Data across states. Retrieved from http://datacenter.kidscount.org/data/acrossstates/Default.aspx

Aurora Lights. (2011). A community and strip mining. Retrieved January/31, 2012, from http://auroralights.org/map project/theme.php?theme=hazy\&article=5

Benedum Collaborative. (2011). Welcome to the home of the Benedum Collaborative. Retrieved March/4, 2012, from http://benedumcollaborative.wvu.edu/

Common Core State Standards Initiative. (2010). National governors association and state education chiefs launch common state academic standards. Retrieved April 24, 2012, from http://www.corestandards.org/articles/8-national-governorsassociation-and-state-education-chiefs-launch-common-state-academic-standards

Forehand, M. (2005). Bloom's Taxonomy: From emerging perspectives on learning, teaching and technology. Retrieved from http://projects.coe.uga.edu/epltt/index.php?title=Bloom's_Taxonomy

Oxford English Dictionary. (2010). Citizen. Retrieved, 2, from http://dictionary.oed.com.www.libproxy.wvuedu/cgi/entry/50040478?query typ $\underline{\mathrm{e}=\text { word \&queryword }=\text { citizen } \& \text { first }=1 \& \max \text { to } \_ \text {show }=10 \& \text { sort type }=\text { alpha\&resu }}$ lt place $=1 \&$ search id=RuaC-gDlpHV-14746\&hilite $=20040478$ 
Promise Scholarship Program Staff. (2012). West Virginia PROMISE scholarship.

Retrieved March/4 from

https://secure.cfwv.com/Financial_Aid_Planning/Scholarships/Scholarships and _Grants/West_Virginia_PROMISE.aspx

U.S. Census Bureau. (2011a). West Virginia. Retrieved January/31, 2012, from http://quickfacts.census.gov/qfd/states/54000.html

U.S. Census Bureau. (2011b). Blacksville. Retrieved June/29, 2012, from

http://quickfacts.census.gov/qfd/states/54000.html

http://factfinder2.census.gov/faces/tableservices/jsf/pages/productview.xhtml?src $=\mathrm{bkmk}$

West Virginia Department of Education. (2009). Teach 21. Retrieved January/4, 2012. from http://wvde.state.wv.us/teach21/

West Virginia Department of Education. (2005). Twelfth grade social studies. Retrieved 4/26, 2011, from http://wveis.k12.wv.us/Teach21/public/cso/popUp.cfm

West Virginia Department of Education. (2004). Global 21: Content standards and objectives. Retrieved from http://wveis.k12.wv.us/Teach21/public/cso/popUp.cfm

West Virginia Kids Count Fund. (2012). Kids Count Data Book. Retrieved from http://www.wvkidscountfund.org/ 